\title{
Avoidance of Timeout from Response-Independent Schedules of Food or Sucrose Water with and without a Limited Hold on Consumption
}

\author{
August F. Holtyn \\ West Virginia University
}

Follow this and additional works at: https://researchrepository.wvu.edu/etd

\section{Recommended Citation \\ Holtyn, August F., "Avoidance of Timeout from Response-Independent Schedules of Food or Sucrose Water with and without a Limited Hold on Consumption" (2012). Graduate Theses, Dissertations, and Problem Reports. 4868.}

https://researchrepository.wvu.edu/etd/4868

This Dissertation is protected by copyright and/or related rights. It has been brought to you by the The Research Repository @ WVU with permission from the rights-holder(s). You are free to use this Dissertation in any way that is permitted by the copyright and related rights legislation that applies to your use. For other uses you must obtain permission from the rights-holder(s) directly, unless additional rights are indicated by a Creative Commons license in the record and/ or on the work itself. This Dissertation has been accepted for inclusion in WVU Graduate Theses, Dissertations, and Problem Reports collection by an authorized administrator of The Research Repository @ WVU.

For more information, please contact researchrepository@mail.wvu.edu. 
Avoidance of Timeout from Response-Independent Schedules of Food or Sucrose Water with and without a Limited Hold on Consumption

\author{
August F. Holtyn \\ Dissertation Submitted to the \\ Eberly College of Arts and Sciences at West Virginia University \\ in partial fulfillment of the requirements for the degree of
Doctor of Philosophy
in
Psychology

\author{
Michael Perone, Ph.D., Chair \\ Kennon A. Lattal, Ph.D. \\ Elizabeth G. Kyonka, Ph.D. \\ Miranda N. Reed, Ph.D. \\ Nathalie Singh-Corcoran, Ph.D. \\ Department of Psychology
}

\title{
Morgantown, West Virginia \\ 2012
}

Keywords: avoidance; timeout; variable-time schedule; response competition; limited hold; rats 


\begin{abstract}
Avoidance of Timeout from Response-Independent Schedules of Food or Sucrose Water with and without a Limited Hold on Consumption
\end{abstract}

August F. Holtyn

Research on the relative aversiveness of timeout from lean and rich schedules of food delivery has yielded discrepant findings. Some research has shown that a lean schedule maintains higher avoidance response rates than a rich schedule (Thomas, 1964, 1965b; van Haaren \& Anderson, 1998) - suggesting that timeout from a lean schedule is more aversive than timeout from a rich schedule - while other research has shown the opposite (D'Andrea, 1971; Richardson \& Baron, 2008). The present study was based on the notion that the conflicting results may have arisen from differences in procedural details that influenced the effect of the food schedules on behavior that may compete with avoidance. At issue was whether a limited hold on consumption increases attending to the magazine (i.e., the site of food delivery) and decreases avoidance. When a limited hold is present, behavior directed toward the magazine may compete with avoidance, and thus compromise the validity of avoidance response rates as a measure of the aversiveness of timeout. When a limited hold is absent, competition between magazine-directed behavior and avoidance responding should be reduced, allowing avoidance response rates to serve as a valid measure of the aversiveness of timeout. Sixteen rats pressed a lever to avoid a 30-s timeout from a schedule of free food deliveries. Across conditions, the food deliverieseither pellets or sucrose water-were arranged on a response-independent basis according to different variable-time (VT) schedules. The VT schedule parameter was 0.5-min, 1-min, 2-min, 4-min, and 8-min. A timeout was programmed whenever $30 \mathrm{~s}$ elapsed without a lever press. In Experiment 1, the Limited Hold conditions involved presentation of a dipper of sucrose water for a fixed duration. The Unlimited Hold conditions involved delivery of pellets. Because each pellet remained in the magazine until the rat retrieved it, there was no limited hold on consumption. In Experiment 1, manipulation of the presence or absence of a limited hold was confounded by the item delivered. Experiment 2 was designed to address this confound; sucrose water was delivered in every condition. In some conditions, the sucrose water deliveries incorporated a limited hold as in Experiment 1: The dipper was raised for a fixed duration. In other conditions, the dipper remained in a raised position until the rat's head entered and exited the magazine as detected by a photocell. Regardless of whether a limited hold was present or absent, the rate of avoidance increased as the rate of food delivery was raised. This indicates that the aversiveness of timeout from a schedule of free food delivery is directly related to the richness of the schedule. 


\section{Acknowledgements}

I do not think I can sufficiently thank Mike Perone for being my advisor for the past four years. I consider myself extremely fortunate to have had the opportunity to learn from him. He is the best mentor and teacher a student could ask for!

I would like to thank the members of my committee, Mike Perone, Andy Lattal, Liz Kyonka, Miranda Reed, and Natahlie Singh-Corcoran for their helpful comments and suggestions on this document and their time and flexibility throughout this process.

There are a few additional people I would like to thank for several reasons. I thank Andy Lattal for the opportunity to conduct research within his lab. I am grateful for the experience and knowledge I have gained while working in the Lattal lab. I thank my officemates, Andrés García Penagos, Ellen Brosh, and Meagan Follett, who I am indebted to for their support, humor, and friendship, and, most importantly, for putting up with me. I thank Shana Bailey, Carlos Cançado, Aimee Giles, Trenton Gum, Ezra Hall, Sally Huskinson, Dave Jarmolowicz, Stephanie (Steven) Kincaid, Tonya Marsteller, Sarra Nazem, Sacha Pence, and Allison Tetreault for their friendship and support throughout my graduate career. You all made my time in the graduate program tremendously more enjoyable. Thank you to Sally Huskinson for help running sessions and for giving me much needed days off from the LSB!

I especially thank Ben Myers for his unwavering patience, encouragement, and support, and his constant belief in me. 


\section{Table of Contents}

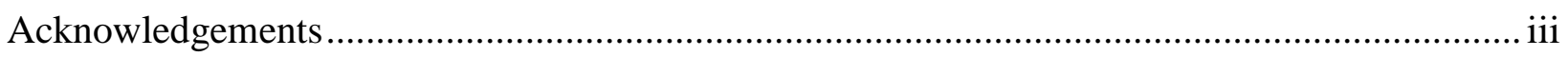

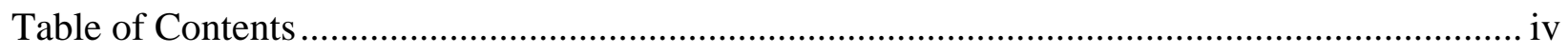

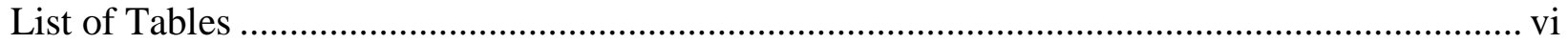

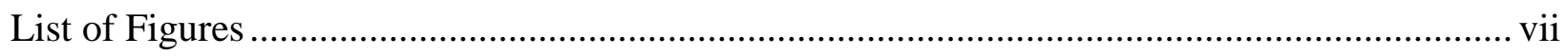

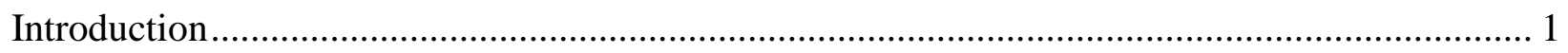

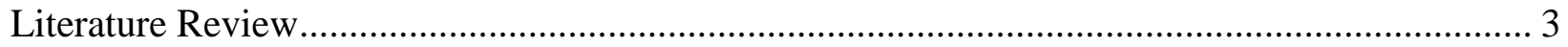

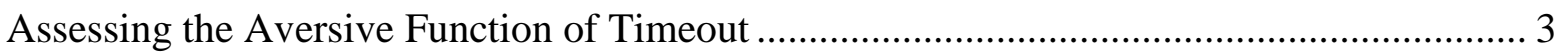

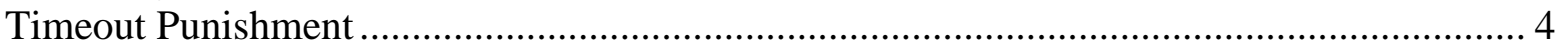

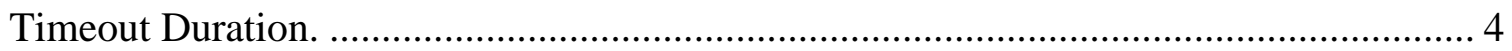

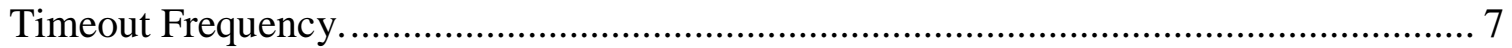

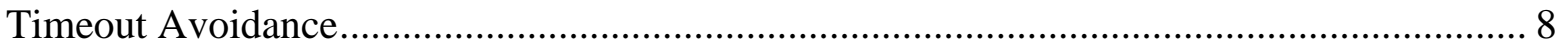

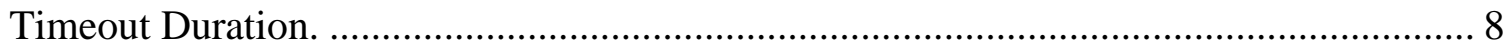

Schedule of Food Delivery. ....................................................................................... 10

The Role of Response Competition in Timeout Avoidance ................................................. 11

Range of Food Delivery Rates.................................................................................... 12

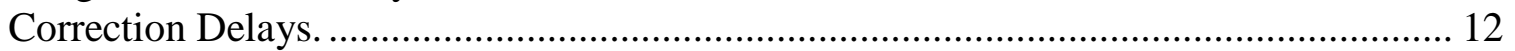

Response-Dependent and Response-Independent Schedules.......................................... 15

Limited Hold on Consumption.................................................................................. 16

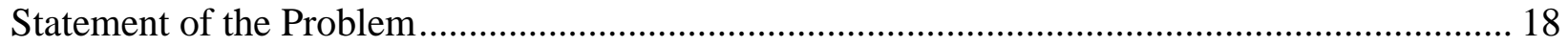

General Method and Preliminary Results ............................................................................... 20

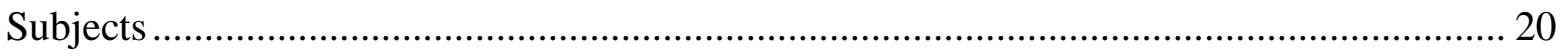

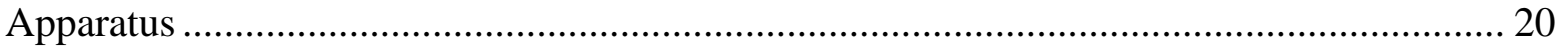

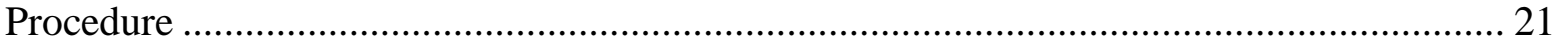

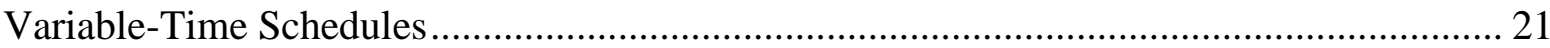

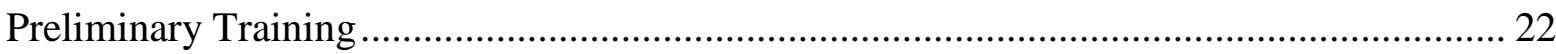

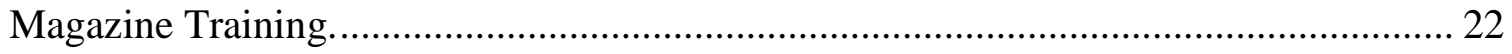

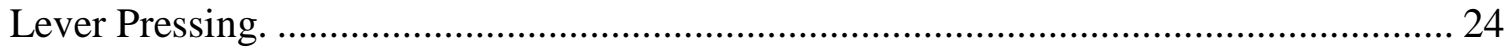

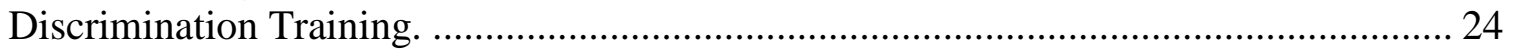

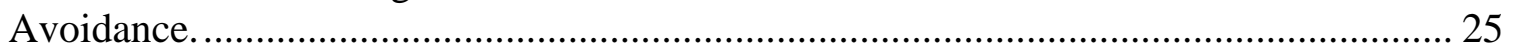

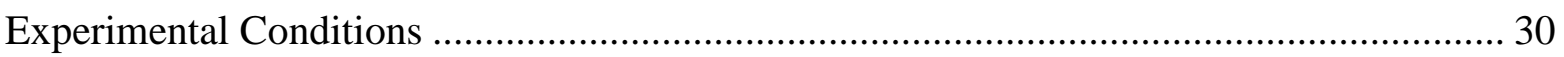

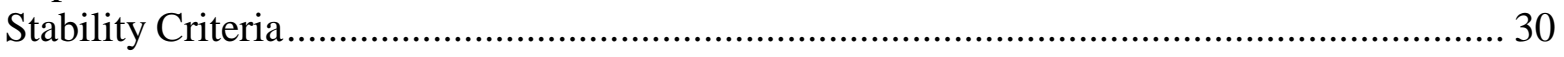

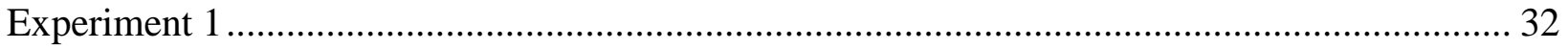

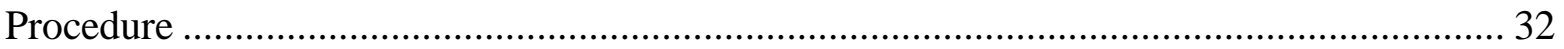

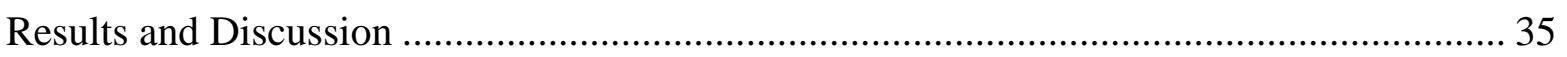

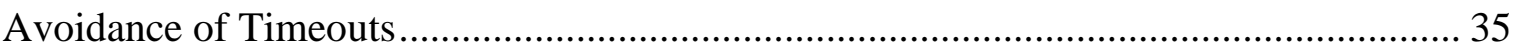

Avoidance Efficiency....................................................................................... 38

Within-Session Responding ..................................................................................... 41

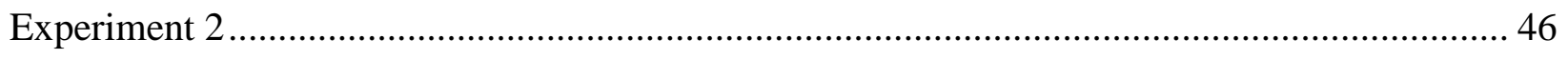

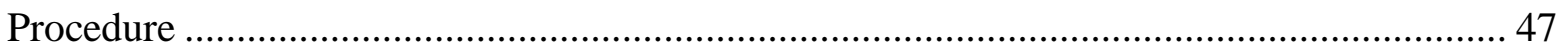




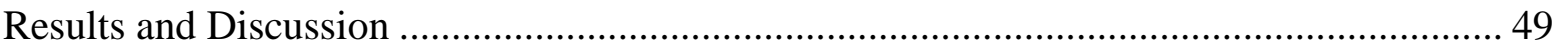

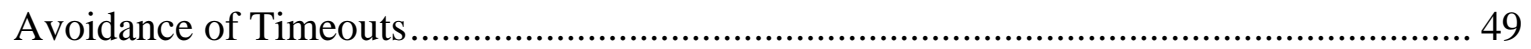

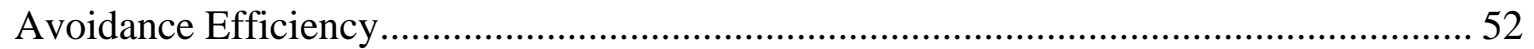

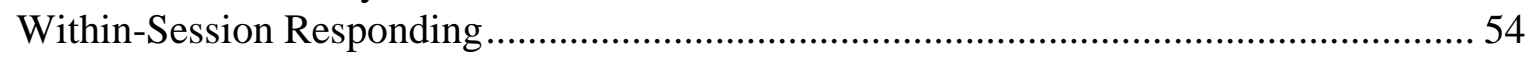

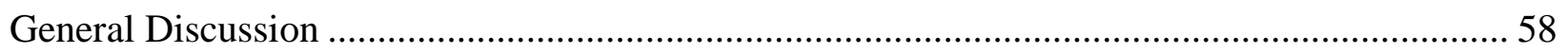

The Continued Effectiveness of Aversive Stimuli....................................................... 59

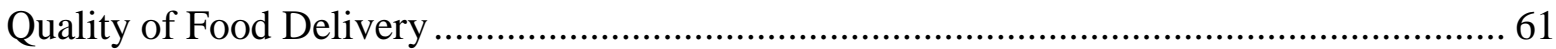

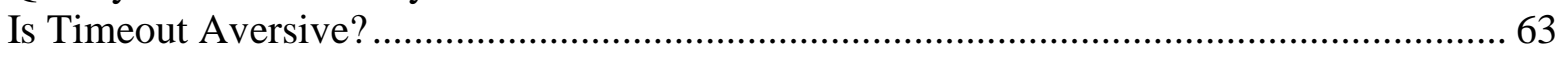

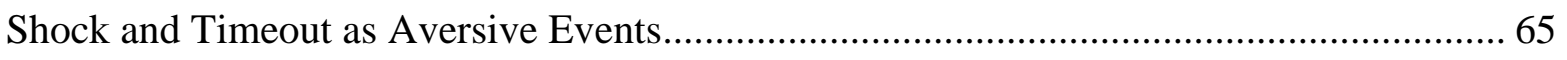

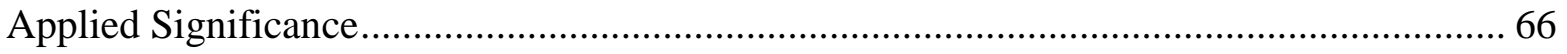

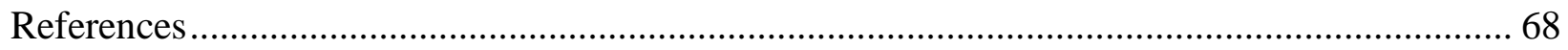

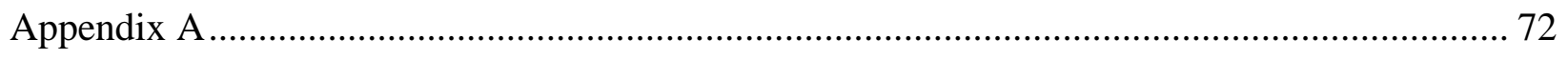

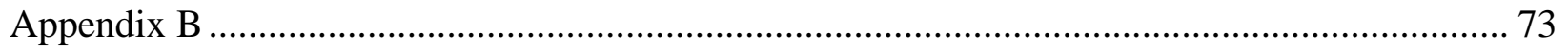

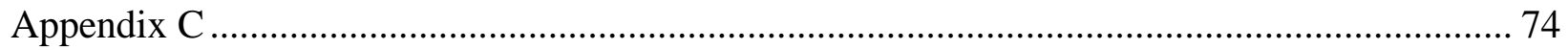

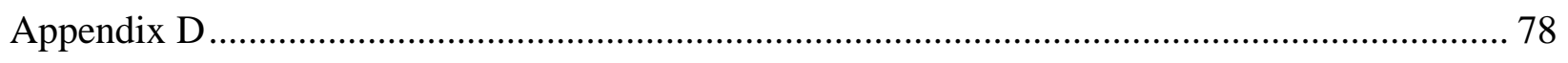

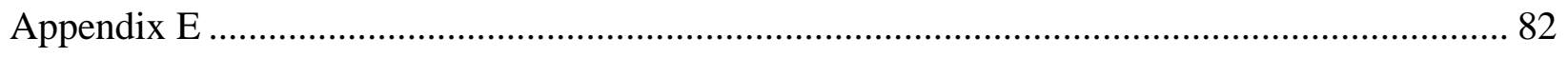

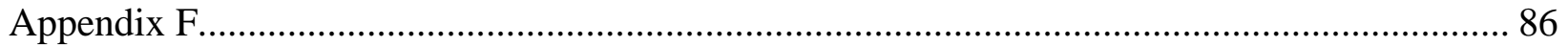




\section{List of Tables}

Table 1. Procedural details from five experiments that manipulated the frequency of food delivery.

Table 2. Received delivery rates aggregated across the last 10 sessions of each condition.

Table 3. Percentages of food deliveries that were postponed by $1 \mathrm{~s}$ because of the delay contingency.

Table 4. Experiment 1. Order of exposure to the different rates of food delivery and the number of sessions at each.

Table 5. Experiment 2. Order of exposure to the different rates of food delivery and the number of sessions at each.

Table C1. Experiment 1. Rates of avoidance responding as a function of 10-min blocks of timein across the last 10 sessions.

Table D1. Experiment 1. Percentages of timeouts avoided as a function of 10-min blocks of time-in across the last 10 sessions.

Table E1. Experiment 2. Rates of avoidance responding as a function of 10-min blocks of timein across the last 10 sessions.

Table F1. Experiment 2. Percentages of timeouts avoided as a function of 10-min blocks of time-in across the last 10 sessions. 


\section{List of Figures}

Figure 1. Avoidance responses plotted as a function of the frequency of food deliveries from four experiments that used response-independent schedules.

Figure 2. (Preliminary training, rats that received water deliveries). Avoidance responses per session when the escape (EX) option was available and unavailable and when plain water or sucrose water was delivered.

Figure 3. (Preliminary training, rats that received water deliveries). The probability of escape when plain water or sucrose water was delivered.

Figure 4. (Preliminary training, rats that received pellet deliveries). Avoidance responses per session when the escape option was available and unavailable and the probability of escape.

Figure 5. (Experiment 1, Unlimited Hold then Limited Hold). Rates of avoidance responding and percentage of timeouts avoided as a function of the food delivery rate per min.

Figure 6. (Experiment 1, Limited Hold then Unlimited Hold). Rates of avoidance responding and percentage of timeouts avoided as a function of the food delivery rate per min.

Figure 7. Experiment 1. Response efficiency as a function of hours of exposure to the avoidance schedule.

Figure 8. Experiment 1. Response efficiency as a function of the delivery rate per min.

Figure 9. Response efficiency as a function of the delivery rate per min. Results re-analyzed from Experiment 1 of Richardson and Baron (2008).

Figure 10. Experiment 1 (Unlimited Hold). Rates of avoidance responding and percentage of timeouts avoided as a function of 10-min blocks of time-in across the last 10 sessions.

Figure 11. Experiment 1 (Limited Hold). Rates of avoidance responding and percentage of timeouts avoided as a function of 10-min blocks of time-in across the last 10 sessions.

Figure 12. (Experiment 2, Unlimited Hold then Limited Hold). Rates of avoidance responding and percentage of timeouts avoided as a function of the food delivery rate per min.

Figure 13. (Experiment 2, Limited Hold then Unlimited Hold). Rates of avoidance responding and percentage of timeouts avoided as a function of the food delivery rate per min.

Figure 14. Experiment 2. Response efficiency as a function of hours of exposure to the avoidance schedule.

Figure 15. Experiment 2. Response efficiency as a function of the delivery rate per min. 
Figure 16. Experiment 2 (Unlimited Hold). Rates of avoidance responding and percentages of timeouts avoided as a function of 10-min blocks of time-in across the last 10 sessions.

Figure 17. Experiment 2 (Limited Hold). Rates of avoidance responding and percentages of timeouts avoided as a function of 10-min blocks of time-in across the last 10 sessions.

Figure 18. Rates of avoidance responding when food was delivered at a rate of 2 per min during the initial exposure and the replication of this condition.

Figure 19. Rates of avoidance responding when pellets and sucrose water were delivered at a rate of 0.25 or 0.125 per min and at a rate of 1 or 2 per min. 


\section{Introduction}

The term "operant behavior" refers to actions that are maintained by their consequences. When the presentation of a stimulus contingent on an action increases the likelihood that the action will be repeated, the stimulus is classified as a positive reinforcer. In the paradigm case of positive reinforcement, a food-deprived pigeon, confined within a small experimental chamber, pecks a plastic response key and grain is occasionally presented as a consequence. In some experimental arrangements, periods of positive reinforcement (when responding occasionally produces food) are juxtaposed with periods in which reinforcement is withheld (when responding has no programmed consequence). The behavioral effect of these periods of non-reinforcementtimeout from positive reinforcement-depends upon details of the experimental environment. In some cases, a pigeon will actively respond to produce a timeout, an effect suggesting that the period of positive reinforcement is aversive (Appel, 1963; Azrin, 1961). More commonly, it is the timeout that appears to have aversive functions. Perhaps this is not surprising. What may be surprising, however, is that our understanding of the factors that determine the aversiveness of timeout is incomplete.

Consider a study conducted by D'Andrea (1971) in which rats were trained to avoid timeout. Periods during which food was occasionally delivered, independent of responding, were interrupted by timeouts lasting $1 \mathrm{~min}$. In some conditions, food was arranged at a rate of 2 deliveries per min, on average. In other conditions, the food deliveries were arranged at a rate of 1 per min, on average. Rats could avoid timeouts by pressing a response lever. Across conditions, the timeouts occurred every $15 \mathrm{~s}$ unless the rat pressed the lever, in which case the timeout was postponed by $7.5 \mathrm{~s}, 15 \mathrm{~s}$, or $45 \mathrm{~s}$. A higher rate of avoidance was seen when food 
was delivered more frequently. This suggests that timeout from a rich schedule is more aversive than timeout from a lean schedule.

Now consider a study conducted by Thomas (1965b) in which pigeons were trained to avoid timeout. Periods during which food was occasionally delivered, independent of responding, were interrupted by timeouts lasting $5 \mathrm{~min}$. In some conditions, food was arranged at a rate of 0.33 deliveries per min, on average. In other conditions, the food deliveries were arranged at a rate of 1 per min, on average. Pigeons could avoid timeouts by pecking a response key. Across conditions, the timeouts occurred every $10 \mathrm{~s}$ unless the pigeon pecked the key, in which case the timeout was postponed by 20 s, 30 s, 60 s, or 120 s. A higher rate of avoidance was seen when food was delivered less frequently. This suggests that timeout from a lean schedule is more aversive than timeout from a rich schedule-a result quite different from that obtained by D'Andrea (1971).

It seems only reasonable to assume that the effect of timeout from a schedule of positive reinforcement should depend on the parameters of the schedule. There is a theoretical basis for predicting that timeout from a rich schedule should be more aversive than timeout from a lean schedule. According to the delay-reduction hypothesis (Fantino, 1977), a stimulus correlated with a reduction in the overall rate of reinforcement will acquire an aversive function (and a stimulus will acquire a reinforcing function if it is correlated with an increase in the overall rate of reinforcement) (for reviews, see Fantino, 1969, 1977; Fantino, Preston, \& Dunn, 1993). Timeout from a rich schedule of reinforcement is correlated with a greater reduction in the overall rate of reinforcement relative to timeout from a lean schedule of reinforcement. Accordingly, timeout from a rich schedule should be more aversive than timeout from a lean schedule. The delay-reduction hypothesis has been supported in a wide variety of experiments 
(Case \& Fantino, 1981; Preston \& Fantino, 1991; Williams \& Fantino, 1994) and suggests that timeout from a rich schedule should be more aversive. As noted previously, timeout studies have reported discrepant findings on the relation between food delivery rates and the aversiveness of timeout; the present study was designed to address this discrepancy.

What follows is a review of research concerned with the aversive function of timeout from positive reinforcement. The first section examines the classification of timeout as an aversive event. The later sections discuss experiments that have used timeout as a punisherwhen the presentation of timeout contingent on an action decreased the likelihood that the action was repeated-and as a negative reinforcer-when the removal of timeout contingent on an action increased the likelihood that the action was repeated.

\section{Literature Review}

\section{Assessing the Aversive Function of Timeout}

Two procedures, punishment and avoidance, are employed to examine the aversiveness of timeout. In a typical punishment procedure, food is occasionally delivered contingent on a pigeon's key pecks according to a variable-interval (VI) schedule. On a VI schedule, food is delivered for the first response after a variable interval of time since the last food delivery. The average of each of these intervals characterizes the schedule parameter. Food is delivered on a response-dependent basis, that is, the pigeon must peck the key to produce the delivery of food. Once responding stabilizes, key pecks also produce timeouts. The effect of timeout is assessed by comparing the rate of key pecking before and after the introduction of timeout; if timeout is aversive, it should reduce rates of pecking. In a typical avoidance procedure, food is occasionally delivered according to a variable-time (VT) schedule. On a VT schedule, the intervals between food deliveries are arranged in a manner similar to the VI schedule, but food is 
delivered on a response-independent basis, that is, the pigeon does not have to peck the key to produce the delivery of food. The VT schedule is interrupted by timeouts that are presented periodically unless the pigeon pecks a response key, in which case the timeout is postponed. Evidence for the aversive function of timeout comes from the observation that a pigeon will consistently peck the response key to avoid timeout.

\section{Timeout Punishment}

The following sections review research on the aversiveness of timeout within the punishment paradigm. The first section considers the manipulation of timeout duration. Although some studies report that raising the duration will increase the magnitude of suppression (Flory \& Lickfett, 1974; Kaufman \& Baron, 1968; Striefel, 1972; Thomas, 1968), other studies report no systematic relation between timeout duration and suppression (Dunn, 1990; Kramer \& Rilling, 1969; Nader \& Morgan, 2001). The final section addresses research that has manipulated the timeout schedule parameter, that is, manipulated the frequency of timeout. Although a variety of schedules have been examined, including ratio (Baron \& Kaufman, 1969; Branch, Nicholson, \& Dworkin, 1977; Kaufman \& Baron, 1968; McMillan, 1967; Thomas, 1968) and interval schedules (Nader \& Morgan, 2001; van Haaren \& Anderson, 1994) only two studies have directly manipulated the frequency of timeout (Dunn, 1990; Thomas, 1968).

Timeout Duration. Kaufman and Baron (1968, Experiment 2) found that raising the timeout duration increased the magnitude of suppression. In the baseline condition, rats' first and second lever presses were reinforced by presentation of a dipper filled with milk, while the third lever press had no programmed consequence. In the punishment conditions, the first and second lever presses were again reinforced, however, a timeout followed the third response. During timeouts, the white noise otherwise present during the session was turned off and a 500- 
cps tone was turned on. After a timeout, the tone was turned off, the white noise was turned on, and the ratio schedule was reinstated. Across punishment conditions, timeout duration was manipulated in the following order: $120 \mathrm{~s}, 10 \mathrm{~s}, 60 \mathrm{~s}$, and $90 \mathrm{~s}$.

Analyses were based on the time between each of the responses in the three-response sequence. In the baseline condition, all three responses occurred closely together (most were less than $4 \mathrm{~s}$ apart). In the punishment condition, the first and second responses continued to occur closely together. The second and third responses were more widely separated, indicating that the consequence of the third response-the timeout-was punitive. This punishment effect increased as the timeout duration was raised. For example, when the timeout duration was $10 \mathrm{~s}$, the time between the second and third responses averaged $4 \mathrm{~s}, 8 \mathrm{~s}$, and $8 \mathrm{~s}$ across the three rats, and when the timeout duration was $120 \mathrm{~s}$, the time averaged $62 \mathrm{~s}, 26 \mathrm{~s}$, and $29 \mathrm{~s}$.

Flory and Lickfett (1974) also found that the aversiveness of timeout increased as the timeout duration was raised. Rats' lever presses were reinforced with food on a fixed-interval (FI) 1-min schedule, so that a press after 1 min elapsed produced food. When drinking water was placed in the experimental chamber, schedule-induced polydipsia was observed. The term “schedule-induced polydipsia" was introduced by Falk (1961) after observing that rats responding on some intermittent schedules of food reinforcement would drink an excessive amount of water (about four times their normal daily intake) between reinforcements. After the rate of drinking stabilized, each lick on the drinking tube resulted in a timeout, during which the response lever was retracted and the FI schedule was suspended. Across phases the timeout duration was as follows: $10 \mathrm{~s}, 20 \mathrm{~s}, 40 \mathrm{~s}$, and $80 \mathrm{~s}$. The rate of drinking decreased as the timeout duration was raised. For example, when timeouts were $10 \mathrm{~s}$, the mean rate of drinking, across the three rats, was 0.37 licks per min, and when timeouts were $80 \mathrm{~s}$, the rate was 0.08 licks per 
min. This suggests that a longer timeout is more aversive (i.e., more punitive) than a shorter timeout.

The notion that the magnitude of suppression is a direct function of the timeout duration has not been unambiguously supported. In a study by Kramer and Rilling (1969), pigeons' key pecks were maintained by a schedule that differentially reinforced low rates of responding (DRL schedule). Food was delivered after interresponse times (IRTs) that were longer than $20 \mathrm{~s} \mathrm{(DRL}$ 20-s). During punishment sessions, IRTs shorter than $20 \mathrm{~s}$ were followed by a timeout. Across sessions, the timeout duration was changed in a quasi-random fashion; the durations were $5 \mathrm{~s}, 10$ $\mathrm{s}$, and $20 \mathrm{~s}$. Timeout punished short IRTs in all pigeons (the percentage of short IRTs decreased), but little difference was observed across the three timeout durations.

Nader and Morgan (2001) also reported that raising the timeout duration failed to change the magnitude of suppression. Nader and Morgan studied cocaine self-administration by rhesus monkeys by way of a four-component multiple schedule. In each component, lever presses resulted in the delivery of cocaine $(0.03 \mathrm{mg} / \mathrm{kg} /$ injection $)$ according to an FI 5 -min schedule. Each component lasted $30 \mathrm{~min}$, occurred once within a session, and was separated by a $30 \mathrm{~s}$ inter-trial interval. Once responding stabilized, timeouts were imposed in the second and fourth components according to a VI 30-s schedule. During timeouts, the chamber lights were turned off and lever presses had no programmed consequence, but the FI schedule continued to advance. Across conditions, the timeout duration was $10 \mathrm{~s}, 30 \mathrm{~s}$, or $60 \mathrm{~s}$. The timeouts were effective punishers: Self-administration decreased in 65 percent of the 48 different combinations of cocaine dose and timeout duration (collapsed across monkeys). Raising the timeout duration, however, did not systematically affect the magnitude of suppression. 
Timeout Frequency. Thomas (1968) reported that raising the frequency of timeout led to greater suppression of responding. Pigeons were exposed to two concurrently available VI 180-s schedules of food reinforcement. A fixed-ratio (FR) schedule of timeout was superimposed on one of the VI schedules. On an FR schedule, a consequence is delivered after a specified number of responses. The FR schedule was manipulated across conditions as follows: $50,25,10$ and 2. As the frequency of timeout was raised (by reducing the FR requirement), the rate of responding on the punished alternative decreased. For example, when the schedule of timeout was FR 25, the absolute response rate averaged 8, 20, and 37 responses per min across the three pigeons, and when the schedule of timeout was FR 2, the rate averaged 5, 12, and 8 responses per min.

Dunn (1990, Experiment 1) failed to replicate Thomas’s (1968) results. Pigeons were exposed to a VI 45-s schedule of reinforcement on the right key and a VI 90-s schedule on the left. Only one key was turned on at a time; a pigeon could change to the other key by making four responses on the center key. Across conditions, timeout was arranged for responses on either key according to VI schedules. The VI schedule parameters were $45 \mathrm{~s}, 90 \mathrm{~s}$, and $180 \mathrm{~s}$. Timeout decreased responding relative to baseline: Collapsed across timeout frequency, the rate of responding on the right key decreased by 6 to 42 percent. Raising the frequency of timeout, however, did not have systematic effects.

Timeout can be an effective punisher, but the environmental circumstances that determine its ability to punish responding are unclear. Raising the timeout duration has, in some experimental arrangements, led to greater suppression of responding, while in other arrangements, raising the duration has not increased suppression. Changes in the frequency of timeout have been less studied than timeout duration, but the same inconsistencies exist. 


\section{Timeout Avoidance}

The following sections review research on the aversiveness of timeout within the avoidance paradigm. ${ }^{1}$ The first section considers the manipulation of timeout duration. One study found that raising the duration affects avoidance response rates (Thomas, 1965a), while other studies did not (Defulio \& Hackenberg, 2007; Pietras \& Hackenberg, 2000). The next section considers the schedule of food delivery. In some cases, a rich schedule maintained lower avoidance response rates than a lean schedule (Thomas 1964, 1965b; van Haaren \& Anderson, 1998). In other cases, a rich schedule maintained higher response rates (D'Andrea, 1971; Richardson \& Baron, 2008).

Timeout Duration. Thomas (1965a, Experiment 4) reported that raising the timeout duration increased avoidance response rates, at least up to a point. Pigeons' pecks were reinforced according to a variable-ratio (VR) 140 schedule, so that a peck after 140 responses, on average, produced food. Timeouts occurred every $60 \mathrm{~s}$ unless the pigeon pecked an avoidance key, in which case the timeout was postponed by $60 \mathrm{~s}$. Across conditions, four timeout durations were investigated: $0.5 \mathrm{~min}, 2 \mathrm{~min}, 5 \mathrm{~min}$, and $15 \mathrm{~min}$. The relation between avoidance response rates and timeout duration was curvilinear: Rates were moderate at $0.5 \mathrm{~min}$ and $2 \mathrm{~min}$, highest at $5 \mathrm{~min}$, and lowest at $15 \mathrm{~min}$ (avoidance response rates averaged across pigeons were, 1.7, 1.9, 3.2, and 0.9 responses per min, respectively).

Defulio and Hackenberg (2007, Experiment 1) extended Thomas's (1965a) work by manipulating timeout duration across a wider range, but they did not observe the same relation

\footnotetext{
${ }^{1}$ Previous research on shock avoidance has shown that raising the time by which each response postpones shock decreases the rate of avoidance (e.g., Sidman, 1953). A similar relation between response rate and postponement time has been shown in the timeout avoidance literature (see, D’Andrea, 1971; Defulio \& Hackenberg, 2007; Galbicka \& Branch, 1983; Pietras \& Hackenberg, 2000; Thomas, 1965b). These studies suggest that animals are sensitive to time, or the temporal nature of the avoidance schedule. Because this relation between avoidance response rates and postponement time reflects temporal control and does not directly reflect the aversiveness of timeout, it will not be considered in the current review.
} 
between duration and avoidance response rates. Pigeons' pecks were reinforced with food according to a VI 360-s schedule. Across conditions, timeouts occurred every $15 \mathrm{~s}, 30 \mathrm{~s}$, or $60 \mathrm{~s}$ unless the pigeon pecked an avoidance key, in which case the timeout was postponed by $15 \mathrm{~s}, 30$ s, or $60 \mathrm{~s}$. Each of these postponement times was examined at the following timeout durations: 15 s, 30 s, 60 s, 75 s, 120 s, 150 s, 300 s, and 600 s. Raising the timeout duration did not consistently increase avoidance response rates. For example, for one pigeon, when the postponement interval was $15 \mathrm{~s}$, the rate of avoidance averaged 4.4 responses per min at a timeout duration of $15 \mathrm{~s}, 4.4$ at $30 \mathrm{~s}, 5.2$ at $75 \mathrm{~s}$, and 3.6 at $150 \mathrm{~s}$.

Thomas (1965a, Experiment 4) and Defulio and Hackenberg (2007, Experiment 1) used discriminated avoidance procedures: The period between timeouts was split into four equal segments. As time elapsed without an avoidance response, the key color changed. Pecks on the avoidance key restarted the interval and reset the food key to the initial color. Both studies found that avoidance response rates were highest in the presence of the stimulus that had the closest temporal proximity to timeout.

One might expect that a stimulus preceding timeout would develop an aversive function through pairing of the stimulus with timeout. Because the pigeons tended to wait until this stimulus was present to peck the avoidance key, one may argue that this provides evidence that timeout is not aversive. This explanation overlooks the discriminative function of the stimuli. Pecks on the avoidance key in the presence of the stimulus with the closest temporal proximity to timeout produce the longest postponement in the period until timeout. Consider an experimental arrangement in which each avoidance response postpones timeout by $30 \mathrm{~s}$. A peck at $29 \mathrm{~s}$ into the postponement period postpones a timeout that would have occurred in $1 \mathrm{~s}$ to occur in $30 \mathrm{~s}$, a difference of $29 \mathrm{~s}$. By comparison, a peck at $1 \mathrm{~s}$ into the period postpones a timeout that would 
have occurred in $29 \mathrm{~s}$ to occur in $30 \mathrm{~s}$, a difference of just $1 \mathrm{~s}$. Thus, a peck later in the period has a greater consequence than a peck earlier in the period. The stimuli preceding timeout or shock serve a discriminative function that signals periods during which responding is most effective (Defulio \& Hackenberg, 2007; Hineline, 1984).

Schedule of Food Delivery. Three experiments found that a rich schedule of food delivery maintained lower avoidance response rates than a lean schedule. In an experiment by Thomas (1964), pigeons' pecks on one key were reinforced with food according to a VI 9-min schedule and pecks on a second key postponed a 5-min timeout by $60 \mathrm{~s}$. As the food schedule was enriched from VI 9-min to VI 1-min, the rate of avoidance decreased. A series of reversals confirmed that the avoidance rate was lower on the richer schedule. In an additional experiment by Thomas (1965b) using pigeons, food was delivered independent of responding, in the presence of a green key, according to a VT 1-min schedule. In other conditions, food was delivered according to a VT 3-min schedule. Food was not delivered for a 5-min period in the presence of a red key (the timeout); however, across conditions the pigeons could postpone timeouts by 20 s, 30 s, 60 s, or 120 s by pecking the green key. Avoidance response rates were lower on the richer schedule (VT 1-min). Van Haaren and Anderson (1998) also found that timeout from rich schedules maintain less avoidance than that from lean schedules. Rats responded on a two-component multiple schedule; in the rich component, food was delivered on a random-time (RT) 30-s schedule and in the lean component, an RT 120-s schedule. Lever presses postponed a 50-s timeout by $20 \mathrm{~s}$. For most of the rats, there were lower rates of avoidance on the richer schedule. The results of these studies suggest that timeout from a rich schedule is less aversive than that from a lean schedule.

D’Andrea (1971) reported that avoidance response rates were higher on the richer of two 
schedules. Across conditions, food was delivered to rats on a response-independent basis, according to a VT 0.5 -min or a VT 1-min schedule. Timeouts occurred every $15 \mathrm{~s}$ unless the rat pressed a lever, in which case the timeout was postponed by $7.5 \mathrm{~s}, 15 \mathrm{~s}$, or $45 \mathrm{~s}$. When food was delivered on the richer schedule, the rate of avoidance was higher than when food was delivered on the leaner schedule. Richardson and Baron (2008) also found that timeout from rich schedules maintain more avoidance than that from lean schedules. Food was delivered to rats on a response-independent basis according to a VT schedule with the following parameters: $0.5,1$, 2,4 , and 8 min. Timeouts occurred every $30 \mathrm{~s}$ unless the rat pressed a lever, in which case the timeout was postponed by $30 \mathrm{~s}$. As the rate of food delivery was raised, the rate of avoidance increased. The results of these studies suggest that timeout from a rich schedule is more aversive than that from a lean schedule.

\section{The Role of Response Competition in Timeout Avoidance}

The timeout avoidance studies that have been reviewed here vary across many dimensions. Two of these dimensions include the timeout duration and the schedule of food delivery. Raising the timeout duration has, in some experimental arrangements, increased avoidance response rates, while in other arrangements, raising the duration has not. Failure to find a systematic relation between timeout duration and avoidance response rates is not surprising given that timeout is rarely contacted when consistent avoidance responding is established (a subject may not contact the changes in duration). The effect of different schedules of food delivery is more controversial. Some studies have reported a higher rate of avoidance from a lean schedule compared to a rich schedule, while other studies have reported the opposite. In an attempt to understand this discrepancy, it may be important to consider other procedural details. These include: the range of food delivery rates, a programmed delay between avoidance 
responses and food deliveries (correction delay), the response-dependent or the responseindependent delivery of food, and the presence or absence of a limited hold on consumption.

Range of Food Delivery Rates. Figure 1 displays avoidance response rates as a function of the frequency of food deliveries for the studies that manipulated the rate of responseindependent food. The filled and unfilled symbols represent responding across subjects (within each panel, data from the same subject are plotted using the same symbol). The overall pattern of responding in Richardson and Baron's (2008) study shows a positive relation: As the frequency of food delivery increases, rates of avoidance increase. This pattern is evident even though within-subject changes in avoidance response rates are sometimes inconsistent-for two subjects, avoidance response rates decreased in some instances in which the schedule of food delivery was enriched (from 0.25 per $\min$ to 0.5 per min and 1 per min to 2 per $\min$ ). If Richardson and Baron had not compared a range of delivery rates, the relation between avoidance response rates and the frequency of food delivery would be less clear. The other studies shown in Figure 1 were limited inasmuch as parametric manipulations of the rate of food delivery were restricted to two levels. The present research examined timeout avoidance across a range of delivery rates as done by Richardson and Baron.

Correction Delays. Table 1 summarizes the experiments that investigated timeout avoidance when the frequency of food delivery was manipulated. For each experiment, the following information is presented: the authors, the year of publication, the subject species, the schedules of food delivery, if a delay between avoidance responses and food deliveries was programmed (correction delay), if the schedules of food delivery were response-independent, and whether a direct relation between food delivery rate and avoidance response rates was reported. 


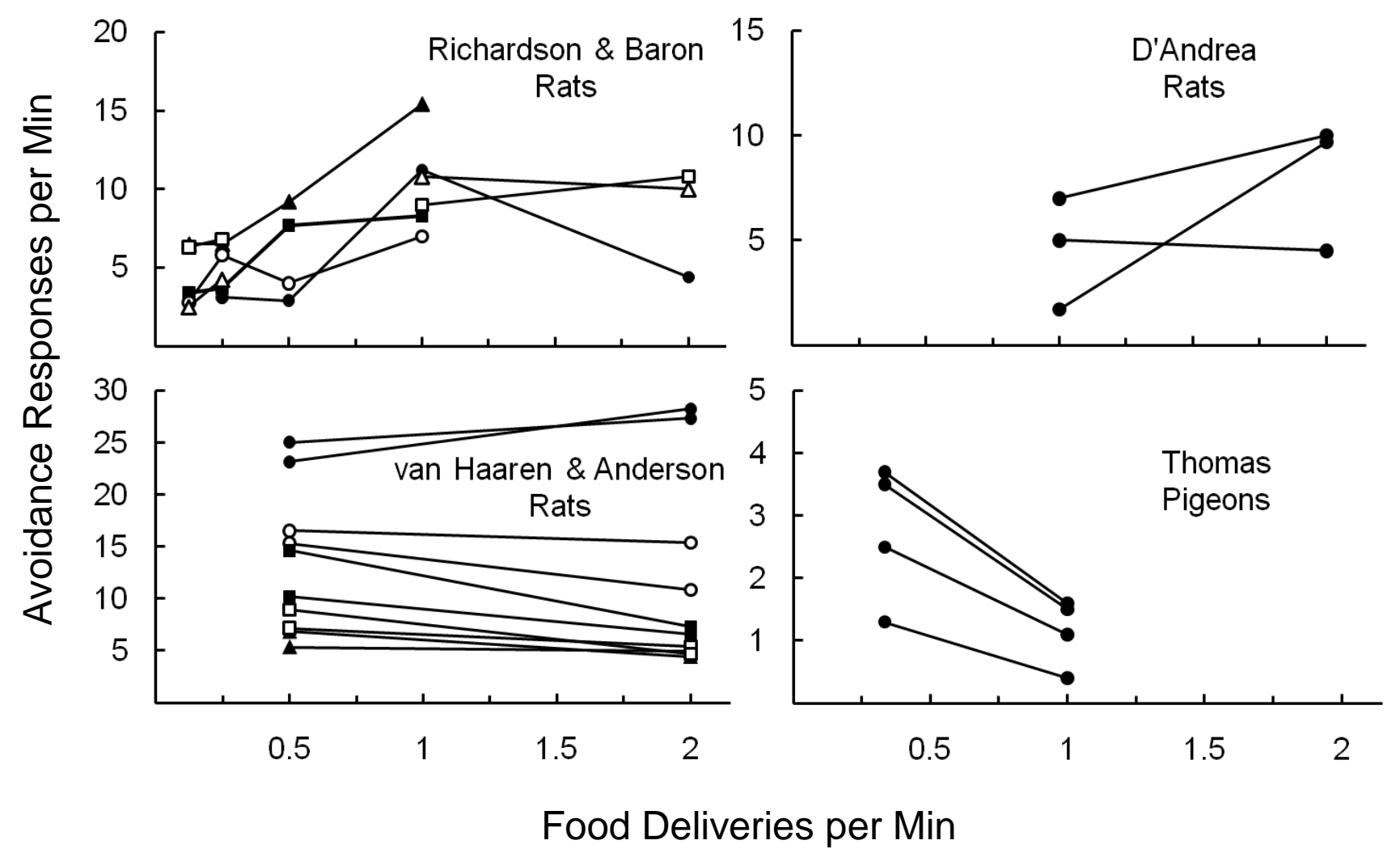

Figure 1. Avoidance responses plotted as a function of the frequency of food deliveries per min. The top and bottom panels display avoidance response rates across four experiments (identified by the authors' names) that manipulated the frequency of food deliveries using responseindependent schedules. The filled and unfilled symbols represent responding across subjects (within each panel, data from the same subject are plotted using the same symbol). The type of subject species is shown in each panel. 
Table 1

Procedural details from five experiments that manipulated the frequency of food delivery. Food was delivered according to a variable-interval (VI), variable-time (VT), or random-time (RT) schedule. The correction delay indicates if a delay between avoidance responses and food deliveries was programmed. A direct relation indicates that as the food delivery rate was raised, avoidance response rates increased.

\begin{tabular}{|c|c|c|c|c|c|c|}
\hline Author(s) & Year & Subjects & $\begin{array}{l}\text { Food } \\
\text { Schedule } \\
\text { in minutes }\end{array}$ & $\begin{array}{l}\text { Correction } \\
\text { Delay } \\
\text { in seconds }\end{array}$ & $\begin{array}{l}\text { Response } \\
\text { Indepen- } \\
\text { dent food }\end{array}$ & $\begin{array}{l}\text { Direct } \\
\text { Relation }\end{array}$ \\
\hline Thomas & 1964 & Pigeons & $\begin{array}{l}\text { VI } 1 \\
\text { VI } 9\end{array}$ & none & No & No \\
\hline Thomas & 1965 & Pigeons & $\begin{array}{l}\text { VT } 1 \\
\text { VT } 3\end{array}$ & 4 & Yes & No \\
\hline D'Andrea & 1971 & Rats & $\begin{array}{l}\text { VT } 0.5 \\
\text { VT } 1\end{array}$ & none & Yes & Yes \\
\hline $\begin{array}{l}\text { van Haaren } \\
\& \\
\text { Anderson }\end{array}$ & 1998 & Rats & $\begin{array}{l}\text { RT } 0.5 \\
\text { RT } 2\end{array}$ & 2 & Yes & No \\
\hline $\begin{array}{l}\text { Richardson } \\
\& \\
\text { Baron }\end{array}$ & 2008 & Rats & $\begin{array}{l}\text { VT } 0.5 \\
\text { VT } 1 \\
\text { VT } 2 \\
\text { VT } 4 \\
\text { VT } 8\end{array}$ & 3,6 & Yes & Yes \\
\hline
\end{tabular}


As shown in Table 1, in three of the five experiments, a delay was programmed after each avoidance response during which food was not delivered. Although these correction delays were used to prevent the adventitious reinforcement of responding (i.e., the delivery of food after an avoidance response) they may have functioned as a negative punisher; the delaying of food could have decreased the likelihood of lever pressing. If the correction delays functioned as a negative punisher, the magnitude of the punisher would differ across the lean and rich schedules of food delivery. The delay would be contacted only occasionally in the lean schedule (because there is a low rate of food delivery, only a few responses would delay a delivery). But in the rich schedule, responses would be more likely to delay the delivery of food. A denser punishment schedule would be arranged in the richer schedule and could result in a larger reduction in avoidance response rates.

Of the three studies that used correction delays, two (Thomas, 1965b; van Haaren \& Anderson, 1998) reported that avoidance response rates decreased as the schedule of food delivery was enriched, which is what one would predict if the correction delays functioned as a negative punisher. However, Richardson and Baron (2008, Experiment 3) lengthened the correction delay from $3 \mathrm{~s}$ to $6 \mathrm{~s}$ (if the correction delays functioned as a negative punisher, a longer delay would have a greater punitive effect) and reported no change in avoidance response rates. The authors noted that their delay contingency was rarely contacted (i.e., following less than 10 percent of total responses). The degree to which the correction delays were contacted in Thomas and van Haaren and Anderson's experiments is unknown.

Response-Dependent and Response-Independent Schedules. When food deliveries are response-dependent, time spent engaged in the target response (i.e., the response that produces food) will compete with avoiding timeout. If the rate of food delivery is raised, the rate 
of responding for food is likely to increase as well. The increased competition between responding for food and avoiding timeout would tend to reduce rates of avoidance responding. Thomas (1964) compared avoidance response rates when rich and lean schedules of food delivery were response-dependent. As the schedule of food delivery was enriched from VI 9min to VI 1-min, avoidance response rates dropped to zero. Because the response-dependent schedule competed with avoidance responding, avoidance response rates were lower when food was presented at a higher rate.

When food deliveries are response-independent, there is not a target response that will compete with avoiding timeout. The degree of response competition should be reduced from that engendered by a response-dependent schedule. Thus, it is less likely that the validity of avoidance response rates as a measure of the aversiveness of timeout will be compromised when a response-independent schedule of food delivery is used. It is important to remember, however, that when a response-independent schedule is used, the animal must still engage in several behaviors to actually consume the food that is delivered. These behaviors often are not measured; a target response is selected and other behaviors that occur during experimental sessions are ignored. This is a pragmatic approach. When these unmeasured behaviors interfere with the target response, however, they require consideration. This will be discussed in the following section.

Limited Hold on Consumption. As shown in Table 1, two of the three studies that did not report a direct relation used pigeons as subjects and access to grain as the reinforcer (Thomas, 1964; 1965b). In comparison, the two studies that did report a direct relation used rats as subjects and pellet deliveries as the reinforcer (D'Andrea, 1971; Richardson \& Baron, 2008). 
In operant research with pigeons, access to grain is made available typically by raising a hopper for a set period. Therefore, the amount of food that a pigeon obtains from a raised hopper will depend on how quickly the pigeon reaches the hopper; the magnitude and the immediacy of the reinforcer depend on the pigeon's latency. The term "limited hold" describes circumstances in which a reinforcer must be obtained within a set period of time. A limited hold on access to grain may shape a certain kind of behavior that will tend to minimize the latency to reach a raised hopper, that is, a greater degree of attending to the hopper.

Thomas (1965b) used an experimental arrangement in which access to grain was delivered on a response-independent basis and pecks on a key postponed timeout. In this arrangement, the time the pigeon spends attending to the hopper may compete with responding on the key. If the rate of food delivery is raised, the degree of attending to the hopper is likely to increase as well. The increased competition between attending to the hopper and avoiding timeouts would tend to reduce rates of avoidance responding.

In operant research with rats, the method of food delivery may shape a different kind of behavior than that seen with pigeons. Food is dispensed into a magazine and remains in the magazine until consumed; there is no limited hold on consumption. Regardless of how fast the rat reaches the magazine, the magnitude of the pellet will not change (although immediacy will be affected). Now consider an experimental arrangement, similar to that used by D'Andrea (1971) and Richardson and Baron (2008), in which food is delivered on a response-independent basis and lever presses postpone timeout. Because there is no limited hold on food consumption, there is less response competition between attending to the magazine and avoiding timeouts. The magnitude of the pellet does not depend on a short latency. Thus, competition between 
magazine-directed behavior and avoidance responding should be reduced, allowing avoidance response rates to serve as a measure of the aversiveness of timeout.

An examination of procedural details reveals that some of the experiments that manipulated the frequency of food delivery incorporated contingencies that compete with avoidance. These include a negative punisher (i.e., the correction delay), responding for response-dependent food, and the presence of a limited hold on consumption. Although each of these variables merits further examination, the present research examined the effects of a limited hold on consumption.

\section{Statement of the Problem}

Research on the relative aversiveness of timeout from lean and rich schedules of food delivery has yielded discrepant findings. Thomas $(1964,1965 b)$ observed that pigeons responded to avoid timeouts from a lean schedule at a higher rate than they did to avoid timeouts from a rich schedule. As the rate of food delivery was enriched, the rate of avoidance decreased. This inverse relation between food delivery rates and avoidance response rates suggests that timeout from a rich schedule is less aversive than timeout from a lean schedule. D'Andrea (1971) and Richardson and Baron (2008), however, reported the opposite relation using rats: As the rate of food delivery was enriched, the rate of avoidance increased. This direct relation suggests that timeout from a rich schedule is more aversive than timeout from a lean schedule.

The present study was based on the notion that the conflicting results may have arisen from differences in procedural details that influenced the effect of the food schedules on behavior that may compete with avoidance. Thomas $(1964,1965 \mathrm{~b})$ used pigeons as subjects and D’Andrea (1971) and Richardson and Baron (2008) used rats. When food is delivered to pigeons, a hopper is raised for a set period; the amount of food a pigeon obtains will depend on 
the pigeon's latency to reach the hopper. This limited hold on consumption may shape behavior that will minimize the latency to reach the hopper, that is, a greater degree of attending to the hopper. When food is delivered to rats, it is dispensed into a magazine and remains in the magazine until consumed; there is no limited hold on consumption. At issue was whether a limited hold on consumption increases attending to the magazine and decreases avoidance.

When a limited hold is present, behavior directed toward the magazine may compete with avoidance, and thus compromise the validity of avoidance response rates as a measure of the aversiveness of timeout. When a limited hold is absent, competition between magazine-directed behavior and avoidance responding should be reduced, allowing avoidance response rates to serve as a measure of the aversiveness of timeout. The present research examined how a limited hold on consumption affects avoidance of timeout. In Experiment 1, the Limited Hold conditions involved presentation of a dipper of sucrose water for a fixed period. The Unlimited Hold conditions involved delivery of pellets. Because each pellet remained in the magazine until the rat retrieved it, there was no limited hold on consumption. Whether any differences in rates of avoidance were due to the order in which rats were exposed to the Limited Hold and Unlimited Hold conditions was examined. Four rats experienced the Unlimited Hold conditions before the Limited Hold conditions, and four rats experienced the conditions in the opposite order.

In Experiment 1, manipulation of the presence or absence of a limited hold was confounded by the item delivered: pellets in the Unlimited Hold conditions and sucrose water in the Limited Hold conditions. Experiment 2 was designed to address this confound. Sucrose water was delivered in every condition. In some conditions, the sucrose water deliveries incorporated a limited hold as in Experiment 1: The dipper was raised for a fixed duration. In other conditions, the dipper remained in a raised position until the rat's head entered and exited 
the magazine as detected by a photocell. Thus, the use of a photocell removed the limited hold on sucrose water deliveries. Experiment 2 also evaluated the effects of the order of the Limited Hold and Unlimited Hold conditions. Four rats experienced the Limited Hold conditions before the Unlimited Hold conditions, and four rats experienced the opposite order.

\section{General Method and Preliminary Results}

Experiments 1 and 2 had a number of elements in common. These include the method used to establish the baseline behavior and the results of this preliminary training. The following section will describe the general method and the results of the preliminary training.

\section{Subjects}

A total of 16 experimentally naïve, male Sprague-Dawley rats were studied (8 per experiment). The rats were maintained at $80 \%( \pm 2 \%)$ of their free-feeding body weights by pellet (45 mg Bioserv pellets) or sucrose water ( $30 \%$ sucrose, $0.1 \mathrm{~mL}$ ) deliveries during the experimental sessions and, if necessary, by supplemental feedings in the home cage at least 30 min after the sessions. Target weights were adjusted periodically according to growth charts provided by the supplier and water was freely available in the home cages. All rats were housed individually in a temperature-controlled room with a 12:12 hr reversed light/dark cycle. For details on the preparation of the sucrose water, see Appendix A. For an example of the growth charts, see Appendix B.

\section{Apparatus}

Sessions were conducted in eight identical operant chambers enclosed in ventilated sound attenuating chests (Med Associates Inc., St. Albans, VT). Each chamber was $29 \mathrm{~cm}$ long, $22 \mathrm{~cm}$ high and $24 \mathrm{~cm}$ deep. The ceiling and sidewalls were constructed of Plexiglas, and the end walls of stainless steel. The floor consisted of 19 stainless-steel rods $0.5 \mathrm{~cm}$ in diameter spaced 
approximately $1.3 \mathrm{~cm}$ apart. On the front wall were two retractable levers. Each lever was 4.4 $\mathrm{cm}$ wide, $1.3 \mathrm{~cm}$ thick, and protrudes $1.9 \mathrm{~cm}$ into the chamber when inserted. The inside edges of the levers were spaced $11.4 \mathrm{~cm}$ apart $(5.7 \mathrm{~cm}$ from the middle of the wall). The tops of the levers were positioned $8 \mathrm{~cm}$ from the floor. Approximately $5 \mathrm{~cm}$ above each lever was a white cue light (No. 1820 bulb). Depending on the experiment, either food or sucrose water was dispensed into a magazine centered on the front wall. The rat's head entries into the magazine were detected with a photocell. General illumination was provided by a houselight (No. 1820 bulb) located on the back wall. White noise $(85 \mathrm{~dB})$ masked extraneous sounds. Experimental events were controlled and recorded using a computer with Med Associates interfacing hardware and MED-PC IV@ software.

\section{Procedure}

Sessions were conducted 7 days per week at approximately the same time of day. Before each session, the rats were settled in the chamber for 5 min with the chamber lights turned off and the levers retracted. This was done to minimize the effects of handling on behavior during the experiment. Sessions began with the onset of the houselight, the onset of white noise and, in most cases, the insertion of the left or right lever (counterbalanced across rats) into the chamber. Except as noted below, sessions lasted for $60 \mathrm{~min}$ of time-in; the time-in period excluded the duration of food deliveries and the duration of timeouts. For simplicity, the term "food delivery" will be used to refer to both pellet deliveries and sucrose water deliveries when the nature of the item delivered does not matter.

\section{Variable-Time Schedules}

Across conditions, each rat was exposed to various rates of food deliveries arranged on a response-independent basis according to different variable-time (VT) schedules. The VT 
schedules had mean durations of $0.5 \mathrm{~min}, 1 \mathrm{~min}, 2 \mathrm{~min}, 4 \mathrm{~min}$, and $8 \mathrm{~min}$, yielding mean rates of food delivery of 2 per min, 1 per min, 0.5 per min, 0.25 per min, and 0.125 per min. The VT schedules consisted of 15 intervals that were generated using the constant probability distribution described by Fleshler and Hoffman (1962).

Table 2 shows received delivery rates across the last 10 sessions of each condition. Results are organized based on the programmed rate of food delivery and the presence or absence of a limited hold. For present purposes, the presence or absence of a limited hold is not important. What is important is that the received rates closely approximated the programmed rates in all conditions except when deliveries were programmed at a rate of 0.125 per min. In this condition, less than 15 intervals were selected in a given session (i.e., to arrange this food delivery rate within an hour of time-in time, only 7.5 deliveries could occur); this resulted in greater between-session variability in the number of deliveries per session depending on which of the 15 intervals were selected, at random. However, the received rates in the 0.125 per min condition were still lower than those in the 0.25 per min condition.

\section{Preliminary Training}

For some rats, preliminary training was initially conducted with plain water rather than sucrose water because the original plan was to use plain water. For reasons discussed in the Avoidance section, water deliveries were replaced with sucrose water deliveries.

Magazine Training. Each rat was placed in the chamber with the response levers retracted. Food was available; depending on the experiment, either pellets were in the magazine or a dipper filled with water was raised. The dipper remained in the raised position until the rat's head entered the magazine. Thereafter, the dipper remained raised for $3 \mathrm{~s}$. If the rat failed to discover the food within $2 \mathrm{~min}$ to $3 \mathrm{~min}$, an additional delivery occurred. After the food was 
Table 2

Received delivery rates across the last 10 sessions of each condition. The "High" condition consisted of 2 deliveries per min (1 per min for Rats A3 and A16) and the "Low" condition consisted of 0.125 deliveries per min (0.25 per min for Rats A1, A6, A12, A14, A15, and A16).

Experiment 1.

\begin{tabular}{|c|c|c|c|c|c|c|c|c|c|}
\hline & \multicolumn{9}{|c|}{ Programmed Deliveries per Min } \\
\hline & 2 & 1 & 0.5 & 0.25 & 0.125 & 2 & High & Low & High \\
\hline Rat & \multicolumn{6}{|c|}{ Unlimited Hold (Pellets) } & \multicolumn{3}{|c|}{ Limited Hold (Sucrose) } \\
\hline A1 & 1.95 & 0.99 & 0.48 & 0.23 & 0.092 & 1.96 & 1.97 & 0.23 & 1.98 \\
\hline A3 & 1.96 & 0.98 & 0.48 & 0.23 & 0.103 & 1.96 & 0.98 & 0.113 & 0.98 \\
\hline A5 & 1.98 & 0.98 & 0.48 & 0.23 & 0.143 & 1.98 & 1.98 & 0.107 & 1.98 \\
\hline A6 & 1.98 & 0.98 & 0.49 & 0.23 & -- & 1.98 & 1.98 & 0.23 & 1.98 \\
\hline & \multicolumn{9}{|c|}{ Programmed Deliveries per Min } \\
\hline & 2 & 1 & 0.5 & 0.25 & 0.125 & 2 & High & Low & High \\
\hline Rat & \multicolumn{6}{|c|}{ Limited Hold (Sucrose) } & \multicolumn{3}{|c|}{ Unlimited Hold (Pellets) } \\
\hline A7 & 1.96 & 0.98 & 0.48 & 0.23 & 0.117 & 1.98 & 1.97 & 0.100 & 1.96 \\
\hline A8 & 1.98 & 0.98 & 0.48 & 0.23 & -- & -- & -- & -- & -- \\
\hline A9 & 1.98 & 0.98 & 0.48 & 0.23 & 0.128 & 1.98 & 1.98 & 0.103 & 1.98 \\
\hline A10 & 1.98 & 0.98 & 0.48 & 0.23 & 0.115 & 1.98 & 1.98 & 0.117 & 1.98 \\
\hline
\end{tabular}

Experiment 2.

\begin{tabular}{|c|c|c|c|c|c|c|c|c|c|}
\hline & \multicolumn{9}{|c|}{ Programmed Deliveries per Min } \\
\hline & 2 & 1 & 0.5 & 0.25 & 0.125 & 2 & High & Low & High \\
\hline Rat & \multicolumn{6}{|c|}{ Limited Hold (Sucrose) } & \multicolumn{3}{|c|}{ Unlimited Hold (Sucrose) } \\
\hline A11 & 1.97 & 0.98 & 0.48 & 0.23 & 0.123 & 1.98 & 1.98 & 0.135 & 1.97 \\
\hline A12 & 1.98 & 0.98 & 0.48 & 0.23 & -- & 1.98 & 1.98 & 0.23 & 1.98 \\
\hline A13 & 1.98 & 0.98 & 0.48 & 0.23 & 0.130 & 1.98 & 1.98 & 0.110 & 1.98 \\
\hline \multirow[t]{3}{*}{ A14 } & 1.98 & 0.98 & 0.48 & 0.23 & 0.113 & 1.98 & 1.98 & 0.23 & 1.98 \\
\hline & \multicolumn{9}{|c|}{ Programmed Deliveries per Min } \\
\hline & 2 & 1 & 0.5 & 0.25 & 0.125 & 2 & High & Low & High \\
\hline Rat & \multicolumn{6}{|c|}{ Unlimited Hold (Sucrose) } & \multicolumn{3}{|c|}{ Limited Hold (Sucrose) } \\
\hline A15 & 1.98 & 0.98 & 0.48 & 0.23 & -- & 1.98 & 1.98 & 0.23 & 1.98 \\
\hline A16 & 1.97 & 0.98 & 0.48 & 0.23 & -- & 1.98 & 0.98 & 0.23 & 0.98 \\
\hline A17 & 1.98 & 0.98 & 0.48 & 0.23 & 0.122 & 1.98 & 1.97 & 0.138 & 1.98 \\
\hline A18 & 1.96 & 0.98 & 0.48 & 0.23 & 0.133 & 1.98 & 1.98 & 0.118 & 1.98 \\
\hline
\end{tabular}


consumed, additional food was delivered after increasing amounts of time. For example, at the outset, food was delivered within $15 \mathrm{~s}$ or $20 \mathrm{~s}$ after the last delivery, but by the end of training, the deliveries were spaced about $30 \mathrm{~s}$ apart. Magazine training continued until the rat was observed to promptly approach the magazine upon delivery of food. More specifically, training was complete when the following criteria were met: (a) the last 5 deliveries were, on average, at least $30 \mathrm{~s}$ apart, (b) the rat's head was at least 3 inches away from the magazine when each of the last 5 deliveries occurred, and (c) the rat consumed each of the last 5 deliveries within $2 \mathrm{~s}$ to $3 \mathrm{~s}$ of delivery.

Lever Pressing. Lever pressing was established by reinforcing responses with food. Later, control of responding was transferred to a schedule in which lever presses postponed timeouts. Training began with the insertion of the active lever into the chamber, and every lever press resulted in the immediate delivery of food. During food deliveries, the cue light above the active lever was turned on, the lever retracted, and a click sounded. Sessions ended after 60 food deliveries and lever-press training continued until at least 120 deliveries were earned.

Discrimination Training. A two-component multiple schedule was arranged with a VT 0.5-min schedule of food delivery in one component and the absence of any deliveries in the other component ("timeout component"). Component presentations lasted $5 \mathrm{~min}$, and alternated between the VT and timeout components, beginning with the VT component. During the VT component the houselight and white noise were turned on, and during timeout they were turned off. The levers were retracted during both components. The purpose of this procedure was to ensure that each rat experienced timeout from the VT schedule before the avoidance contingency was implemented. 
Discrimination training lasted for 10 sessions. During the first 5 sessions, the fooddelivery periods lasted until the rat's head entered and exited the magazine. For the rats receiving water deliveries, the latency for the rat's head to enter the magazine and the duration spent with its head in the magazine (the consumption time) was recorded each time a delivery occurred. The combined latencies and consumption times for all rats receiving water deliveries across the 5 sessions averaged $6 \mathrm{~s}(S D=1)$. This average was used to establish the duration of subsequent access to the dipper, as follows: For the rats in the Limited Hold conditions, for the remainder of discrimination training, the dipper was raised for a fixed period. The duration of access was initially set at $6 \mathrm{~s}$ and then lowered by $1 \mathrm{~s}$ each session until there was an appreciable decrease in the amount of water consumed within a session (the amount of water consumed was measured by weighing the water before and after sessions). A decrease in the amount of water consumed occurred at a duration of $3 \mathrm{~s}$. This duration was used in the final session of discrimination training and all subsequent sessions. For the rats in the Unlimited Hold conditions, the delivery periods lasted until the rat's head entered and exited the magazine during all of discrimination training.

Avoidance. The active lever was inserted into the chamber. Food was delivered on a VT 0.5-min schedule and timeouts were scheduled to occur every $30 \mathrm{~s}$. Each timeout lasted for $30 \mathrm{~s}$, during which the houselight and white noise were turned off and the VT schedule was suspended. After a timeout, the houselight and white noise were turned on and the VT schedule was reinstated. Pressing the lever postponed the next timeout by $30 \mathrm{~s}$ and was accompanied by brief illumination of the cue light above the active lever.

Because food was delivered on a response-independent basis, a lever press might be followed immediately by a food delivery. To prevent this, food deliveries could not occur within 
$1 \mathrm{~s}$ of a lever press; if a food delivery was scheduled to occur and the rat pressed the lever, the food delivery was delayed by $1 \mathrm{~s}$. Table 3 shows the percentage of food deliveries that were postponed by $1 \mathrm{~s}$ because of the delay contingency. Food deliveries were more likely to be delayed during the conditions that scheduled more frequent deliveries. However, as shown in Table 2 , the delays did not substantially affect the received delivery rates.

During initial avoidance training, to facilitate acquisition, the lever remained in the chamber during timeouts and, after $1 \mathrm{~s}$ had elapsed, a single response ended the timeout and restored the VT schedule. That is, the rat could escape as well as avoid timeouts. Once a majority of responses occurred before the onset of timeout, the escape contingency was removed by retracting the lever during timeouts.

Figure 2 shows the acquisition of avoidance for the rats that received water deliveries. Results are from the last 5 sessions when the escape option was available and plain water was delivered, the first 5 sessions when the escape option was available and sucrose water was delivered, and the first 5 sessions after the escape option was removed. Avoidance responses rarely occurred when plain water was delivered. Because avoidance was not established after 35 sessions with plain water, sucrose water was used instead. When sucrose water was delivered, the number of avoidance responses per session increased and avoidance responding was maintained when the escape option was removed.

Figure 3 shows the probability of escape from the last 5 sessions with plain water and the first 5 sessions with sucrose water. The probability of escape average across rats was .39 ( $S D=$ $0.18)$ when plain water was delivered and $.99(S D=0.02)$ when sucrose water was delivered, suggesting that the timeouts were not aversive when plain water was delivered but were aversive when sucrose water was delivered. 
Table 3

Percentages of food deliveries that were postponed by $1 \mathrm{~s}$ because of the delay contingency. The results are from the last 10 sessions of each condition. The "High" condition consisted of 2 deliveries per min (1 per min for Rats A3 and A16) and the "Low" condition consisted of 0.125 deliveries per min (0.25 per min for Rats A1, A6, A12, A14, A15, and A16).

Experiment 1.

\begin{tabular}{|c|c|c|c|c|c|c|c|c|c|}
\hline & \multicolumn{9}{|c|}{ Programmed Deliveries per Min } \\
\hline & 2 & 1 & 0.5 & 0.25 & 0.125 & 2 & High & Low & High \\
\hline Rat & \multicolumn{6}{|c|}{ Unlimited Hold (Pellets) } & \multicolumn{3}{|c|}{ Limited Hold (Sucrose) } \\
\hline A1 & 31.9 & 3.2 & 2.1 & 2.1 & 0.0 & 19.5 & 18.3 & 0.0 & 8.5 \\
\hline A3 & 33.9 & 38.3 & 4.5 & 0.0 & 0.0 & 30.8 & 17.5 & 1.5 & 5.1 \\
\hline A5 & 11.8 & 12.7 & 5.9 & 2.1 & 1.2 & 5.7 & 5.0 & 0.0 & 5.4 \\
\hline \multirow[t]{3}{*}{ A6 } & 10.1 & 8.8 & 2.1 & 1.4 & -- & 4.4 & 9.1 & 0.7 & 7.3 \\
\hline & \multicolumn{9}{|c|}{ Programmed Deliveries per Min } \\
\hline & 2 & 1 & 0.5 & 0.25 & 0.125 & 2 & High & Low & High \\
\hline Rat & \multicolumn{6}{|c|}{ Limited Hold (Sucrose) } & \multicolumn{3}{|c|}{ Unlimited Hold (Pellets) } \\
\hline A7 & 16.5 & 13.9 & 5.5 & 1.4 & 0.0 & 9.6 & 26.2 & 0.0 & 23.7 \\
\hline A8 & 1.7 & 3.2 & 1.7 & 0.0 & -- & -- & -- & -- & -- \\
\hline A9 & 6.0 & 4.6 & 7.2 & 2.1 & 0.0 & 5.8 & 4.6 & 0.0 & 3.0 \\
\hline A10 & 8.2 & 1.0 & 0.3 & 2.1 & 0.0 & 3.7 & 6.9 & 0.0 & 7.4 \\
\hline \multicolumn{10}{|c|}{ Experiment 2.} \\
\hline & \multicolumn{9}{|c|}{ Programmed Deliveries per Min } \\
\hline & 2 & 1 & 0.5 & 0.25 & 0.125 & 2 & High & Low & High \\
\hline Rat & \multicolumn{6}{|c|}{ Limited Hold (Sucrose) } & \multicolumn{3}{|c|}{ Unlimited Hold (Sucrose) } \\
\hline A11 & 28.6 & 2.9 & 2.1 & 0.7 & 1.4 & 7.6 & 8.3 & 0.0 & 13.1 \\
\hline A12 & 6.6 & 0.2 & 0.3 & 0.7 & -- & 4.5 & 4.4 & 1.6 & 5.4 \\
\hline A13 & 7.6 & 7.3 & 1.7 & 1.4 & 1.3 & 6.9 & 9.7 & 0.0 & 7.7 \\
\hline \multirow[t]{3}{*}{ A14 } & 6.3 & 8.5 & 1.4 & 1.4 & 0.0 & 8.7 & 5.2 & 0.7 & 7.5 \\
\hline & \multicolumn{9}{|c|}{ Programmed Deliveries per Min } \\
\hline & 2 & 1 & 0.5 & 0.25 & 0.125 & 2 & High & Low & High \\
\hline Rat & \multicolumn{6}{|c|}{ Unlimited Hold (Sucrose) } & \multicolumn{3}{|c|}{ Limited Hold (Sucrose) } \\
\hline A15 & 9.3 & 4.9 & 1.7 & 0.0 & -- & 2.6 & 1.8 & 0.0 & 2.4 \\
\hline A16 & 3.7 & 13.9 & 1.7 & 2.1 & -- & 1.8 & 1.3 & 2.1 & 0.3 \\
\hline A17 & 23.1 & 4.9 & 0.3 & 0.7 & 1.4 & 19.4 & 17.6 & 2.4 & 2.4 \\
\hline A18 & 23.4 & 16.1 & 5.2 & 1.4 & 1.3 & 7.2 & 14.8 & 1.4 & 14.6 \\
\hline
\end{tabular}




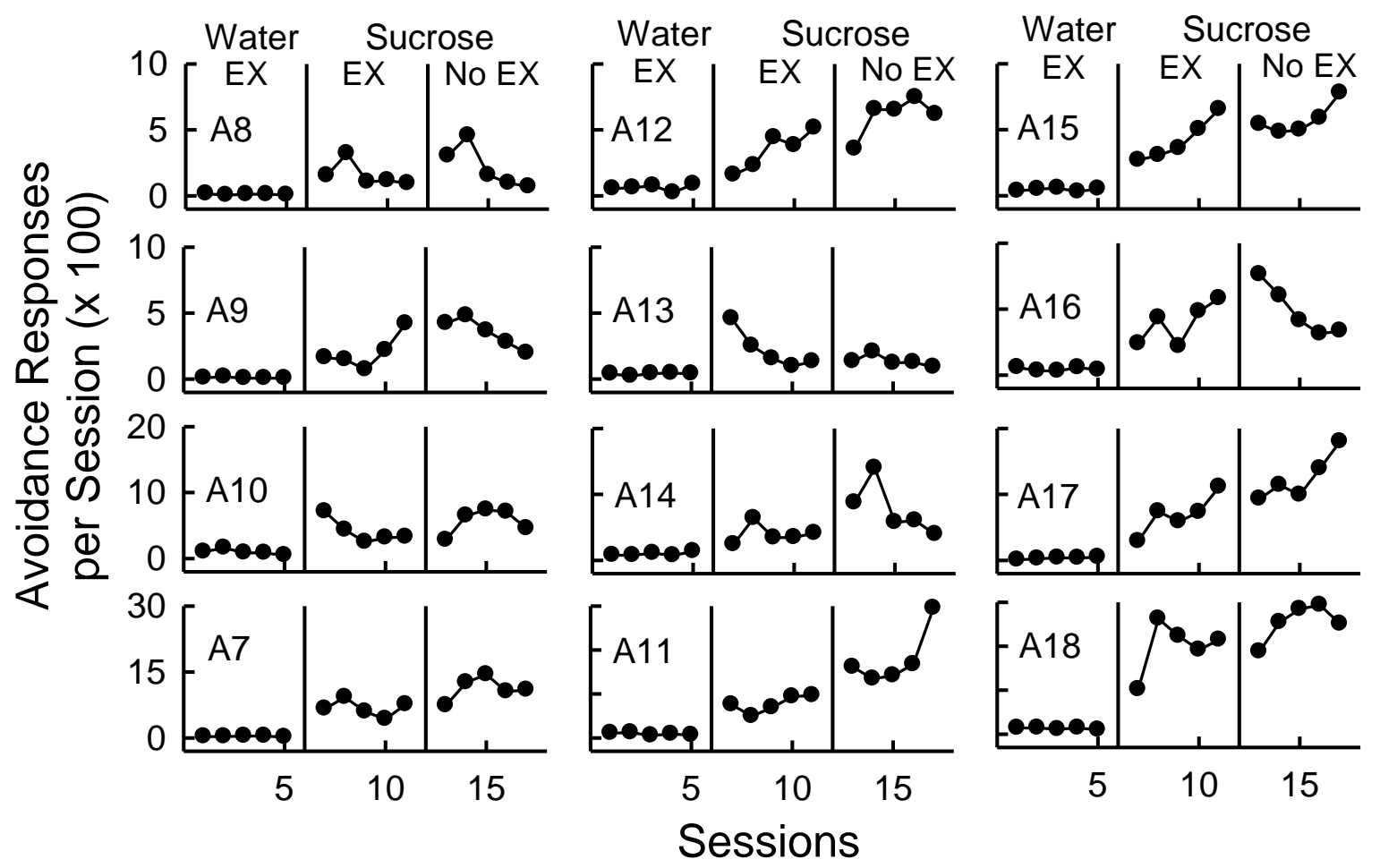

Figure 2. (Preliminary training, rats that received water deliveries). Avoidance responses per session (shown as $1 / 100$ of their value) when the escape (EX) option was available and unavailable. Results are from the last 5 sessions when the escape option was available and plain water was delivered, the first 5 sessions when the escape option was available and sucrose water was delivered, and the first 5 sessions after the escape option was removed. 


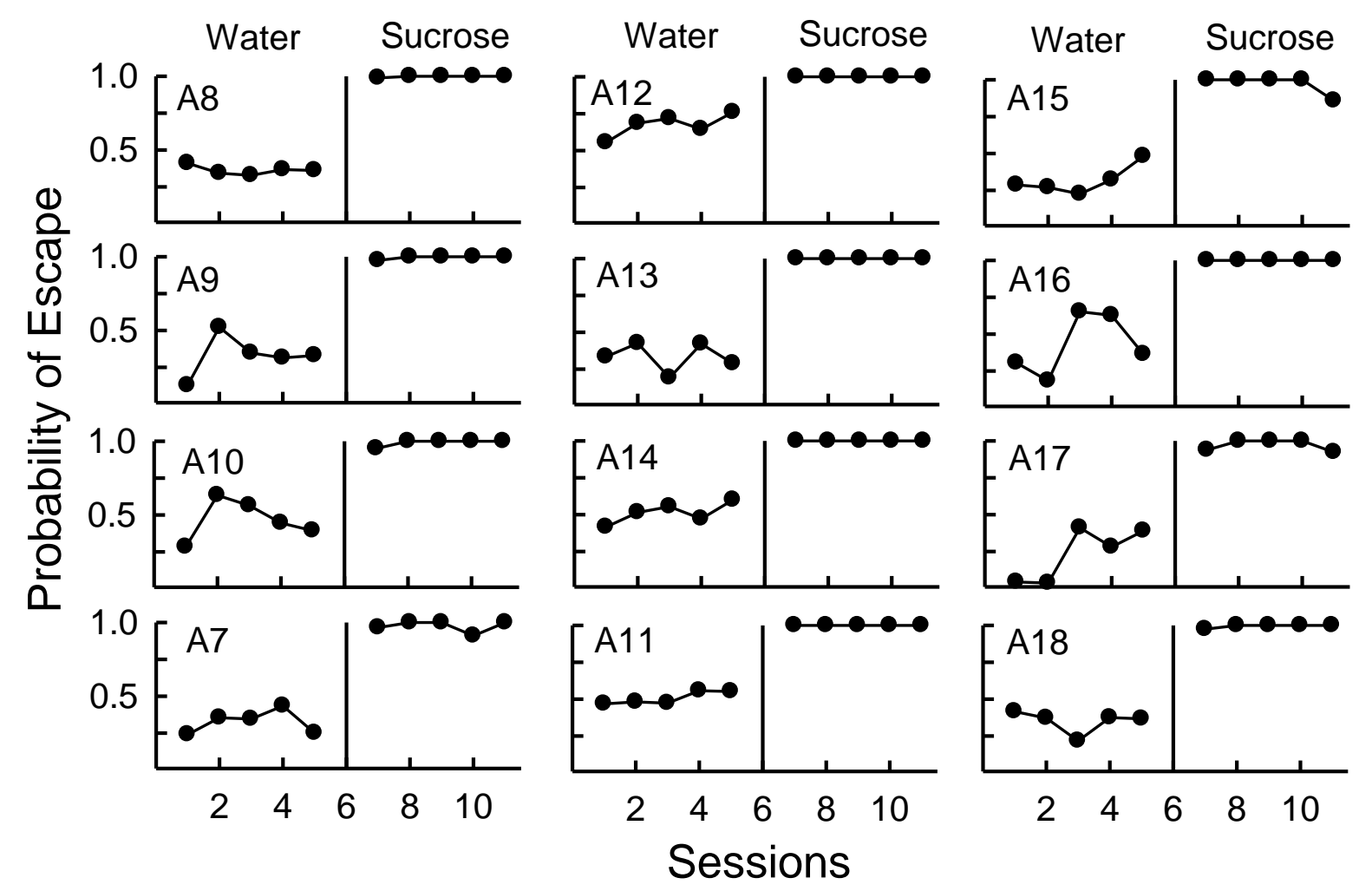

Figure 3. (Preliminary training, rats that received water deliveries). The probability of escape. Results are from the last 5 sessions when plain water was delivered and the first 5 sessions when sucrose water was delivered. 
Figure 4 shows the acquisition of avoidance for the rats that received pellets. The results are from all sessions that were conducted with the escape option and the first 10 sessions following its removal. The left half of the figure shows the number of avoidance responses per session when the escape option was available and unavailable. The right half shows the probability of escape during the sessions in which the escape option was available. When the escape option was available, the number of avoidance responses increased across sessions for Rats A3 and A5 and decreased for Rats A1 and A6. Although there were individual subject differences in the between-session trend of the number of avoidance responses, the probability of escape averaged across rats was $.98(S D=0.04)$, suggesting that the timeouts were aversive. When the escape option was removed, 3 of the 4 rats avoided at a higher rate.

\section{Experimental Conditions}

Each rat was exposed to eight or nine experimental conditions which differed in terms of the rate of food delivery. The order of conditions is discussed in further detail in the procedure section of each experiment. Across all conditions, timeouts occurred every $30 \mathrm{~s}$ in the absence of responding. Each response postponed the timeout by $30 \mathrm{~s}$.

\section{Stability Criteria}

Conditions lasted for at least 20 sessions and continued until the rate of responding on the avoidance lever was stable across 10 consecutive sessions. Responding was judged as stable when the following criteria were met: (a) the difference between the mean of the first 5 sessions and the mean of the last 5 sessions was within 15 percent of the 10 -session mean and (b) there was no increasing or decreasing trend over the 10 sessions, as judged by visual inspection of the graphed rates. 


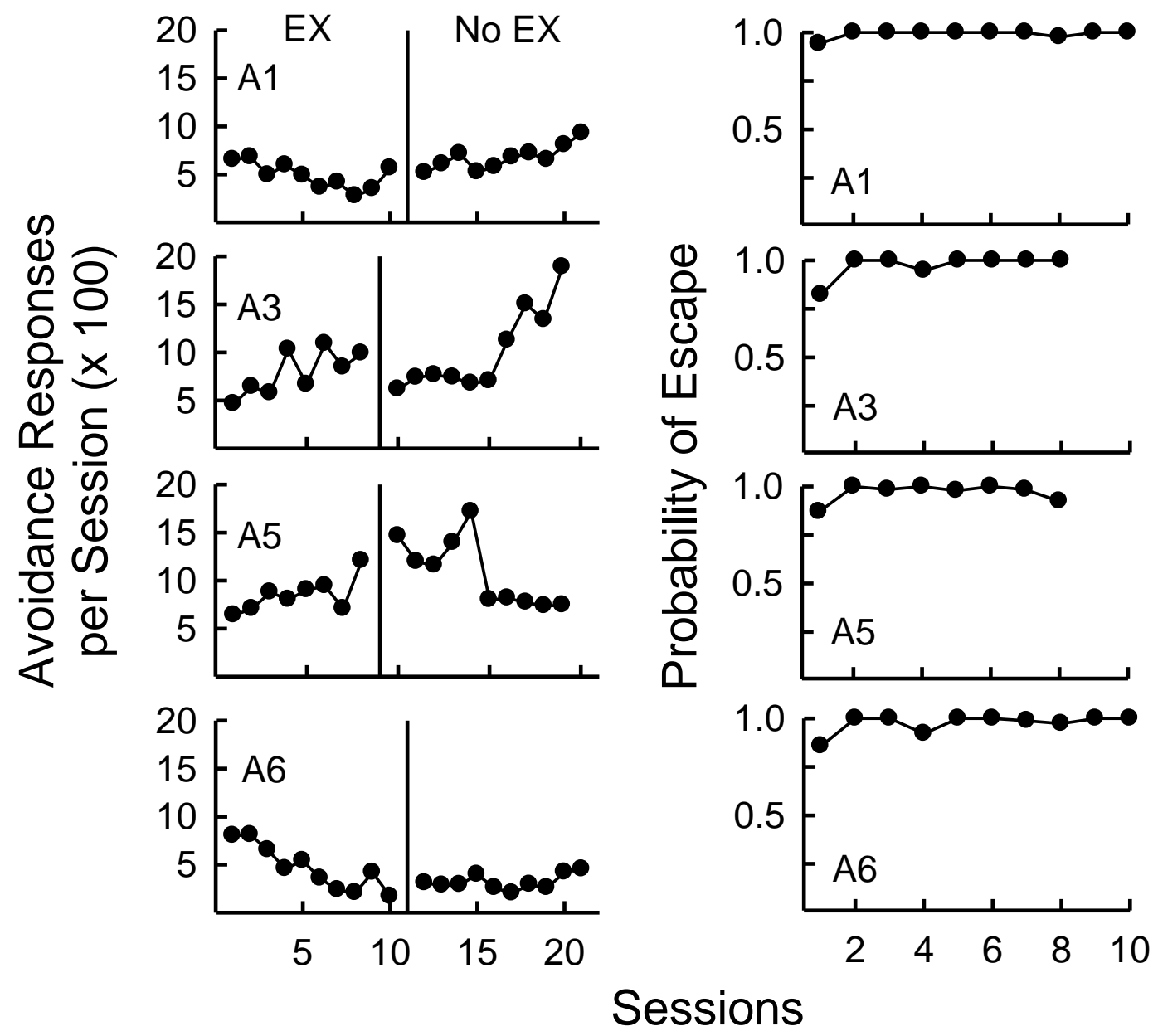

Figure 4. (Preliminary training, rats that received pellet deliveries). Avoidance responses per session (shown as 1/100 of their value) when the escape option was available and unavailable (shown on the left) and the probability of escape (shown on the right). The data points on the left are from all sessions with the escape option and the first 10 sessions following the removal of the escape option. 


\section{Experiment 1}

Experiment 1 assessed how a limited hold on consumption affects avoidance of timeout. The Unlimited Hold conditions involved delivery of pellets: Each pellet remained in the magazine until the rat retrieved it. The Limited Hold conditions involved presentations of a dipper of sucrose water for fixed 3-s periods: If the rat did not promptly approach the dipper, less than the full amount of sucrose water might be consumed. The presence of a limited hold may engender a greater degree of attending to the magazine that might compete with avoidance responding. Thus, it was assumed that competition between magazine-directed behavior and avoidance should differ in the Unlimited Hold and Limited Hold situations.

\section{Procedure}

Table 4 shows the order of exposure to the experimental conditions and the number of sessions in each.

Unlimited Hold then Limited Hold. Pellets were delivered in the Unlimited Hold conditions. The original plan was to expose each rat to the pellet-delivery rates in a descending order ( 2 per min, 1 per $\min , 0.5$ per $\min , 0.25$ per $\min , \& 0.125$ per $\min$ ), followed by a replication of the 2 per min condition. For Rats A1 and A3, the replication was completed before exposure to the 0.125 condition to circumvent the loss of avoidance responding (i.e., avoidance rates were low during the 0.25 condition and there was concern that avoidance responding may cease during a leaner condition). Rat A6 stopped responding after 5 sessions at the 0.125 delivery rate and, therefore, this condition could not be completed.

Then three Limited Hold conditions were arranged in which sucrose water was delivered in fixed 3-s presentations of the dipper. Two sucrose-delivery rates were compared in an A-B-A fashion. The delivery rates were based on the results of the Unlimited Hold conditions: The 
Table 4

Experiment 1. Order of exposure to the different rates of food delivery (2 to 0.125) and the number of sessions at each (shown in parentheses).

\begin{tabular}{|c|c|c|c|c|c|c|c|c|c|}
\hline & \multicolumn{9}{|c|}{ Programmed Deliveries per Min } \\
\hline & 2 & 1 & 0.5 & 0.25 & 0.125 & 2 & High & Low & High \\
\hline Rat & \multicolumn{6}{|c|}{ Unlimited Hold (Pellets) } & \multicolumn{3}{|c|}{ Limited Hold (Sucrose) } \\
\hline A1 & $1(33)$ & $2(23)$ & $3(20)$ & $4(20)$ & $6(20)$ & $5(29)$ & $7(30)$ & $8(21)$ & $9(23)$ \\
\hline A3 & $1(29)$ & $2(20)$ & $3(36)$ & $4(20)$ & $6(20)$ & $5(28)$ & $7(21)$ & $8(20)$ & $9(20)$ \\
\hline A5 & $1(20)$ & $2(22)$ & $3(34)$ & $4(20)$ & $5(20)$ & $6(48)$ & $7(23)$ & $8(20)$ & $9(20)$ \\
\hline A6 & $1(20)$ & $2(22)$ & $3(20)$ & $4(20)$ & -- & $5(30)$ & $6(22)$ & $7(20)$ & $8(52)$ \\
\hline Rat & \multicolumn{6}{|c|}{ Limited Hold (Sucrose) } & \multicolumn{3}{|c|}{ Unlimited Hold (Pellets) } \\
\hline A7 & $1(20)$ & $2(22)$ & $3(24)$ & $5(20)$ & $6(20)$ & $4(20)$ & $7(22)$ & $8(20)$ & $9(24)$ \\
\hline A8 & $2(22)$ & $3(23)$ & $1(20)$ & $4(20)$ & -- & -- & -- & -- & -- \\
\hline A9 & $2(28)$ & $1(20)$ & $3(28)$ & $4(20)$ & $5(20)$ & $6(20)$ & $7(20)$ & $8(20)$ & $9(20)$ \\
\hline A10 & $1(21)$ & $2(20)$ & $3(20)$ & $5(20)$ & $6(20)$ & $4(20)$ & $7(21)$ & $8(20)$ & $9(20)$ \\
\hline
\end{tabular}

Note. The "High" condition consisted of 2 deliveries per min ( 1 per min for Rat A3). The "Low" condition consisted of 0.125 deliveries per min ( 0.25 per min for Rats A1 and A6). 
delivery rates that engendered the greatest difference in the rate of avoidance were compared.

Condition A contained the delivery rate that generated the highest rate of avoidance and Condition B contained the delivery rate that generated the lowest rate of avoidance.

Limited Hold then Unlimited Hold. Fixed 3-s sucrose water deliveries were arranged in the Limited Hold conditions. The original plan was to expose each rat to the sucrose-delivery rates in a descending order ( 2 per min, 1 per min, 0.5 per min, 0.25 per min, \& 0.125 per min), followed by a replication of the 2 per min condition. However, avoidance is often established under conditions that should generate relatively high rates of avoidance or consistent avoidance responding. If the Limited Hold on consumption resulted in an inverse relation between delivery rates and avoidance, the leaner conditions should generate more avoidance. Rats A8 and A9 were first exposed to leaner food delivery rates ( 0.5 and 1 per min, respectively) before exposure to the 2 per min condition. Rat A8 was euthanized for health reasons after the 0.25 per min condition. Finally, for Rats A7 and A10, the replication of the 2 per min condition was completed before exposure to the 0.25 and the 0.125 conditions to circumvent the loss of avoidance.

After the Limited Hold conditions, three Unlimited Hold conditions were arranged in which pellets were delivered. Two pellet-delivery rates were compared in an A-B-A fashion. The delivery rates were based on the results of the Limited Hold conditions: The delivery rates that engendered the greatest difference in the rate of avoidance of timeout were compared. Condition A contained the delivery rate that generated the highest rate of avoidance and Condition B contained the delivery rate that generated the lowest rate of avoidance. 


\section{Results and Discussion}

\section{Avoidance of Timeouts}

Figures 5 and 6 show effects of food delivery rates during time-in on the avoidance of timeout. Results shown in Figure 5 are from the rats first exposed to the Unlimited Hold conditions (when pellets were delivered) and results shown in Figure 6 are from the rats first exposed to the Limited Hold conditions (when sucrose water was delivered). The left half of the figures show avoidance response rates and the right half show the percentage of timeouts avoided as a consequence. The results are means $( \pm 1 \mathrm{SD})$ over the last 10 sessions of each condition.

During the Unlimited Hold and the Limited Hold conditions, the rate of avoidance responding increased as the rate of food delivery was raised. In other words, a direct relation was observed between the rate of food delivery and avoidance responding in the presence and absence of a limited hold. This direct relation was observed regardless of the order of exposure to the Limited Hold and the Unlimited Hold conditions. For 5 of the 8 rats, avoidance rates reached a peak when the rate of delivery was 1 per min ( 0.5 per min for Rat A9), and raising the delivery rate to 2 per min did not matter. During the first replication of the 2 per min condition (unfilled circles), avoidance rates were lower than their original values for 5 of the 8 rats. When a limited hold was added for the rats shown in Figure 5 and removed for the rats shown in Figure 6 , avoidance rates matched or were lower than the rates generated in the preceding conditions that arranged the same delivery rates. The percentage of timeouts avoided (right half of Figures 5 and 6) changed in concert with avoidance responding. The percentage of timeouts avoided was directly related to the rate of food delivery, regardless of the presence or absence of a limited hold. 

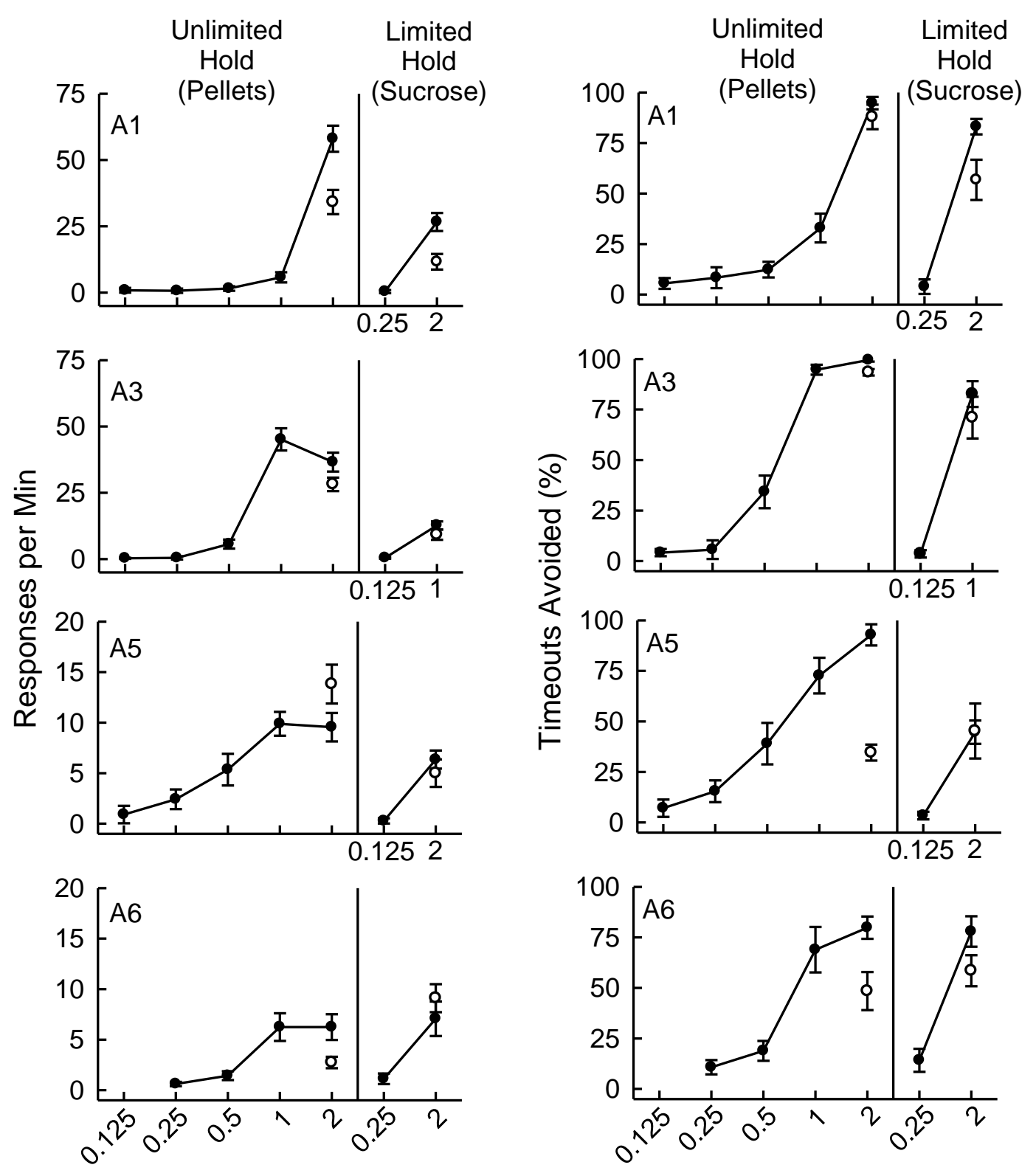

Deliveries per Min

Figure 5. (Experiment 1, Unlimited Hold then Limited Hold). Rates of avoidance responding (shown on the left) and percentage of timeouts avoided (shown on the right) as a function of the food delivery rate per min. The unfilled circles show replications of a given condition. The results are means $( \pm 1 \mathrm{SD})$ over the last 10 sessions of each condition. 


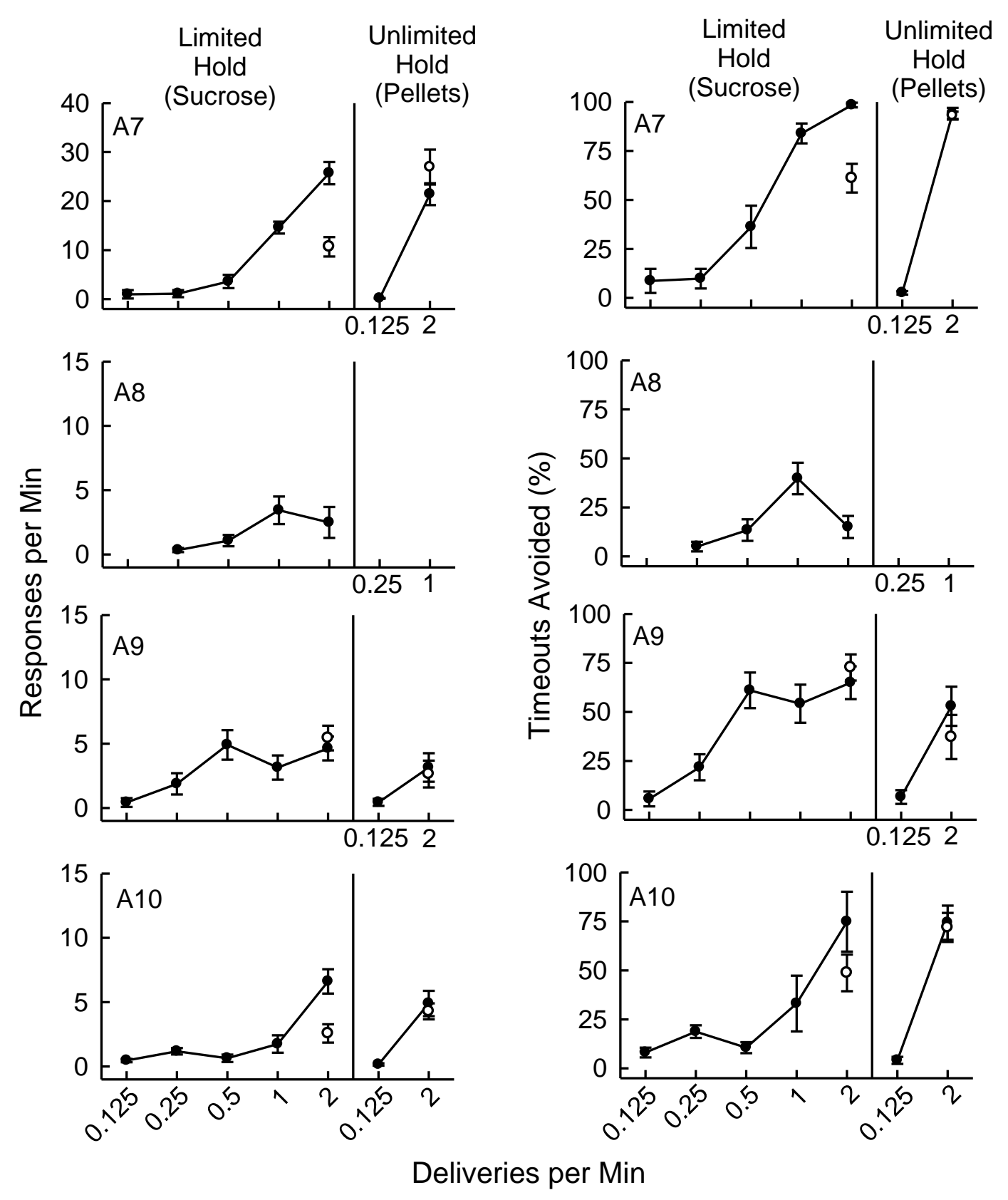

Figure 6. (Experiment 1, Limited Hold then Unlimited Hold). Rates of avoidance responding (shown on the left) and percentage of timeouts avoided (shown on the right) as a function of the food delivery rate per min. The unfilled circles show replications of a given condition. The results are means $( \pm 1$ SD) over the last 10 sessions of each condition. 


\section{Avoidance Efficiency}

Richardson and Baron (2008) reported that the efficiency of avoidance responding increased with exposure to avoidance schedules when they arranged a descending series of food delivery rates. Avoidance responding is more efficient when timeouts are avoided with relatively fewer responses. For example, when timeouts are scheduled to occur every $30 \mathrm{~s}$, an avoidance response at $29 \mathrm{~s}$ into the interval postpones a timeout that would have occurred in $1 \mathrm{~s}$ to occur instead in $30 \mathrm{~s}$, a difference of $29 \mathrm{~s}$. By comparison, a response at $1 \mathrm{~s}$ into the interval postpones a timeout that would have occurred in $29 \mathrm{~s}$ to occur in $30 \mathrm{~s}$, a difference of just $1 \mathrm{~s}$. Thus, an avoidance response later in the interval has a greater consequence than a response earlier in the interval.

Richardson and Baron's (2008) method to calculate an index of efficiency was used to assess efficiency in the present experiment. The time at which the first response occurred within each new response-timeout interval was recorded. A summary measure was calculated for each session by taking the $75^{\text {th }}$ percentile of the distribution of times.

Figure 7 shows the efficiency index over the course of each rat's exposure to the avoidance schedule. Each data point represents the measure of efficiency from one session. Because sessions lasted for $1 \mathrm{hr}$ of time-in, each session involved an $\mathrm{hr}$ of exposure time. Richardson and Baron (2008) reported an increase in efficiency as a function of exposure. This was not observed in the present experiment. Instead, efficiency was more often related to the food delivery rate. For 5 of the 8 rats, responding was more efficient during the leaner food delivery conditions than the richer. Figure 8 shows the measure of efficiency from the last session of each condition as a function of the food delivery rate. Efficiency generally decreased as the rate of food delivery was raised (the exception being efficiency scores for Rat A9). 


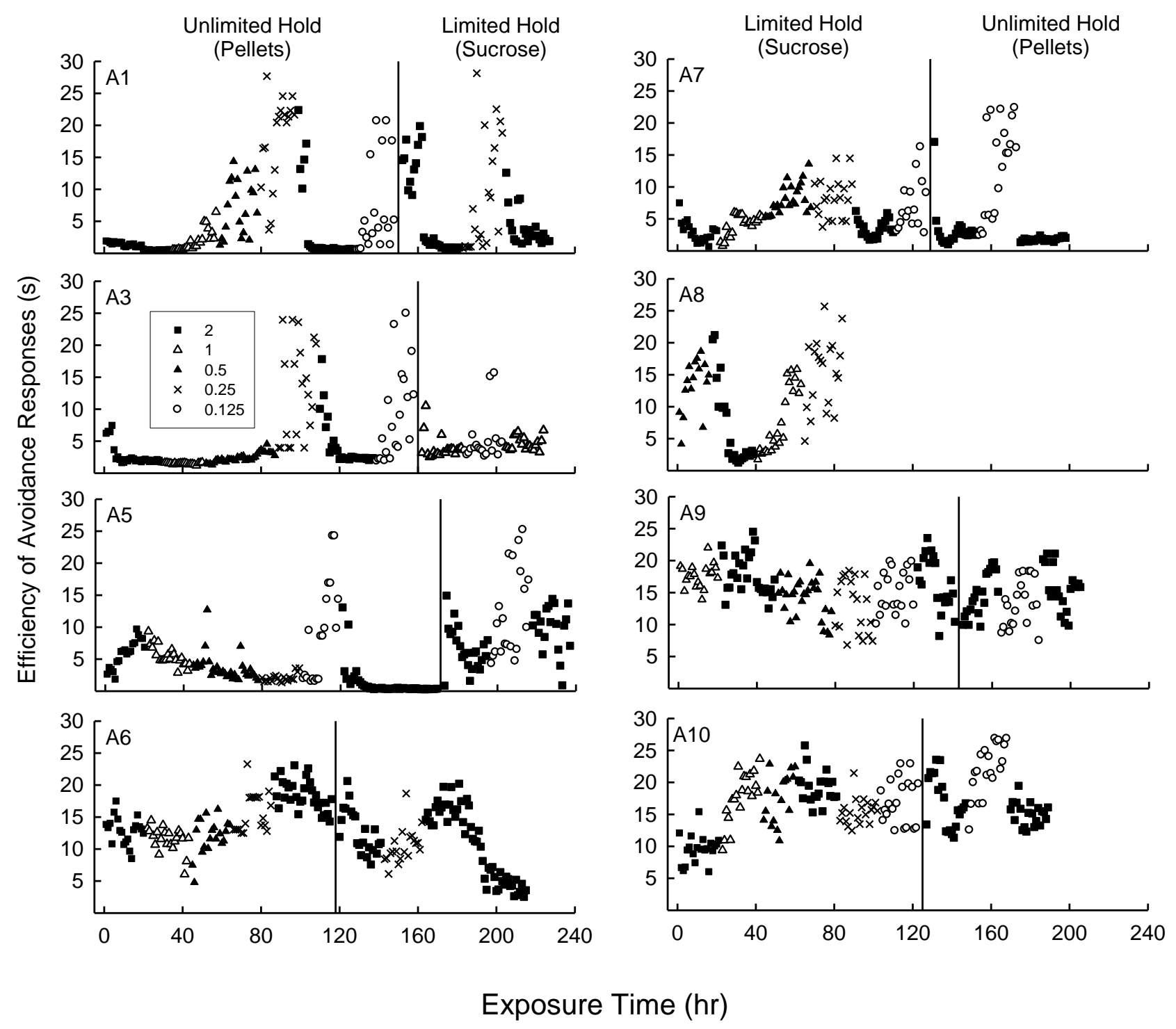

Figure 7. Experiment 1. Response efficiency as a function of hours of exposure to the avoidance schedule. Efficiency was defined by the location of the avoidance response within the 30-s response-timeout interval. An index of efficiency was calculated for each session by taking the $75^{\text {th }}$ percentile of the distribution of times. The food delivery rates $(2,1,0.5,0.25$, and 0.125 per min) are represented by different symbols. Results from the rats initially exposed to the Unlimited Hold are shown on the left and those initially exposed to the Limited Hold are shown on the right. 


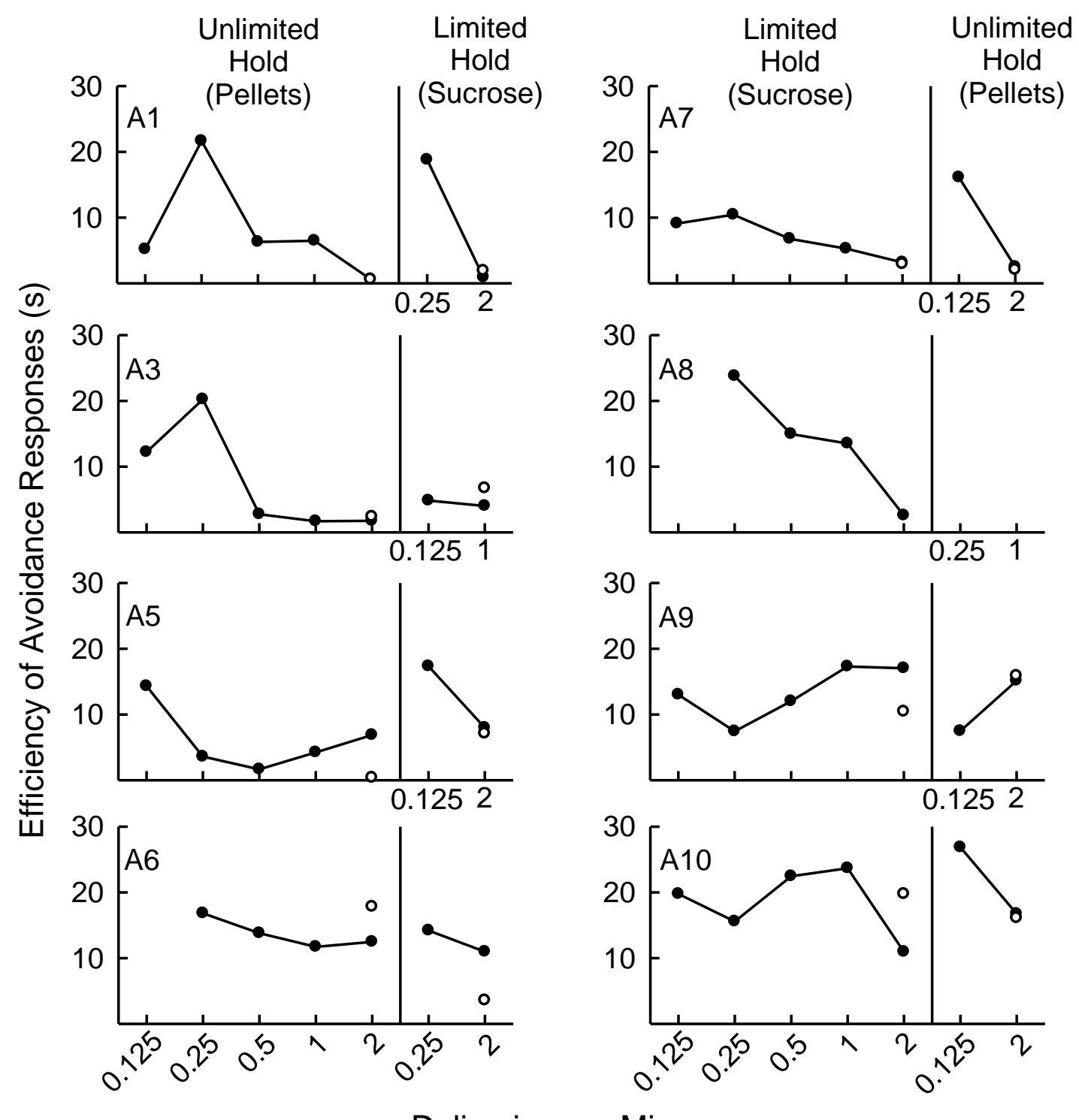

Figure 8. Response efficiency as a function of the delivery rate per min. The unfilled circles show replications of a given condition. Efficiency was defined by the location of the avoidance response within the 30-s response-timeout interval. An index of efficiency was calculated by taking the $75^{\text {th }}$ percentile of the distribution of times. Results are the efficiency measures from the last session at each delivery rate. 
Because of this discrepancy between the present findings and those reported by Richardson and Baron, efficiency scores were extracted from Richardson and Baron's Figure 2 of Experiment 1 and re-plotted as a function of the rate of food delivery; this analysis is shown in Figure 9. In general, efficiency decreased as the rate of food delivery was raised, as seen in the present Experiment (Figure 8).

\section{Within-Session Responding}

Richardson and Baron (2008) reported no systematic differences in avoidance responding within sessions. To assess within-session patterns of responding in the present experiment, the 60 min of time-in was separated into six 10-min blocks and the rate of avoidance and the percentage of timeouts avoided were calculated for each block. An average was found for the last 10 sessions by calculating the mean for each block across the sessions (the average for one block was calculated using 10 values). Results from select delivery rates are shown in Figures 10 and 11 . The conditions that arranged the richest ( 2 per min), intermediate ( 0.5 per min), and leanest $(0.25$ per min or 0.125 per min) schedules of food delivery were selected, as these results are illustrative of the overall effect. The within-session analysis of avoidance response rates from all conditions is shown in Appendix C (Table C1) and the analysis of the percentage of timeouts avoided is shown in Appendix D (Table D1).

Figure 10 shows the within-session analysis for the rats first exposed to the Unlimited Hold condition in which pellets were delivered. When food was delivered at a rate of 2 per min, avoidance responding and the percentage of timeouts avoided was stable across the six blocks. When pellets were delivered at a rate of 0.5 per min, avoidance rates and percentages decreased across blocks. For some rats, the rate of decline occurred gradually across blocks and for others the decline occurred from the first block to the second block and then was stable across the 


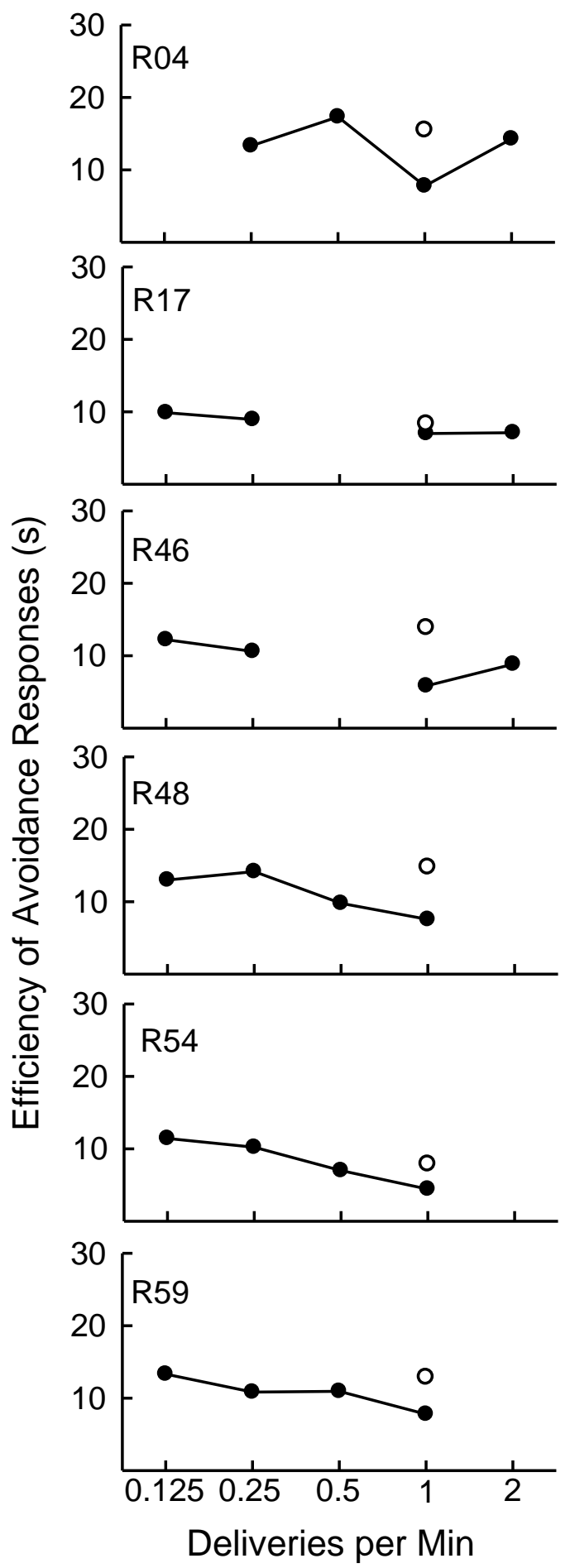

Figure 9. Response efficiency as a function of the delivery rate per min. Results re-analyzed from Experiment 1 of Richardson and Baron (2008). The unfilled circles show replications of a given condition. 

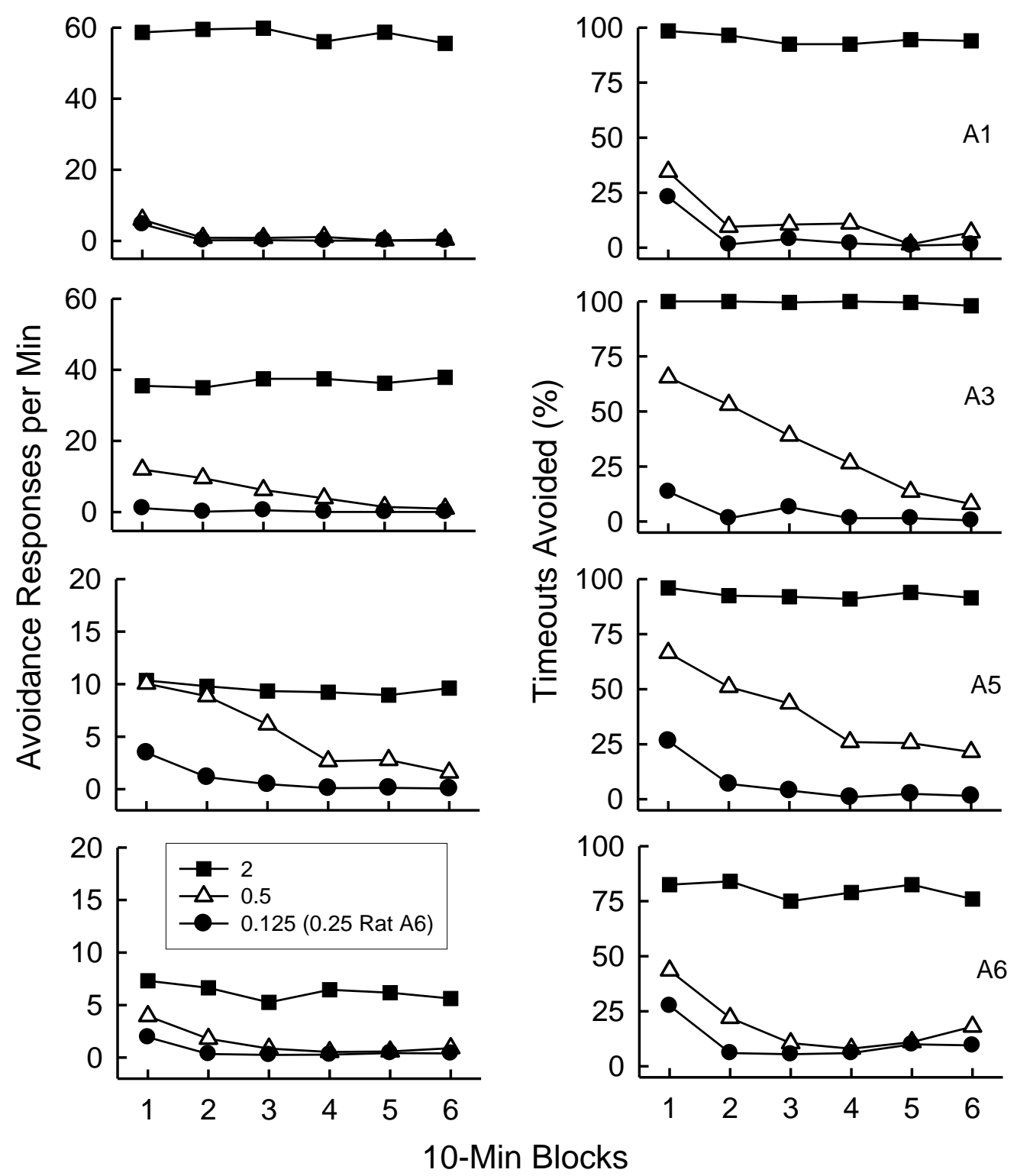

Figure 10. Experiment 1 (Unlimited Hold). Rates of avoidance responding (shown on the left) and percentage of timeouts avoided (shown on the right) as a function of 10-min blocks of time-in across the last 10 sessions. Each data path shows a different food delivery rate $(2,0.5,0.25$, or 0.125 per $\mathrm{min}$ ) from the Unlimited Hold condition. The leanest food delivery rate was 0.125 per min for all rats except A6 for which the leanest food delivery rate was 0.25 per min. 

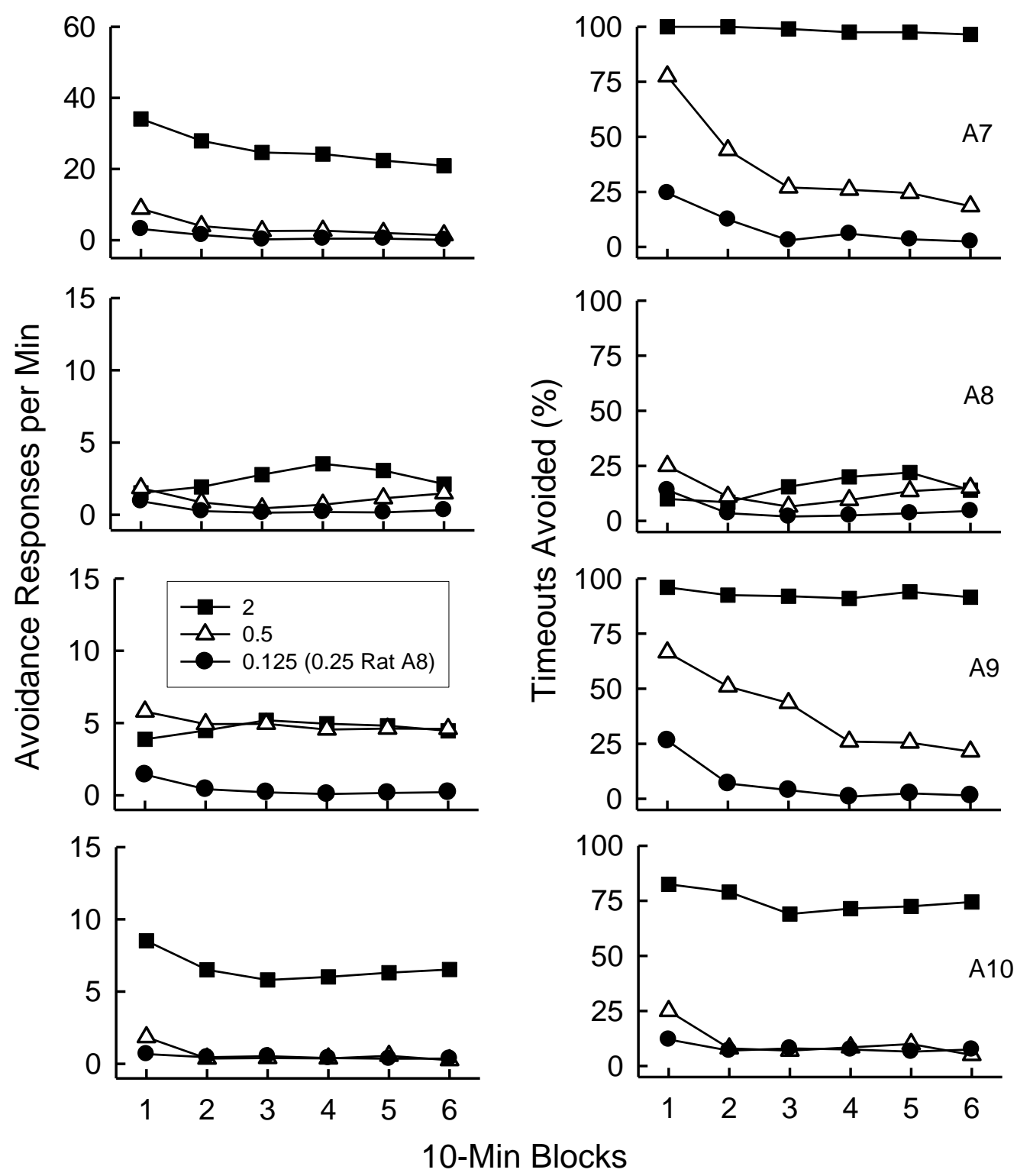

Figure 11. Experiment 1 (Limited Hold). Rates of avoidance responding (shown on the left) and percentage of timeouts avoided (shown on the right) as a function of 10-min blocks of time-in across the last 10 sessions. Each data path shows a different food delivery rate $(2,0.5,0.25$, or 0.125 per $\mathrm{min}$ ) from the Limited Hold condition. The leanest food delivery rate was 0.125 per min for all rats except A8 for which the leanest food delivery rate was 0.25 per min. 
remaining blocks. When pellets were delivered at a rate of 0.25 per min (Rat A6) or 0.125 per min (Rats A1, A3, and A5), avoidance responding and the percentage of timeouts avoided, generally, decreased from the first to the second block and then remained at a low level (however, floor effects may have precluded further decreases). In other words, within-session decreases in responding occurred when pellets were delivered infrequently but did not occur when they were delivered frequently.

Figure 11 shows the within-session analysis for the rats first exposed to the Limited Hold condition in which sucrose water was delivered. Unlike the pattern seen when pellets were delivered, within-session changes in avoidance rates did occur when sucrose water was delivered frequently (at a rate of 2 per min). Avoidance rates decreased after the first block for Rats A7 and A10, and rates increased at blocks 2-3 for Rat A9 and blocks 2-4 for Rat A8 and then decreased across the remaining blocks. The percentage of timeouts avoided typically was stable across blocks (except for Rat A8). When sucrose water was delivered less frequently (at a rate of 0.5 per min and 0.25 per min [Rat A8] or 0.125 per min [Rats A7, A9, and A10]), avoidance rates and percentages decreased from the first to the second block and then remained at a low level or decreased gradually across blocks. In summary, within-session decreases in responding were more likely to occur at all delivery rates when sucrose water was delivered.

Research reporting changes in within-session responding on schedules of reinforcement have suggested that these changes may be due to satiation to the repeated presentation of reinforcers (the "satiety hypothesis," see Killen, 1995) or habituation to aspects of the experimental arrangement (the "habituation hypothesis," see McSweeney, Hinson, \& Cannon, 1996; McSweeney \& Murphy, 2000). In the present experiment, if satiation to the repeated presentation of food occurred or, in other words, if food was less reinforcing after repeated 
presentations, the timeouts would have become less aversive as a session progressed. If the aversiveness of timeout decreased across the session, rates of avoidance should decrease as a consequence. The present data argue against the interpretation that within-session avoidance responding changed due to satiation, when pellets were delivered, as the rate of avoidance was stable throughout the session under the conditions with the greatest number of pellet deliveries (i.e., if satiation caused within-session decreases in avoidance, one would expect that avoidance would be most likely to decrease when food was delivered most frequently). The results cannot rule out satiation as an explanation for within-session changes when sucrose water was delivered as rates of avoidance decreased across the session at all delivery rates.

Habituation also may have contributed to within-session changes in responding. If habituation to the timeouts occurred, the timeouts would become less aversive as a session progressed and rates of avoidance would decrease; however, this decrease in aversiveness should depend on the number of timeouts experienced. Within-session decreases in avoidance rates were least likely to occur when food was delivered frequently; these were the conditions under which the rats experienced the fewest number of timeouts. The notion that habituation to the timeouts may have occurred in the present experiment is consistent with research reporting within-session decreases in responding with non-ingestive reinforcers that are not usually thought to undergo satiation (e.g., Jerome, Moody, Connor, \& Ryan, 1958).

\section{Experiment 2}

In Experiment 1, manipulation of the presence or absence of a limited hold was confounded by the item delivered: Sucrose water in the Limited Hold conditions and pellets in the Unlimited Hold conditions. Experiment 2 was designed to address this confound. Sucrose water was delivered in every condition. In the Limited Hold conditions, the sucrose water was 
delivered as in Experiment 1: The dipper was raised for a fixed $3 \mathrm{~s}$. In the Unlimited Hold conditions, the dipper remained in a raised position until the rat's head entered and exited the magazine as detected by a photocell. Experiment 2 also evaluated whether any differences in rates of avoidance were due to the order in which rats were exposed to the Limited Hold and Unlimited Hold conditions. Four rats experienced the Limited Hold conditions before the Unlimited Hold conditions, and four rats experienced the opposite order.

\section{Procedure}

Table 5 shows the order of exposure to the experimental conditions and the number of sessions in each. The original plan was to expose each rat to the sucrose-delivery rates in a descending order ( 2 per min, 1 per min, 0.5 per min, 0.25 per min, \& 0.125 per min), followed by a replication of the 2 per min condition. The replication was completed earlier than originally planned for Rats A11, A12, A13, A14, and A17, and the 0.125 per min condition was not completed for Rats A12, A15, and A16. These deviations from the plan were undertaken to prevent the loss of avoidance.

Four rats were first exposed to the different delivery rates in the absence of a limited hold - the dipper remained raised until the rat's head entered and exited the magazine. The remaining four were first exposed to the different delivery rates in the presence of a limited hold - the dipper was raised for $3 \mathrm{~s}$. Then, for all rats, two sucrose-delivery rates were compared in an A-B-A fashion. The four rats first exposed to the Unlimited Hold conditions were then exposed to the Limited Hold conditions and those first exposed to the Limited Hold conditions were then exposed to the Unlimited Hold conditions. The delivery rates were based on the results of the preceding conditions: The delivery rates that engendered the greatest difference in the rate of avoidance were compared. Condition A contained the delivery rate that generated 
Table 5

Experiment 2. Order of exposure to the different rates of food delivery (2 to 0.125) and the number of sessions at each (shown in parentheses).

\begin{tabular}{|c|c|c|c|c|c|c|c|c|c|}
\hline & \multicolumn{9}{|c|}{ Programmed Deliveries per Min } \\
\hline & 2 & 1 & 0.5 & 0.25 & 0.125 & 2 & High & Low & High \\
\hline Rat & \multicolumn{6}{|c|}{ Unlimited Hold (Sucrose) } & \multicolumn{3}{|c|}{ Limited Hold (Sucrose) } \\
\hline A15 & $1(30)$ & $2(20)$ & $3(21)$ & $4(20)$ & -- & $5(31)$ & $6(20)$ & $7(20)$ & $8(20)$ \\
\hline A16 & $1(29)$ & $2(34)$ & $3(24)$ & $4(20)$ & -- & $5(39)$ & $6(20)$ & $7(20)$ & $8(20)$ \\
\hline A17 & $1(24)$ & $2(20)$ & $3(20)$ & $5(21)$ & $6(20)$ & $4(35)$ & $7(26)$ & $8(20)$ & $9(21)$ \\
\hline A18 & $1(28)$ & $2(20)$ & $3(20)$ & $4(20)$ & $5(20)$ & $6(32)$ & $7(23)$ & $8(20)$ & $9(20)$ \\
\hline Rat & \multicolumn{6}{|c|}{ Limited Hold (Sucrose) } & \multicolumn{3}{|c|}{ Unlimited Hold (Sucrose) } \\
\hline A11 & $1(21)$ & $2(20)$ & $3(20)$ & $4(20)$ & $6(20)$ & $5(27)$ & $7(26)$ & $8(20)$ & $9(21)$ \\
\hline A12 & $1(42)$ & $2(20)$ & $4(20)$ & $5(20)$ & -- & $3(22)$ & $6(21)$ & $7(20)$ & $8(20)$ \\
\hline A13 & $1(25)$ & $2(20)$ & $3(20)$ & $5(21)$ & $6(20)$ & $4(27)$ & $7(20)$ & $8(20)$ & $9(22)$ \\
\hline A14 & $1(25)$ & $2(25)$ & $3(21)$ & $4(20)$ & $6(20)$ & $5(20)$ & $7(29)$ & $8(20)$ & $9(20)$ \\
\hline
\end{tabular}

Note. The "High" condition consisted of 2 deliveries per min ( 1 per min for Rat A16). The "Low" condition consisted of 0.25 deliveries per min $(0.125$ per min for Rats A11, A13, A17, and A18). 
the highest rate of avoidance and Condition B contained the delivery rate that generated the lowest rate of avoidance.

\section{Results and Discussion}

\section{Avoidance of Timeouts}

Figures 12 and 13 show effects of sucrose-delivery rates during time-in on the avoidance of timeout. Results shown in Figure 12 are from the rats first exposed to the Unlimited Hold conditions and results shown in Figure 13 are from the rats first exposed to the Limited Hold conditions. The left half of the figures show avoidance response rates and the right half show the percentage of timeouts avoided as a consequence. The results are means $( \pm 1 \mathrm{SD})$ over the last 10 sessions of each condition.

During the Unlimited Hold and the Limited Hold conditions, the rate of avoidance responding increased as the rate of sucrose delivery was raised. In other words, a direct relation was observed between the rate of sucrose delivery and avoidance responding in the presence and absence of a limited hold. For Rats A14 and A16, avoidance was higher in the 1 per min than the 2 per min condition. During the first replication of the 2 per min condition (unfilled circles), avoidance rates were lower than their original values for 6 of the 8 rats. When a limited hold was added to the sucrose deliveries for the rats shown in Figure 12 and removed for the rats shown in Figure 13, avoidance rates matched or were lower (or were higher in the case of Rat A13) than the rates generated in the preceding conditions that arranged the same delivery rates. The percentage of timeouts avoided (right half of Figures 12 and 13) changed in concert with avoidance responding. The percentage of timeouts avoided was directly related to the rate of sucrose delivery, regardless of the presence or absence of a limited hold. 

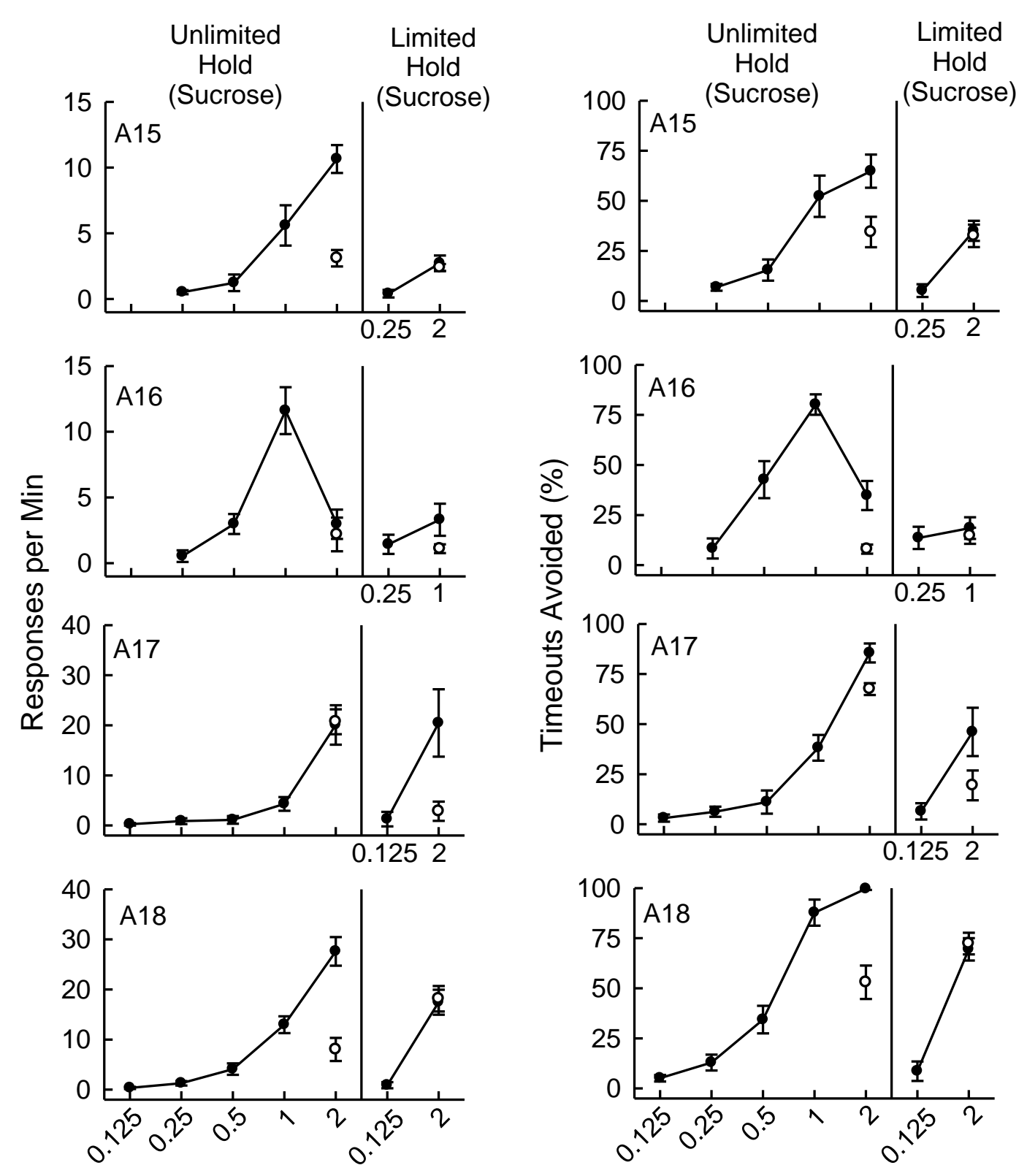

Deliveries per Min

Figure 12. (Experiment 2, Unlimited Hold then Limited Hold). Rates of avoidance responding (shown on the left) and percentage of timeouts avoided (shown on the right) as a function of the food delivery rate per min. The unfilled circles show replications of a given condition. The results are means $( \pm 1 \mathrm{SD})$ over the last 10 sessions of each condition. 

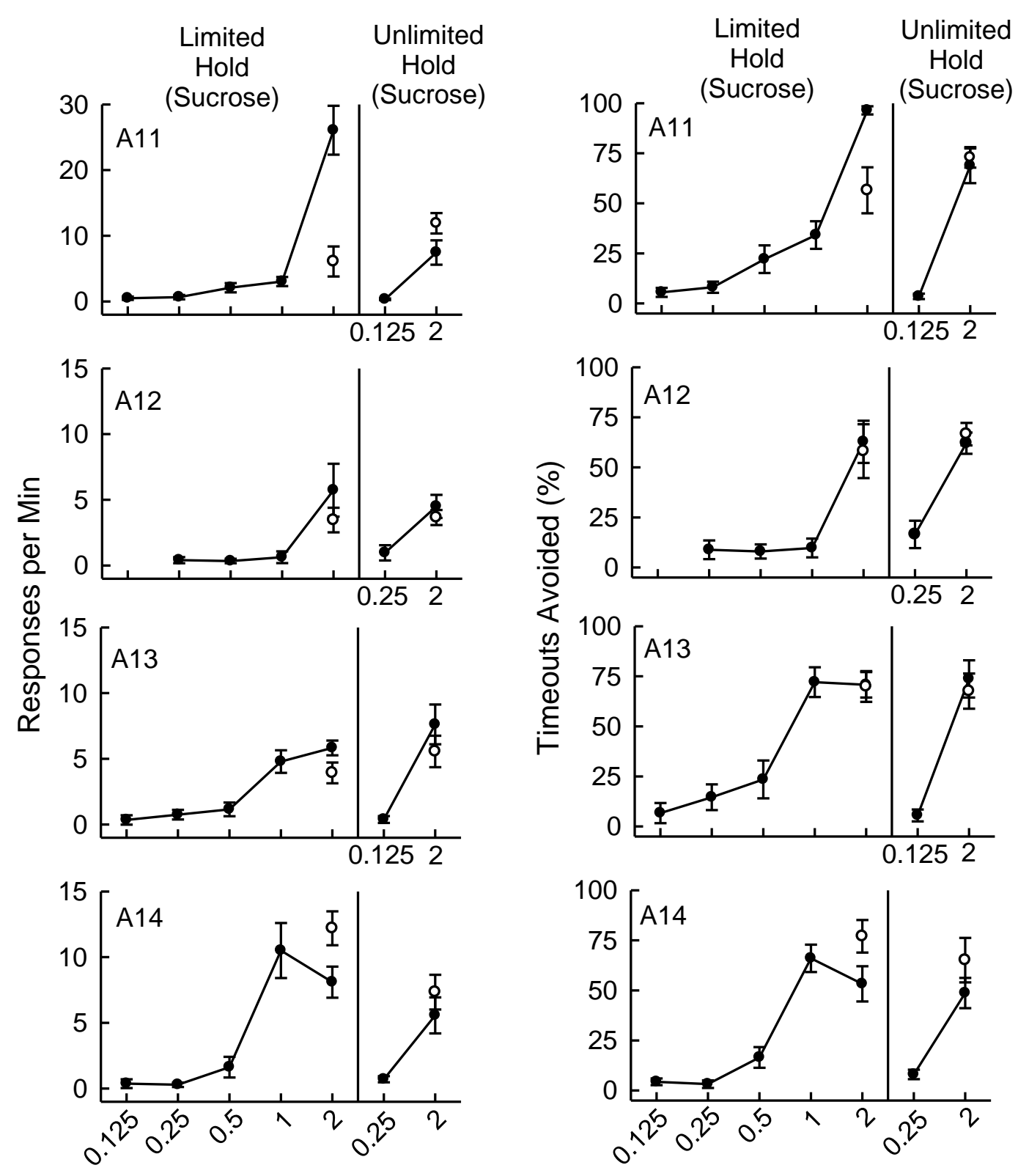

Deliveries per Min

Figure 13. (Experiment 2, Limited Hold then Unlimited Hold). Rates of avoidance responding (shown on the left) and percentage of timeouts avoided (shown on the right) as a function of the food delivery rate per min. The unfilled circles show replications of a given condition. The results are means $( \pm 1 \mathrm{SD})$ over the last 10 sessions of each condition. 


\section{Avoidance Efficiency}

Figure 14 shows the efficiency index over the course of each rat's exposure to the avoidance schedule. Efficiency scores were calculated following the procedure outlined in Experiment 1 . Efficiency was more often related to the rate of sucrose delivery than the length of exposure to the avoidance schedules. As seen in Experiment 1, responding was more efficient during the leaner delivery conditions than the richer. Figure 15 shows the measure of efficiency from the last session of each condition as a function of the sucrose delivery rate; in general, efficiency decreased as the rate of sucrose delivery was raised.

Why was there a negative relation between efficiency and the rate of food delivery? It is possible that the richer schedules hindered sensitivity to time, or the temporal nature of the avoidance schedules. However, there is not sufficient evidence to determine if the location of avoidance responses within the response-timeout interval is due to the temporal properties of the avoidance schedule, as only one response-timeout interval was used in the present study. What is needed is evidence of a change in the spacing of avoidance responses with manipulation of the response-timeout interval. To examine whether less efficient responding occurs during richer schedules due to the disruption of temporal control, the efficiency of avoidance responding could be examined at different delivery rates when the duration of the response-timeout interval is systematically manipulated. It is also possible, however, that the measure of efficiency is merely an artifact of the relation between food delivery rates and avoidance rates. A richer schedule of food delivery engenders a higher rate of responding, or more responses that occur close together, and a lean schedule engenders a lower rate of responding, or fewer responses that are more widely separated. 

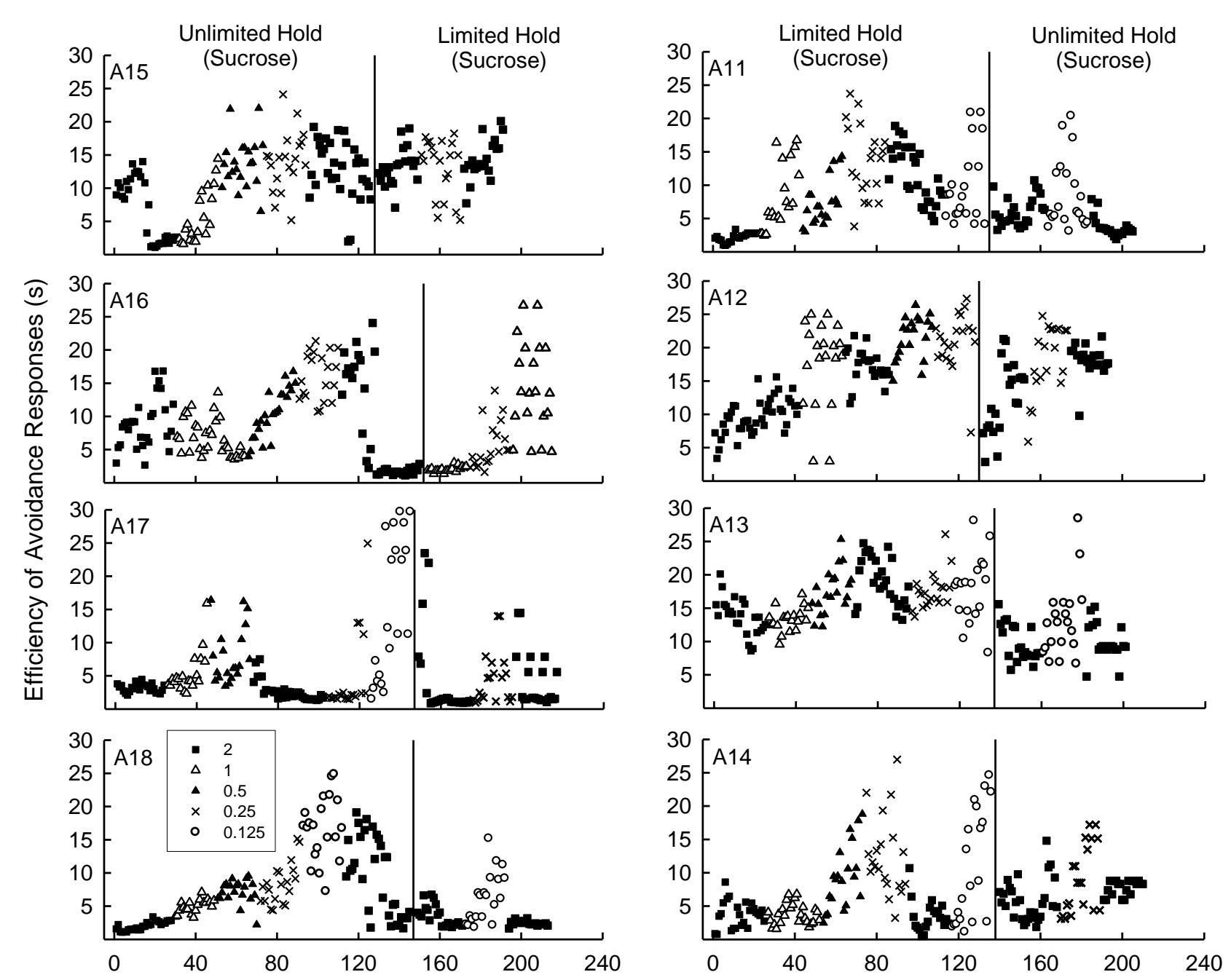

\section{Exposure Time (hr)}

Figure 14. Experiment 2. Response efficiency as a function of hours of exposure to the avoidance schedule. Efficiency was defined by the location of the avoidance response within the 30-s response-timeout interval. An index of efficiency was calculated for each session by taking the $75^{\text {th }}$ percentile of the distribution of times. The food delivery rates $(2,1,0.5,0.25$, and 0.125 per min) are represented by different symbols. Results from the rats initially exposed to the Unlimited Hold are shown on the left and those initially exposed to the Limited Hold are shown on the right. 


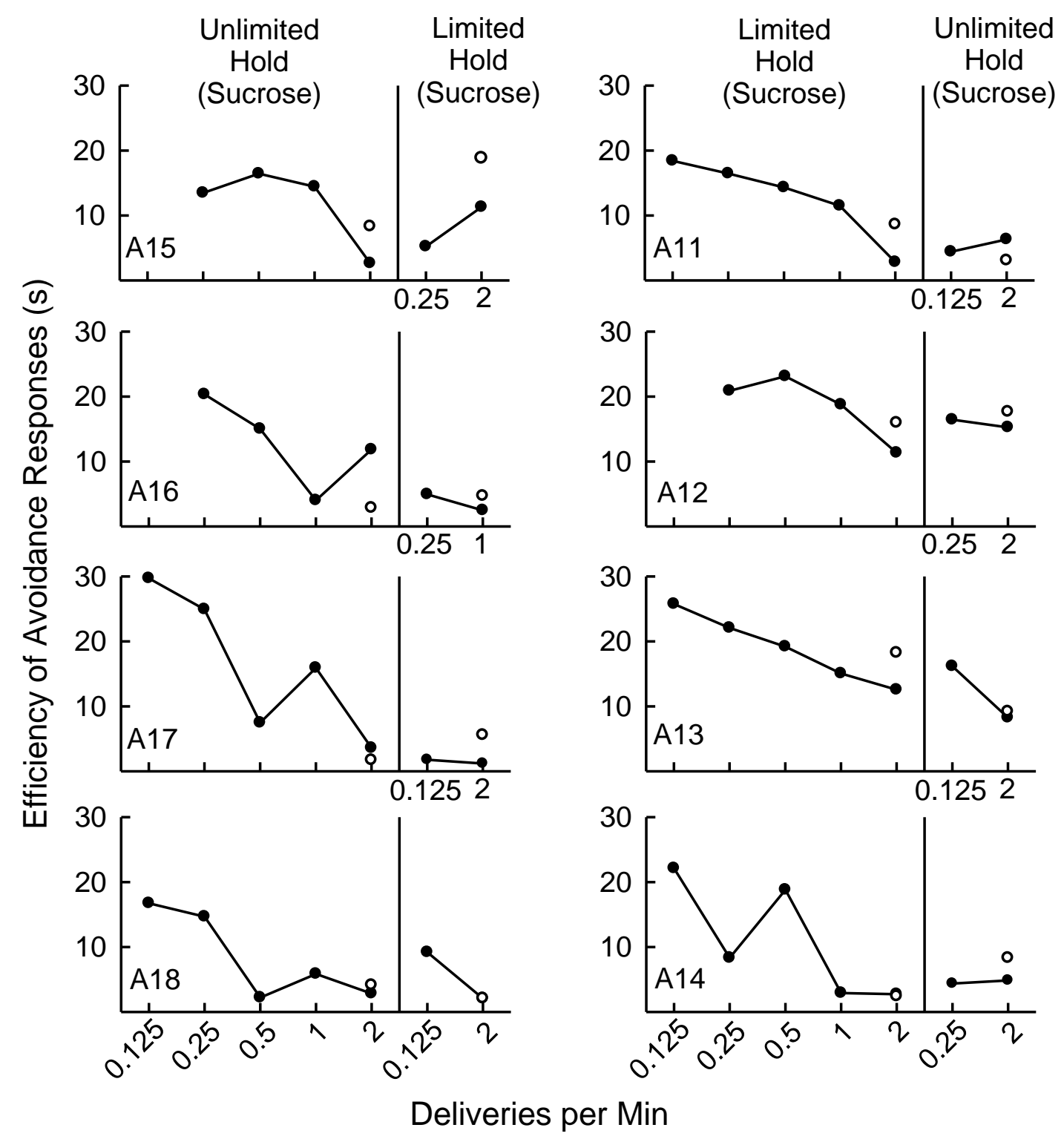

Figure 15. Experiment 2. Response efficiency as a function of the delivery rate per min. The unfilled circles show replications of a given condition. Efficiency was defined by the location of the avoidance response within the 30-s response-timeout interval. An index of efficiency was calculated by taking the $75^{\text {th }}$ percentile of the distribution of times. Results are the efficiency measures from the last session at each delivery rate. 


\section{Within-Session Responding}

To evaluate within-session changes in responding during Experiment 2, the $60 \mathrm{~min}$ of time-in was separated into six 10-min blocks and the rate of avoidance and the percentage of timeouts avoided were calculated for each block. Results from select delivery rates are shown in Figures 16 and 17. The within-session analysis of avoidance response rates from all conditions is shown in Appendix E (Table E1) and the analysis of the percentage of timeouts avoided is shown in Appendix F (Table F1).

Figure 16 shows the within-session analysis for the rats first exposed to the Unlimited Hold condition. When sucrose water was delivered at a rate of 2 per min, avoidance responding gradually decreased across the six blocks (the exception being Rat A17) while the percentage of timeouts avoided was relatively stable (the exception being Rat A15). When sucrose water was delivered at the leaner rates (at a rate of 0.5 per min and 0.25 per min [Rats A15 and A16] or 0.125 per min [Rats A17 and A18]), avoidance rates and percentages either gradually decreased across blocks or decreased by the third block and then remained at a low level. Figure 17 shows the within-session analysis for the rats first exposed to the Limited Hold condition. At all delivery rates, within-session decreases in avoidance responding occurred, typically from the first to the second block. The percentage of timeouts avoided changed in concert with the avoidance rates.

Within-session decreases in responding did not occur when pellets were delivered frequently (Experiment 1), but they did occur when sucrose water was delivered frequently. Within-session changes in avoidance responding may have occurred due to satiation to the repeated presentation of sucrose water (the "satiety hypothesis," see Killen, 1995) or habituation to aspects of the experimental arrangement (the "habituation hypothesis," see McSweeney, 


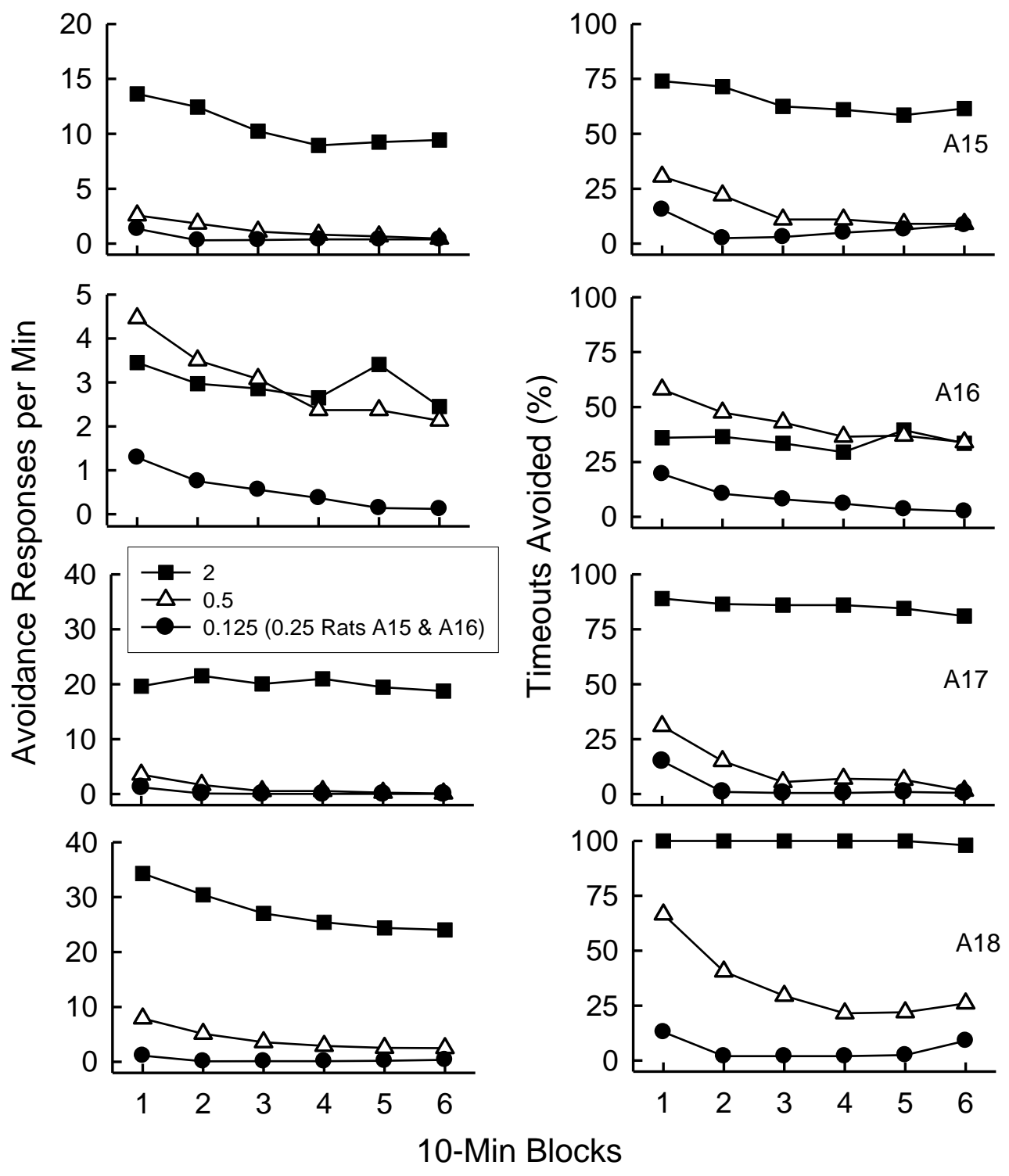

Figure 16. Experiment 2 (Unlimited Hold). Rates of avoidance responding (shown on the left) and percentages of timeouts avoided (shown on the right) as a function of 10-min blocks of time-in across the last 10 sessions. Each data path shows a different food delivery rate $(2,0.5,0.25$, or 0.125 per min) from the Unlimited Hold condition. The leanest food delivery rate was 0.125 per min for all rats except A15 and A16 for which the leanest food delivery rate was 0.25 per min. 


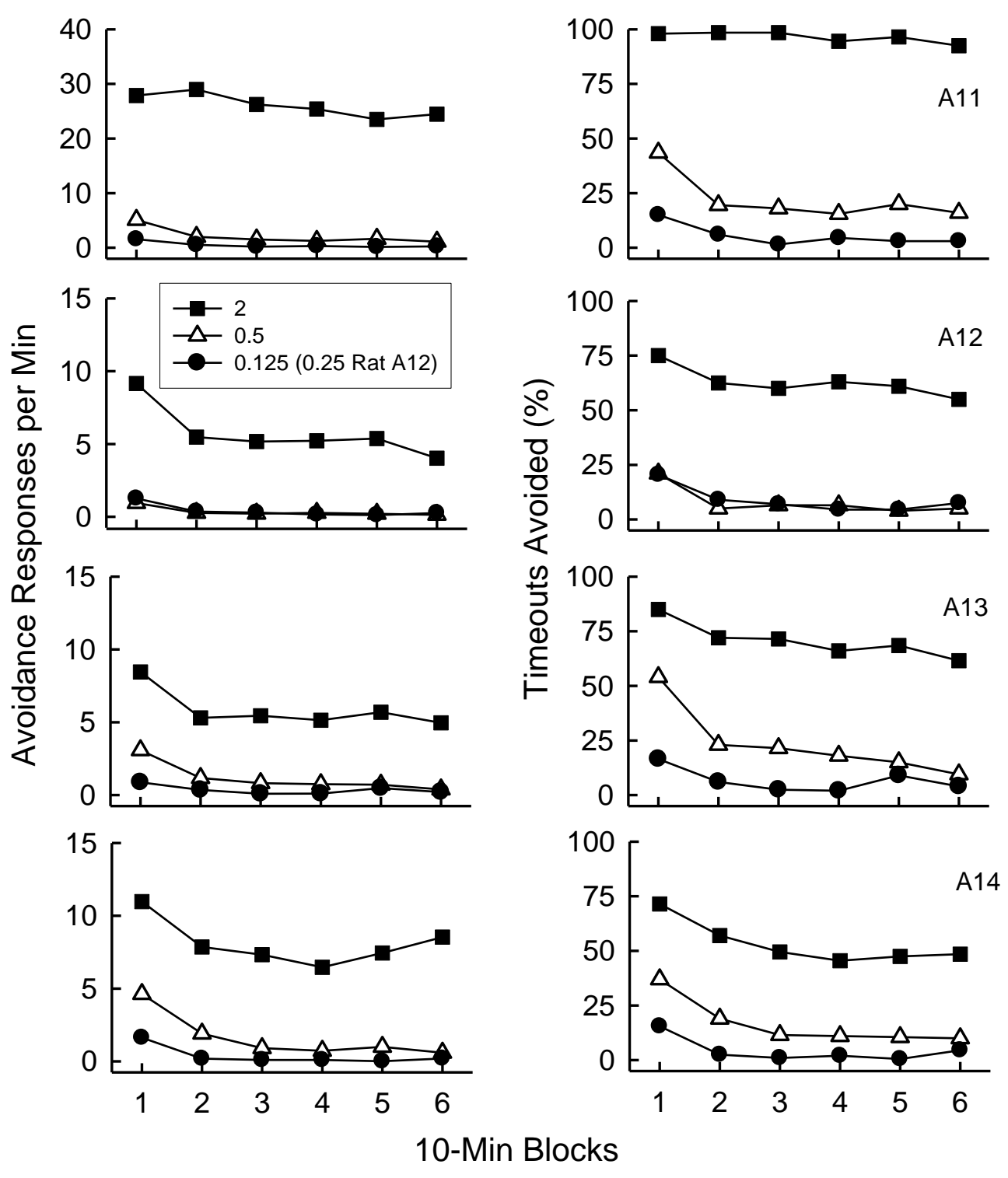

Figure 17. Experiment 2 (Limited Hold). Rates of avoidance responding (shown on the left) and percentages of timeouts avoided (shown on the right) as a function of 10-min blocks of time-in across the last 10 sessions. Each data path shows a different food delivery rate $(2,0.5,0.25$, or 0.125 per min) from the Limited Hold condition. The leanest food delivery rate was 0.125 per min for all rats except A12 for which the leanest food delivery rate was 0.25 per min. 
Hinson, \& Cannon, 1996; McSweeney \& Murphy, 2000). The present results cannot definitively rule out satiation as a factor contributing to within-session changes, however, habituation (or a combination of the two) may have occurred as well.

\section{General Discussion}

The present study was designed to address whether timeout from a rich schedule of food delivery is more or less aversive than timeout from a lean schedule. There is a theoretical basis for predicting that timeout from a rich schedule should be more aversive than timeout from a lean schedule (Fantino, 1977; Ferster, 1960). However, research that has assessed the relative aversiveness of timeout from lean and rich schedules using avoidance procedures has yielded discrepant findings (D’Andrea, 1971; Richardson \& Baron, 2008; Thomas, 1964, 1965b; van Haaren \& Anderson, 1998). The present study was based on the notion that the conflicting results may have arisen from differences in procedural details that influenced the effect of the food schedules on behavior that may compete with avoidance.

At issue was whether a limited hold on consumption increases attending to the magazine (i.e., the site of food delivery) and decreases avoidance as a consequence. It was hypothesized that behavior directed toward the magazine would compete with avoidance when a limited hold was present. But when a limited hold was absent, competition between magazine-directed behavior and avoidance would be reduced, allowing avoidance rates to serve as a valid measure of the aversiveness of timeout. The anticipated effect was not observed. Instead, regardless of whether a limited hold was present or absent, the rate of avoidance increased as the rate of food delivery was raised.

If a limited hold on consumption does not underlie the discrepancy in the timeout avoidance literature, the question remains, what might be the cause of the discrepant findings? 
In the first section below, the effectiveness of aversive stimuli after repeated presentations will be discussed as a possible answer to this question. In the remaining sections, additional factors that determine the aversiveness of timeout, specifically, the quality of food deliveries and the classification of timeout as an aversive event will be considered. A comparison between shock and timeout and the applied significance of the present findings will be addressed.

\section{The Continued Effectiveness of Aversive Stimuli}

The amount of exposure to the timeouts may have affected the relation between food delivery rates and avoidance. Evidence for this can be found in the literature on punishment. Responding that is punished by electric shock sometimes recovers to pre-punishment levels after the continued or repeated presentation of shock (for a discussion of this recovery process, see Azrin \& Holz, 1966). More generally, the effectiveness of an aversive event may be diminished after repeated presentations. In the present study, and the study conducted by Richardson and Baron (2008), when the richer delivery conditions were repeated, avoidance response rates (and the percentage of timeouts avoided) often did not recover to their original values. Figure 18 shows the rate of avoidance responding when food was delivered at a rate of 2 per min during the initial exposure and the replication of this condition from the present study. For 11 of the 15 rats, rates of avoidance were lower during the replication than during the initial condition. It is possible that this occurred because, throughout the intervening conditions, the rats experienced numerous timeouts.

In the studies reporting an inverse relation between the rate of food delivery and avoidance response rates, subjects completed the conditions arranging a lower rate of food delivery before those arranging a higher rate. For example, in Thomas's (1965b) experiment, the pigeon completed four conditions at the leaner VT 3-min schedule (the response-timeout interval 


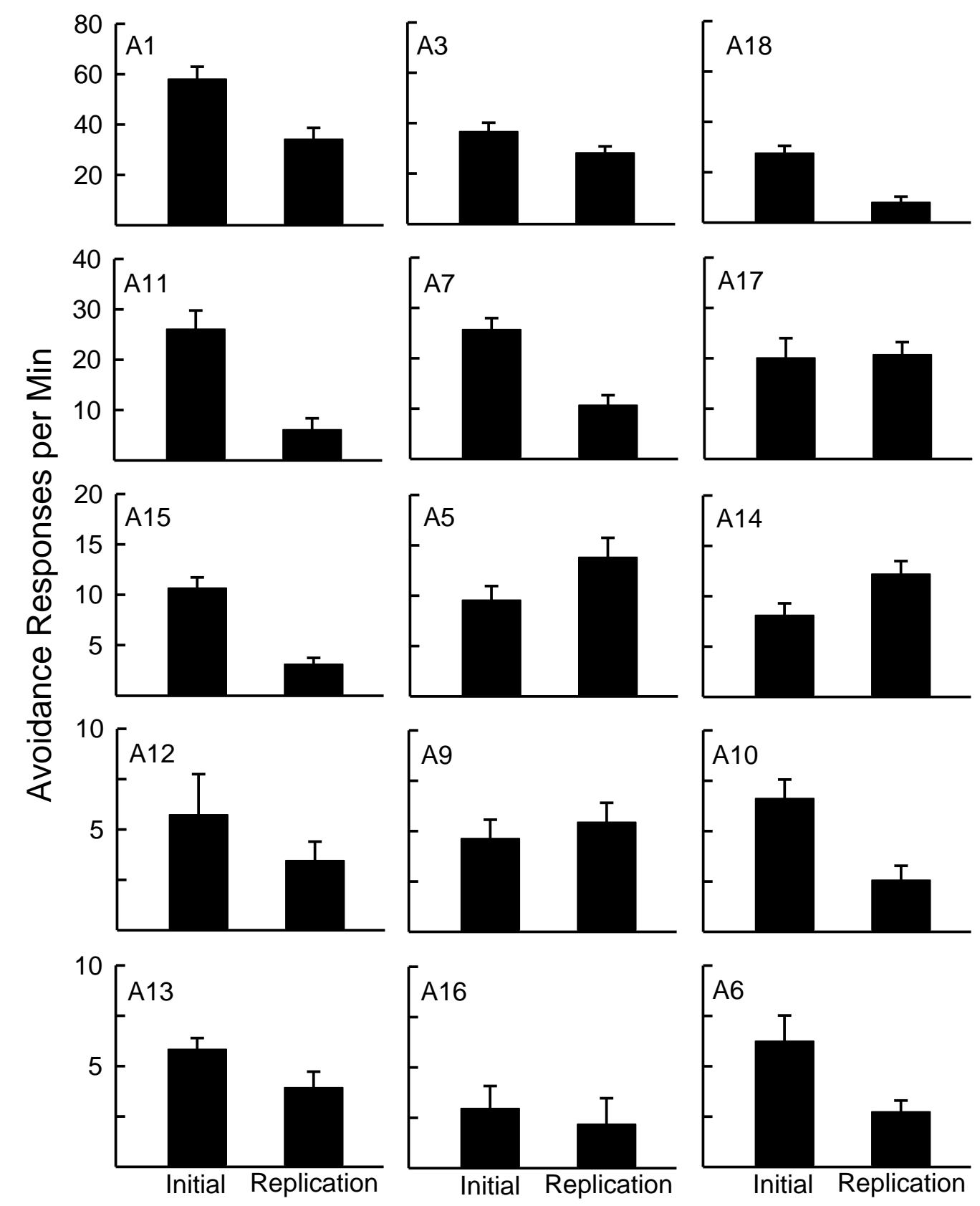

Figure 18. Rates of avoidance responding when food was delivered at a rate of 2 per min during the initial exposure and the replication of this condition. Results are means from the stable sessions and error bars extend two SD. 
was increased from $20 \mathrm{~s}$ to $120 \mathrm{~s}$ across these four sessions) before being exposed to the richer VT 1-min schedule. In comparison, the studies reporting a direct relation exposed subjects to the richer conditions first. If the effectiveness of timeout is reduced after continued exposure, raising the rate of food delivery may not override this loss of effectiveness. Finally, the experiments reporting an inverse relation only compared two delivery rates. If the rate of food deliveries were parametrically manipulated, perhaps a broader picture would have revealed a direct relation between food delivery and avoidance rates.

\section{Quality of Food Delivery}

The present study focused on the relation between the aversiveness of timeout and the rate (or quantity) of food deliveries during time-in. The quality of food deliveries during time-in is also an important variable. Richardson and Baron (2008, Experiment 3) compared rates of avoidance responding when regular pellets and sweetened pellets were delivered at a rate of 1 per min. Avoidance response rates were higher when sweetened pellets were delivered than when regular pellets were delivered. Evidence for the effects of the quality of the item delivered can be found in the present study. Figure 19 provides a comparison of avoidance rates when pellets and sucrose water were delivered at a rate of 2 per min ( 1 per min for Rat A3) and 0.125 per min (0.25 per min for Rats A1 and A6). Data from replications of the 2 per min condition in which the same item was delivered were combined. At both delivery rates, rates of avoidance were typically different when the different food items were delivered. However, whether rates of avoidance were higher when pellets or when sucrose water was delivered varied within and between subjects. Additional evidence of the effects of the quality of the free food comes from preliminary training. Avoidance of timeout was not established when plain water was delivered, 


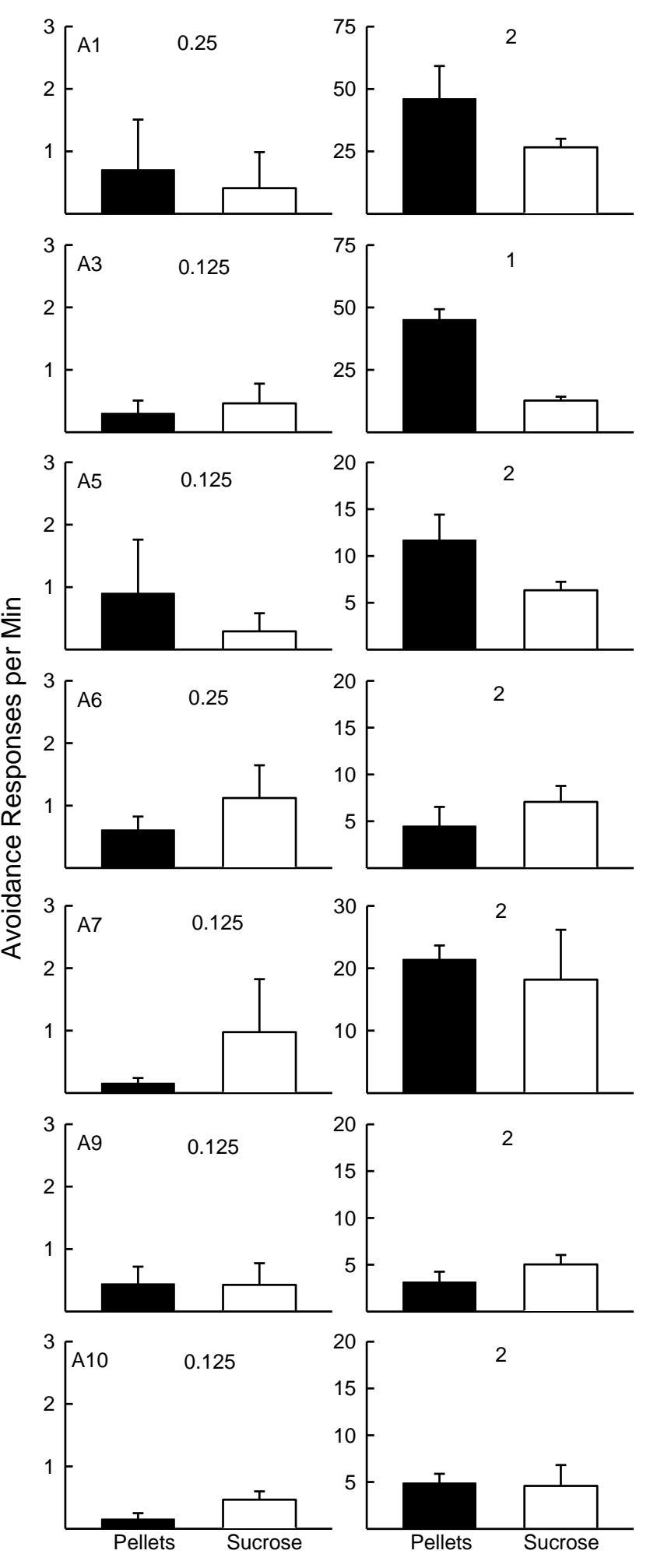

Figure 19. Rates of avoidance responding when pellets (filled bars) and sucrose water (unfilled bars) were delivered at a rate of 0.25 or 0.125 per min (shown on the left) and at a rate of 1 or 2 per min (shown on the right). Results are means from the stable sessions and error bars extend two SD. 
but avoidance was established when sucrose water was delivered - a finding that underscores the importance of the quality of the free food.

The present results replicate and extend the findings reported by Richardson and Baron in showing that not only the rate, but also the quality of food delivery can affect the rate of avoidance responding. However, a more direct examination of the interaction of the rate and quality of food deliveries could be arranged by parametrically manipulating the concentration of the sucrose water and the rate of delivery.

\section{Is Timeout Aversive?}

In a classic review of the experimental literature, Leitenberg (1965) asked if timeout from positive reinforcement really is an aversive event. Based on the experimental evidence available at the time, Leitenberg suggested that timeout did satisfy the major criteria of an aversive event, but that the evidence was not definitive. The problem was that changes in responding intended to reflect the aversiveness of timeout may, as a consequence, have increased the frequency of positive reinforcement. By avoiding timeout an animal can replace timeouts with periods in which reinforcement can be obtained and, as a consequence, the animal may earn a higher frequency of reinforcement. Increases in the frequency of reinforcement also may occur with punishment procedures. By responding at a slower rate an animal can reduce the number of timeouts and, therefore, increase access to a period in which reinforcement is available. In the studies reviewed by Leitenberg, changes in the rate of food reinforcement and the rate of timeout were confounded. This left open the possibility that changes in responding could be attributed to either reinforcement or timeout.

Following the publication of Leitenberg's paper, several researchers sought to answer the question put forth regarding the nature of timeout. Two punishment studies (Branch, Nicholson, 
\& Dworkin, 1977; Kaufman \& Baron, 1968) and one avoidance study (Pietras \& Hackenberg, 2000) demonstrated that timeout can function as an aversive event in the absence of increases in reinforcement frequency. Branch, Nicholson, and Dworkin (1977) compared responsedependent and response-independent timeouts that were superimposed on a random-interval (RI) 1-min schedule. The response-dependent timeouts occurred after every three responses, on average. The response-independent timeouts occurred at the same temporal location as the response-dependent timeouts. Response-dependent timeouts suppressed responding by 35 to 50 percent, whereas response-independent timeouts did not suppress responding. Therefore, changes in the frequency of reinforcement did not determine the effects of timeout. Kaufman and Baron (1968) examined the effects of timeout in the absence of increases in the frequency of reinforcement by using a ratio schedule. On a ratio schedule, a reinforcer is delivered after a specified number of responses are made; if the rate of responding decreases, the frequency of reinforcement will decrease as well. Pietras and Hackenberg (2000) examined the effects of timeout when postponement did not result in an increase in reinforcement frequency. They employed a discrete-trial procedure in which a response at the beginning of a trial postponed timeouts to the end of the trial. The pigeons consistently avoided timeout in the absence of changes in the overall frequency of reinforcement.

By addressing the concerns put forth by Leitenberg (1965), the above studies do not support an interpretation of the effects of timeout based solely on changes in the frequency of positive reinforcement. Some may argue that the effects of timeout should be explained in terms of positive reinforcement except when responding does not increase the frequency of positive reinforcement (e.g., Leitenberg, 1965). A similar argument could be made for studies examining the aversiveness of shock. For example, when a rat presses a lever to avoid shock, it is often 
unclear whether lever pressing is maintained by removal of periods of danger (negative reinforcement) or production of periods of safety (positive reinforcement). Studies using punishment and avoidance procedures, whether the aversive stimulus is shock or timeout, have mainly been conceptualized as falling into the area of aversive control (for reviews regarding the distinction between positive and negative reinforcement, see Baron \& Galizio, 2005; Michael, 1975). The present research followed this established tradition.

\section{Shock and Timeout as Aversive Events}

In the study of aversive control within the basic laboratory, shock is a commonly used stimulus. Because of a large body of research conducted with shock, it often serves as a reference stimulus when assessing the aversive function of other stimuli. Most research supports the notion that timeout functions in a comparable manner as shock when studied under similar experimental arrangements (DeFulio \& Hackenberg, 2007; Kaufman \& Baron, 1968; McMillan, 1967; Richardson \& Baron, 2008; Thomas, 1965; van Haaren \& Zarcone, 1994). Variables that control avoidance of shock often have counterparts in the avoidance of timeout. An exception to this general finding was seen in the present study.

Research on avoidance of shock that has parametrically manipulated the intensity of shock has reported an "all-or-none" effect. There is a minimum intensity of shock needed to establish and maintain avoidance—-shock below this value (around 1.0 mA) does not engender avoidance - and raising the shock intensity above this value does not result in further increases in the rate of shock avoidance (de Souza, de Moraes, \& Todorov, 1984). If the intensity of shock within shock-avoidance procedures and the rate of food deliveries within avoidance of timeout procedures are factors that determine the relative aversiveness of these events, it seems plausible that the all-or-none effect reported with avoidance of shock would have a parallel in avoidance 
of timeout. In the present study, the all-or-none effect was not seen with avoidance of timeout. Low rates of food delivery established a low rate of avoidance and raising the rate of food delivery resulted in further increases in avoidance of timeout. However, if the rate of food delivery was raised beyond the highest frequency used in the present study, perhaps the rate of avoidance would be insensitive to these changes, as is seen with avoidance of shock above intensities of $1.0 \mathrm{~mA}$.

\section{Applied Significance}

Although timeout is one of the most commonly used tools to change behavior in the natural environment little laboratory research has been conducted on its use. As a result, we lack an understanding of when it is and is not an appropriate method. Several of the rules-of-thumb or recommendations for using timeout (e.g., timeouts should last 1 min for every year of age, timers should be used to signal the duration of timeouts, a repeated return procedure should be used when a child will not stay in timeout) have not been empirically validated (Brantner \& Doherty, 1983; Everett, 2010; Defulio \& Hackenberg, 2007; Lerman \& Vorndran, 2002; Solnick, Rincover, \& Peterson, 1977; Turner \& Watson, 1999). When common recommendations have been examined empirically, they are sometimes found to be contraindicated (e.g., Donaldson \& Vollmer, 2011). An understanding of the factors that determine the aversiveness of timeout may lead to improved interventions for changing behavior.

The present study demonstrated that the aversiveness of timeout depends on the characteristics of the time-in environment. Timeout from a relatively impoverished environment is unlikely to be an effective tool for changing behavior, whereas timeout from a relatively enriched environment is likely to be effective. Failure to consider the characteristics of the timein environment in relation to the timeout environment may be a sizeable mistake. This is 
underscored by the finding that, similar to research from the basic animal laboratory, timeout can have a reinforcing effect if the conditions during timeout are more favorable than those during time-in (Solnick, Rincover, \& Peterson, 1977; Steeves, Martin, \& Pear, 1970).

In basic research with animals, relatively rich and lean time-in environments can be generated by manipulating the quantity and the quality of food deliveries. These food deliveries serve a biologically relevant purpose, as the animals are typically food deprived. Manipulation of the time-in environment in classrooms, homes, and other social institutions may prove to be more challenging. Teachers and caregivers may not be able restructure the time-in environment nor have control over relevant establishing operations. If direct manipulation of the time-in environment is not feasible, the use of timeout may be recommended for use only in certain situations. For example, if a student engages in disruptive behavior during recess, timeout may be effective at reducing the disruptive behavior. In comparison, if the student engages in disruptive behavior during math class, timeout may be less likely to reduce disruptive behavior and, therefore, should not be the recommended intervention.

Basic laboratory research can assist in identifying those factors that are important for users of timeout to consider. However, further research will be needed to develop a bridge between basic laboratory research and problems relevant to clinical settings. Translation of basic research findings to applied settings and vice-versa will be necessary. 


\section{References}

Appel, J. B. (1963). Aversive aspects of a schedule of positive reinforcement. Journal of the Experimental Analysis of Behavior, 6, 423-428.

Azrin, N. H. (1961). Time-out from positive reinforcement. Science, 133, 382-383.

Azrin, N. H., \& Holz, W. C. (1966). Punishment. In W. K. Honig (Ed.), Operant behavior: Areas of research and application (pp. 380-447). New York: Appleton-Century-Crofts.

Baron, A., \& Galizio, M. (2005). Positive and negative reinforcement: Should the distinction be preserved? The Behavior Analyst, 28, 85-98.

Baron, A., \& Kaufman, A. (1969). Time-out punishment: Preexposure to time-out and opportunity to respond during time-out. Journal of Comparative and physiological psychology, 67, 479-485.

Branch, M. N., Nicholson, G., \& Dworkin, S. I. (1977). Punishment-specific effects of pentobarbital: Dependency on the type of punisher. Journal of the Experimental Analysis of Behavior, 28, 285-293.

Brantner, J.P., \& Doherty, M.A. (1983). A review of timeout: A conceptual and methodological analysis. In S. Axelrod \& J. Apsche (Eds.), The effects of punishment on human behavior (pp. 87-132). New York: Academic Press.

Case, D. A., \& Fantino, E. (1981). The delay-reduction hypothesis of conditioned reinforcement and punishment: Observing behavior. Journal of the Experimental Analysis of Behavior, 35, 93-108.

D'Andrea, T. (1971). Avoidance of timeout from response-independent reinforcement. Journal of the Experimental Analysis of Behavior, 15, 319-325.

Defulio, A., \& Hackenberg, T. D. (2007). Timeout from reinforcement: Restoring a balance between analysis and application. Mexican Journal of Behavior Analysis, 33, 37-44.

De Souza, D. D., de Moraes, A. B. A., \& Todorov, J. C. (1984). Shock intensity and signaled avoidance responding. Journal of the Experimental Analysis of Behavior, 42, 67-74.

Donaldson, J. M., \& Vollmer, T. R. (2011). An evaluation and comparison of time-out procedures with and without release contingencies. Journal of Applied Behavior Analysis, 44, 693-705.

Dunn, R. (1990). Timeout from concurrent schedules. Journal of the Experimental Analysis of Behavior, 53, 163-174. 
Everett, G. E. (2010). Time-out in special education settings: The parameters of previous implementation. North American Journal of Psychology, 12, 159-170.

Falk, J. L. (1961). Production of polydipsia in normal rats by an intermittent food schedule. Science, 133, 195-196.

Fantino, E. (1969). Choice and rate of reinforcement. Journal of the Experimental Analysis of Behavior, 12, 723-730.

Fantino, E. (1977). Conditioned reinforcement: Choice and information. In W. K. Honig \& J. E. R. Staddon (Eds.), Handbook of operant behavior (pp. 313-339). Englewood Cliffs, NJ: Prentice-Hall.

Fantino, E., Preston, R. A., \& Dunn, R. (1993). Delay reduction: Current status. Journal of the Experimental Analysis of Behavior, 60, 159-169.

Ferster, C. B. (1960). Suppression of a performance under differential reinforcement of low rates by a pre-timeout stimulus. Journal of the Experimental Analysis of Behavior, 3, 143-153.

Fleshler, M., \& Hoffman, H. S. (1962). A progression for generating variable-interval schedules. Journal of the Experimental Analysis of Behavior, 5, 529-530.

Flory, R. K., \& Lickfett, G. G. (1974). Effects of lick-contingent timeout on schedule-induced polydipsia. Journal of the Experimental Analysis of Behavior, 21, 45-55.

Galbicka, G., \& Branch, M. (1983). Stimulus-food relations and free-operant postponement of timeout from response-independent food presentation. Journal of the Experimental Analysis of Behavior, 40, 153-163.

Hineline, P. N. (1984). Aversive control: A separate domain? Journal of the Experimental Analysis of Behavior, 42, 495-509.

Jerome, E. A., Moody, J. A., Connor, T. J., \& Ryan, J. (1958). Intensity of illumination and the rate of responding in a multiple-door situation. Journal of Comparative and Physiological Psychology, 51, 47-49.

Kaufman, A. \& Baron, A. (1968). Suppression of behavior by timeout punishment when suppression results in loss of positive reinforcement. Journal of the Experimental Analysis of Behavior, 11, 595-607.

Killeen, P. R. (1995). Economics, ecologics, and mechanics: The dynamics of responding under conditions of varying motivation. Journal of the Experimental Analysis of Behavior, 64, 405-431. 
Kramer, T. J., \& Rilling, M. (1969). Effects of timeout on spaced responding in pigeons. Journal of the Experimental Analysis of Behavior, 12, 283-288.

Leitenberg, H. (1965). Is timeout from positive reinforcement an aversive event? A review of the experimental evidence. Psychological Bulletin, 64, 428-441.

Lerman, D. C. \& Vorndran, C. M. (2002). On the status of knowledge for using punishment: Implications for treating behavior disorders. Journal of Applied Behavior Analysis, 35, 431-464.

McMillan, D. E. (1967). A comparison of the punishing effects of response-produced shock and response-produced time out. Journal of the Experimental Analysis of Behavior, 10, 439449.

McSweeney, F. K., Hinson, J. M., \& Cannon, C. B. (1996). Sensitization-habituation may occur during operant conditioning. Psychological Bulletin, 120, 256-271.

McSweeney, F. K., \& Murphy, E. S. (2000). Criticisms of the satiety hypothesis as an explanation for within-session decreases in responding. Journal of the Experimental Analysis of Behavior, 74, 347-361.

Michael, J. (1975). Positive and negative reinforcement, a distinction that is no longer necessary; or a better way to talk about bad things. Behaviorism, 3, 33-44.

Nader, M. A., \& Morgan, D. (2001). Effects of negative punishment contingencies on cocaine self-administration by rhesus monkeys. Behavioural Pharmacology, 12, 91-99.

Pietras, C. J., \& Hackenberg, T. D. (2000). Timeout postponement without increased reinforcement frequency. Journal of the Experimental Analysis of Behavior, 74, 147-164.

Preston, R., \& Fantino, E. (1991). Conditioned reinforcement value and choice. Journal of the Experimental Analysis of Behavior, 55, 155-175.

Richardson, J.V., \& Baron, A. (2008). Avoidance of timeout from response-independent food: effects of delivery rate and quality. Journal of the Experimental Analysis of Behavior, 89, 169-181.

Sidman, M. (1953). Avoidance conditioning with brief shock and no exteroceptive warning signal. Science, 118, 157-158.

Solnick, J. V., Rincover, A., \& Peterson, C. R. (1977). Some determinants of the reinforcing and punishing effects of timeout. Journal of Applied Behavior Analysis, 10, 415-424. 
Steeves, J., Martin, G., \& Pear, J. (1970). Self-imposed time-out by autistic children during an operant training program. Behavior Therapy, 1, 371-381.

Striefel, S. (1972). Timeout and concurrent fixed-ratio schedules with human subjects. Journal of the Experimental Analysis of Behavior, 17, 213-219.

Thomas, J. R. (1964). Avoidance of time-out from VI schedules of positive reinforcement. Journal of the Experimental Analysis of Behavior, 7, 168.

Thomas, J. R. (1965a). Discriminated time-out avoidance in pigeons. Journal of the Experimental Analysis of Behavior, 8, 329-338.

Thomas, J. R. (1965b). Time-out avoidance from a behavior-independent contingency. Psychonomic Science, 3, 217-218.

Thomas, J. R. (1968). Fixed-ratio punishment by timeout of concurrent variable-interval behavior. Journal of the Experimental Analysis of Behavior, 11, 609-616.

Turner, H. S., \& Watson, T. S. (1999). Consultant's guide for the use of time-out in the preschool and elementary school classroom. Psychology in the Schools, 36, 135-148.

van Haaren, F., \& Anderson, K. G. (1994). Effects of chlordiazepoxide, buspirone and cocaine on behavior suppressed by timeout presentation. Behavioral Pharmocology, 8, 174-182.

van Haaren, F., \& Anderson, K. G. (1998). Avoidance of time-out from response-independent food presentation: Effects of chlordiazepoxide and buspirone. Pharmacology Biochemistry and Behavior, 61, 207-214.

Williams, W. A., \& Fantino, E. (1994). Delay reduction and optimal foraging: Variable-ratio search in a foraging analogue. Journal of the Experimental Analysis of Behavior, 61, 465477. 


\section{Appendix A}

\section{Preparation of Sucrose Water}

A $30 \%$ sucrose water solution was prepared by completing the following steps:

1. An empty container was placed on a scale and the scale was reset to zero by pressing the "tare" button (this was done to measure the contents of the container without measuring the weight of the container itself).

2. $30 \mathrm{~g}$ of granulated pure cane sugar was added to the container (the sugar was purchased at a local grocery store).

3. Deionized water was then added to the sugar until the scale read $100 \mathrm{~g}$.

4. The quantity of sucrose water could be increased by increasing the amount of sugar and water while maintaining the same proportion. For example, using $150 \mathrm{~g}$ of sugar and adding water until $500 \mathrm{~g}$ is reached would also yield a $30 \%$ solution. 


\section{Appendix B}

\section{Sample Growth Charts}

1. Ad libitum weights are measured and recorded when the rats are 10 weeks old and the weight for each rat is placed in the row labeled "Initial Ad Lib Weights."

2. The row labeled "Calendar Date" begins when eat rat is 10 weeks old and a new target weight for each rat is calculated every week for weeks $10-14$, every 2 weeks for weeks 16 20 , and every 4 weeks for weeks $24-60$.

3. Target weights are calculated via the following steps:

a. Relative gain (the amount of weight each rat should gain) is determined by subtracting the 10-week ad lib weight for each rat by the projected weight (based on growth charts provided by the supplier for male Sprague-Dawley rats) and dividing this result by the 10 -week weight.

b. One is added to the relative gain and 80 percent of this value is calculated.

c. This product is multiplied by the 10 -week weight.

\begin{tabular}{|c|c|c|c|c|c|c|c|c|c|c|}
\hline & & Initial Ad Lib Weights --> & 273 & 291 & 285 & 280 & 292 & 291 & 289 & 290 \\
\hline Weeks & Days & Calendar Date & A1 & A3 & A5 & A6 & A7 & A8 & A9 & A10 \\
\hline 10 & 70 & Friday, August 05, 2011 & 218 & 233 & 228 & 224 & 234 & 233 & 231 & 232 \\
\hline 11 & 77 & Friday, August 12, 2011 & 231 & 246 & 241 & 236 & 247 & 246 & 244 & 245 \\
\hline 12 & 84 & Friday, August 19, 2011 & 243 & 259 & 253 & 249 & 260 & 259 & 257 & 258 \\
\hline 13 & 91 & Friday, August 26, 2011 & 252 & 268 & 263 & 258 & 269 & 268 & 267 & 267 \\
\hline 14 & 98 & Friday, September 02, 2011 & 261 & 278 & 272 & 268 & 279 & 278 & 276 & 277 \\
\hline 16 & 112 & Friday, September 16, 2011 & 270 & 288 & 282 & 277 & 289 & 288 & 286 & 287 \\
\hline 18 & 126 & Friday, September 30, 2011 & 282 & 301 & 295 & 289 & 302 & 301 & 299 & 300 \\
\hline 20 & 140 & Friday, October 14, 2011 & 294 & 314 & 307 & 302 & 315 & 314 & 311 & 313 \\
\hline 24 & 168 & Friday, November 11, 2011 & 306 & 327 & 320 & 314 & 328 & 327 & 324 & 325 \\
\hline 28 & 196 & Friday, December 09, 2011 & 319 & 340 & 333 & 327 & 341 & 340 & 337 & 338 \\
\hline 32 & 224 & Friday, January 06, 2012 & 328 & 349 & 342 & 336 & 350 & 349 & 347 & 348 \\
\hline 36 & 252 & Friday, February 03, 2012 & 337 & 359 & 352 & 345 & 360 & 359 & 356 & 358 \\
\hline 40 & 280 & Friday, March 02, 2012 & 346 & 369 & 361 & 355 & 370 & 369 & 366 & 367 \\
\hline 44 & 308 & Friday, March 30, 2012 & 349 & 372 & 364 & 358 & 373 & 372 & 369 & 371 \\
\hline 48 & 336 & Friday, April 27, 2012 & 355 & 378 & 371 & 364 & 380 & 378 & 376 & 377 \\
\hline 52 & 364 & Friday, May 25, 2012 & 364 & 388 & 380 & 373 & 389 & 388 & 385 & 387 \\
\hline 56 & 392 & Friday, June 22, 2012 & 364 & 388 & 380 & 373 & 389 & 388 & 385 & 387 \\
\hline 60 & 420 & Friday, July 20, 2012 & 367 & 391 & 383 & 376 & 393 & 391 & 389 & 390 \\
\hline
\end{tabular}




\section{Appendix C}

Table C1

Within-Session Responding: Avoidance Response Rates (Experiment 1)

Experiment 1. Rates of avoidance responding (responses per min) as a function of 10-min blocks of time-in across the last 10 sessions. Standard deviations are shown in parentheses.

\begin{tabular}{|c|c|c|c|c|c|c|c|c|c|}
\hline \multicolumn{10}{|c|}{ Rat A1 } \\
\hline \multicolumn{10}{|c|}{ Food Deliveries per Min } \\
\hline $10-\min$ & 2 & 1 & 0.5 & 0.25 & 0.125 & 2 & High & Low & High \\
\hline Blocks & \multicolumn{6}{|c|}{ Unlimited Hold (Pellets) } & \multicolumn{3}{|c|}{ Limited Hold (Sucrose) } \\
\hline 1 & $\begin{array}{l}58.65 \\
(6.09)\end{array}$ & $\begin{array}{l}15.09 \\
(4.23)\end{array}$ & $\begin{array}{c}5.96 \\
(4.05)\end{array}$ & $\begin{array}{c}2.60 \\
(2.96)\end{array}$ & $\begin{array}{c}4.71 \\
(5.04)\end{array}$ & $\begin{array}{l}37.49 \\
(4.80)\end{array}$ & $\begin{array}{l}31.59 \\
(7.19)\end{array}$ & $\begin{array}{c}2.22 \\
(3.36)\end{array}$ & $\begin{array}{l}16.10 \\
(2.66)\end{array}$ \\
\hline 2 & $\begin{array}{l}59.51 \\
(9.88)\end{array}$ & $\begin{array}{c}9.11 \\
(5.78)\end{array}$ & $\begin{array}{c}0.87 \\
(0.90)\end{array}$ & $\begin{array}{c}0.60 \\
(1.02)\end{array}$ & $\begin{array}{c}0.17 \\
(0.24)\end{array}$ & $\begin{array}{l}38.11 \\
(4.89)\end{array}$ & $\begin{array}{l}30.81 \\
(6.32)\end{array}$ & $\begin{array}{c}0.05 \\
(0.10)\end{array}$ & $\begin{array}{l}15.54 \\
(4.36)\end{array}$ \\
\hline 3 & $\begin{array}{l}59.83 \\
(9.25)\end{array}$ & $\begin{array}{c}3.36 \\
(2.68)\end{array}$ & $\begin{array}{c}0.85 \\
(0.88)\end{array}$ & $\begin{array}{c}0.52 \\
(0.79)\end{array}$ & $\begin{array}{c}0.21 \\
(0.40)\end{array}$ & $\begin{array}{l}34.20 \\
(7.74)\end{array}$ & $\begin{array}{l}27.87 \\
(5.90)\end{array}$ & $\begin{array}{c}0.06 \\
(0.11)\end{array}$ & $\begin{array}{l}14.52 \\
(3.57)\end{array}$ \\
\hline 4 & $\begin{array}{l}56.06 \\
(4.90)\end{array}$ & $\begin{array}{c}2.98 \\
(2.92)\end{array}$ & $\begin{array}{c}1.11 \\
(2.88)\end{array}$ & $\begin{array}{c}0.22 \\
(0.18)\end{array}$ & $\begin{array}{c}0.07 \\
(0.09)\end{array}$ & $\begin{array}{l}33.47 \\
(7.67)\end{array}$ & $\begin{array}{l}25.02 \\
(4.40)\end{array}$ & $\begin{array}{c}0.01 \\
(0.03)\end{array}$ & $\begin{array}{l}11.55 \\
(4.54)\end{array}$ \\
\hline 5 & $\begin{array}{l}58.69 \\
(6.29)\end{array}$ & $\begin{array}{c}2.02 \\
(1.66)\end{array}$ & $\begin{array}{c}0.14 \\
(0.17)\end{array}$ & $\begin{array}{c}0.16 \\
(0.34)\end{array}$ & $\begin{array}{c}0.09 \\
(0.19)\end{array}$ & $\begin{array}{l}29.41 \\
(8.33)\end{array}$ & $\begin{array}{l}23.24 \\
(3.79)\end{array}$ & $\begin{array}{c}0.04 \\
(0.07)\end{array}$ & $\begin{array}{c}9.41 \\
(6.08)\end{array}$ \\
\hline 6 & $\begin{array}{l}55.57 \\
(4.84) \\
\end{array}$ & $\begin{array}{c}2.03 \\
(3.32) \\
\end{array}$ & $\begin{array}{c}0.36 \\
(0.64) \\
\end{array}$ & $\begin{array}{c}0.14 \\
(0.16) \\
\end{array}$ & $\begin{array}{c}0.07 \\
(0.09) \\
\end{array}$ & $\begin{array}{l}32.22 \\
(8.28) \\
\end{array}$ & $\begin{array}{l}21.32 \\
(4.99) \\
\end{array}$ & $\begin{array}{c}0.08 \\
(0.09) \\
\end{array}$ & $\begin{array}{r}2.70 \\
(3.86) \\
\end{array}$ \\
\hline \multicolumn{10}{|c|}{ Rat A3 } \\
\hline 1 & $\begin{array}{l}35.51 \\
(5.71)\end{array}$ & $\begin{array}{l}42.43 \\
(5.98)\end{array}$ & $\begin{array}{l}11.95 \\
(2.13)\end{array}$ & $\begin{array}{c}1.75 \\
(1.48)\end{array}$ & $\begin{array}{c}1.11 \\
(0.56)\end{array}$ & $\begin{array}{l}28.30 \\
(3.77)\end{array}$ & $\begin{array}{l}16.59 \\
(2.39)\end{array}$ & $\begin{array}{c}1.72 \\
(1.61)\end{array}$ & $\begin{array}{l}11.13 \\
(2.21)\end{array}$ \\
\hline 2 & $\begin{array}{l}34.99 \\
(6.27)\end{array}$ & $\begin{array}{l}47.65 \\
(4.67)\end{array}$ & $\begin{array}{c}9.54 \\
(2.52)\end{array}$ & $\begin{array}{c}0.78 \\
(1.70)\end{array}$ & $\begin{array}{c}0.09 \\
(0.12)\end{array}$ & $\begin{array}{l}28.49 \\
(2.44)\end{array}$ & $\begin{array}{l}13.40 \\
(2.05)\end{array}$ & $\begin{array}{c}0.68 \\
(0.58)\end{array}$ & $\begin{array}{l}10.64 \\
(2.85)\end{array}$ \\
\hline 3 & $\begin{array}{l}37.48 \\
(4.77)\end{array}$ & $\begin{array}{l}45.86 \\
(5.59)\end{array}$ & $\begin{array}{c}6.20 \\
(2.15)\end{array}$ & $\begin{array}{c}0.23 \\
(0.55)\end{array}$ & $\begin{array}{c}0.52 \\
(1.10)\end{array}$ & $\begin{array}{l}28.99 \\
(3.66)\end{array}$ & $\begin{array}{l}12.37 \\
(1.74)\end{array}$ & $\begin{array}{c}0.12 \\
(0.20)\end{array}$ & $\begin{array}{c}9.48 \\
(2.89)\end{array}$ \\
\hline 4 & $\begin{array}{l}37.46 \\
(5.53)\end{array}$ & $\begin{array}{l}43.64 \\
(9.01)\end{array}$ & $\begin{array}{c}3.89 \\
(2.66)\end{array}$ & $\begin{array}{c}0.00 \\
(0.00)\end{array}$ & $\begin{array}{c}0.04 \\
(0.10)\end{array}$ & $\begin{array}{l}27.78 \\
(2.87)\end{array}$ & $\begin{array}{l}10.79 \\
(2.63)\end{array}$ & $\begin{array}{c}0.16 \\
(0.18)\end{array}$ & $\begin{array}{c}8.46 \\
(2.27)\end{array}$ \\
\hline 5 & $\begin{array}{l}36.25 \\
(4.97)\end{array}$ & $\begin{array}{l}45.33 \\
(6.69)\end{array}$ & $\begin{array}{c}1.46 \\
(2.11)\end{array}$ & $\begin{array}{c}0.03 \\
(0.07)\end{array}$ & $\begin{array}{c}0.04 \\
(0.10)\end{array}$ & $\begin{array}{l}28.26 \\
(2.74)\end{array}$ & $\begin{array}{l}11.24 \\
(2.35)\end{array}$ & $\begin{array}{c}0.08 \\
(0.13)\end{array}$ & $\begin{array}{c}7.65 \\
(2.76)\end{array}$ \\
\hline 6 & $\begin{array}{l}37.87 \\
(7.28)\end{array}$ & $\begin{array}{l}45.93 \\
(3.98)\end{array}$ & $\begin{array}{c}0.97 \\
(1.48)\end{array}$ & $\begin{array}{c}0.05 \\
(0.10)\end{array}$ & $\begin{array}{c}0.02 \\
(0.04)\end{array}$ & $\begin{array}{r}27.34 \\
(4.11) \\
\end{array}$ & $\begin{array}{l}11.82 \\
(3.52)\end{array}$ & $\begin{array}{c}0.02 \\
(0.04)\end{array}$ & $\begin{array}{r}7.83 \\
(2.21) \\
\end{array}$ \\
\hline
\end{tabular}

Continued on next page 
Table C1 Continued

\section{Rat A5}

Food Deliveries per Min

\begin{tabular}{|c|c|c|c|c|c|c|c|c|c|}
\hline $10-$ & 2 & 1 & 0.5 & 0.25 & 0.125 & 2 & High & Low & High \\
\hline Blocks & \multicolumn{6}{|c|}{ Unlimited Hold (Pellets) } & \multicolumn{3}{|c|}{ Limited Hold (Sucrose) } \\
\hline 1 & $\begin{array}{l}10.35 \\
(2.37)\end{array}$ & $\begin{array}{l}12.11 \\
(1.66)\end{array}$ & $\begin{array}{l}10.05 \\
(1.96)\end{array}$ & $\begin{array}{c}8.76 \\
(4.36)\end{array}$ & $\begin{array}{c}3.47 \\
(3.27)\end{array}$ & $\begin{array}{l}10.75 \\
(3.55)\end{array}$ & $\begin{array}{c}6.89 \\
(1.01)\end{array}$ & $\begin{array}{c}0.55 \\
(0.25)\end{array}$ & $\begin{array}{c}4.45 \\
(1.75)\end{array}$ \\
\hline 2 & $\begin{array}{c}9.80 \\
(1.85)\end{array}$ & $\begin{array}{l}10.20 \\
(1.65)\end{array}$ & $\begin{array}{c}8.85 \\
(3.58)\end{array}$ & $\begin{array}{c}2.75 \\
(1.47)\end{array}$ & $\begin{array}{c}1.15 \\
(1.62)\end{array}$ & $\begin{array}{l}14.32 \\
(4.53)\end{array}$ & $\begin{array}{c}6.79 \\
(1.67)\end{array}$ & $\begin{array}{c}0.28 \\
(0.57)\end{array}$ & $\begin{array}{c}4.89 \\
(1.75)\end{array}$ \\
\hline 3 & $\begin{array}{c}9.34 \\
(1.00)\end{array}$ & $\begin{array}{l}10.24 \\
(1.36)\end{array}$ & $\begin{array}{c}6.16 \\
(3.51)\end{array}$ & $\begin{array}{c}1.48 \\
(1.43)\end{array}$ & $\begin{array}{c}0.48 \\
(0.80)\end{array}$ & $\begin{array}{l}15.60 \\
(3.54)\end{array}$ & $\begin{array}{c}6.93 \\
(1.68)\end{array}$ & $\begin{array}{c}0.12 \\
(0.17)\end{array}$ & $\begin{array}{c}5.78 \\
(2.05)\end{array}$ \\
\hline 4 & $\begin{array}{c}9.23 \\
(1.34)\end{array}$ & $\begin{array}{c}8.92 \\
(1.83)\end{array}$ & $\begin{array}{c}2.67 \\
(2.43)\end{array}$ & $\begin{array}{c}0.50 \\
(0.45)\end{array}$ & $\begin{array}{c}0.11 \\
(0.18)\end{array}$ & $\begin{array}{l}14.23 \\
(2.31)\end{array}$ & $\begin{array}{c}5.77 \\
(1.49)\end{array}$ & $\begin{array}{c}0.30 \\
(0.46)\end{array}$ & $\begin{array}{c}5.50 \\
(1.47)\end{array}$ \\
\hline 5 & $\begin{array}{c}8.96 \\
(1.10)\end{array}$ & $\begin{array}{c}9.88 \\
(2.01)\end{array}$ & $\begin{array}{c}2.78 \\
(1.70)\end{array}$ & $\begin{array}{c}0.66 \\
(0.46)\end{array}$ & $\begin{array}{c}0.13 \\
(0.16)\end{array}$ & $\begin{array}{l}15.75 \\
(4.75)\end{array}$ & $\begin{array}{c}6.71 \\
(2.15)\end{array}$ & $\begin{array}{c}0.15 \\
(0.28)\end{array}$ & $\begin{array}{c}5.07 \\
(2.36)\end{array}$ \\
\hline 6 & $\begin{array}{c}9.62 \\
(1.46) \\
\end{array}$ & $\begin{array}{r}7.95 \\
(2.35) \\
\end{array}$ & $\begin{array}{r}1.59 \\
(1.09) \\
\end{array}$ & $\begin{array}{r}0.34 \\
(0.30) \\
\end{array}$ & $\begin{array}{c}0.07 \\
(0.09) \\
\end{array}$ & $\begin{array}{l}12.22 \\
(4.48) \\
\end{array}$ & $\begin{array}{r}4.97 \\
(1.19) \\
\end{array}$ & $\begin{array}{c}0.23 \\
(0.31) \\
\end{array}$ & $\begin{array}{r}4.29 \\
(1.40) \\
\end{array}$ \\
\hline \multicolumn{10}{|c|}{ Rat A6 } \\
\hline 1 & $\begin{array}{c}7.31 \\
(2.27)\end{array}$ & $\begin{array}{c}9.94 \\
(1.36)\end{array}$ & $\begin{array}{c}3.95 \\
(1.47)\end{array}$ & $\begin{array}{c}1.94 \\
(0.84)\end{array}$ & -- & $\begin{array}{c}3.01 \\
(0.85)\end{array}$ & $\begin{array}{c}8.01 \\
(1.98)\end{array}$ & $\begin{array}{c}1.88 \\
(1.19)\end{array}$ & $\begin{array}{l}10.29 \\
(2.87)\end{array}$ \\
\hline 2 & $\begin{array}{c}6.64 \\
(2.45)\end{array}$ & $\begin{array}{c}8.31 \\
(1.29)\end{array}$ & $\begin{array}{c}1.79 \\
(0.86)\end{array}$ & $\begin{array}{c}0.35 \\
(0.31)\end{array}$ & -- & $\begin{array}{c}3.25 \\
(1.04)\end{array}$ & $\begin{array}{c}7.40 \\
(2.25)\end{array}$ & $\begin{array}{c}1.50 \\
(1.28)\end{array}$ & $\begin{array}{l}10.41 \\
(1.84)\end{array}$ \\
\hline 3 & $\begin{array}{c}5.26 \\
(1.56)\end{array}$ & $\begin{array}{c}5.53 \\
(1.69)\end{array}$ & $\begin{array}{c}0.86 \\
(0.54)\end{array}$ & $\begin{array}{c}0.26 \\
(0.21)\end{array}$ & -- & $\begin{array}{c}2.96 \\
(0.79)\end{array}$ & $\begin{array}{c}7.51 \\
(2.35)\end{array}$ & $\begin{array}{c}0.91 \\
(0.65)\end{array}$ & $\begin{array}{l}9.22 \\
(2.09)\end{array}$ \\
\hline 4 & $\begin{array}{c}6.46 \\
(1.50)\end{array}$ & $\begin{array}{c}5.18 \\
(2.25)\end{array}$ & $\begin{array}{c}0.53 \\
(0.37)\end{array}$ & $\begin{array}{c}0.28 \\
(0.19)\end{array}$ & -- & $\begin{array}{c}2.72 \\
(1.11)\end{array}$ & $\begin{array}{c}6.61 \\
(2.03)\end{array}$ & $\begin{array}{c}0.73 \\
(0.52)\end{array}$ & $\begin{array}{c}7.30 \\
(2.34)\end{array}$ \\
\hline 5 & $\begin{array}{c}6.18 \\
(2.28)\end{array}$ & $\begin{array}{c}4.47 \\
(2.49)\end{array}$ & $\begin{array}{c}0.58 \\
(0.33)\end{array}$ & $\begin{array}{c}0.43 \\
(0.28)\end{array}$ & -- & $\begin{array}{c}2.48 \\
(0.59)\end{array}$ & $\begin{array}{c}6.42 \\
(2.25)\end{array}$ & $\begin{array}{c}0.89 \\
(0.58)\end{array}$ & $\begin{array}{c}8.72 \\
(2.19)\end{array}$ \\
\hline 6 & $\begin{array}{c}5.62 \\
(1.52)\end{array}$ & $\begin{array}{c}4.03 \\
(2.38)\end{array}$ & $\begin{array}{c}0.90 \\
(0.39)\end{array}$ & $\begin{array}{c}0.40 \\
(0.27)\end{array}$ & -- & $\begin{array}{c}1.99 \\
(0.70)\end{array}$ & $\begin{array}{c}6.44 \\
(1.67)\end{array}$ & $\begin{array}{c}0.82 \\
(0.59)\end{array}$ & $\begin{array}{c}8.69 \\
(2.49) \\
\end{array}$ \\
\hline
\end{tabular}

Continued on next page 
Table C1 Continued

\begin{tabular}{|c|c|c|c|c|c|c|c|c|c|}
\hline \multicolumn{10}{|c|}{ Rat A7 } \\
\hline \multicolumn{10}{|c|}{ Food Deliveries per Min } \\
\hline $10-\min$ & 2 & 1 & 0.5 & 0.25 & 0.125 & 2 & High & Low & High \\
\hline Blocks & \multicolumn{6}{|c|}{ Limited Hold (Sucrose) } & \multicolumn{3}{|c|}{ Unlimited Hold (Pellets) } \\
\hline 1 & $\begin{array}{l}34.08 \\
(4.14)\end{array}$ & $\begin{array}{l}19.17 \\
(2.62)\end{array}$ & $\begin{array}{c}8.82 \\
(2.80)\end{array}$ & $\begin{array}{c}4.97 \\
(3.88)\end{array}$ & $\begin{array}{c}3.14 \\
(2.46)\end{array}$ & $\begin{array}{l}23.65 \\
(6.50)\end{array}$ & $\begin{array}{l}26.94 \\
(4.88)\end{array}$ & $\begin{array}{c}0.55 \\
(0.33)\end{array}$ & $\begin{array}{l}34.72 \\
(4.49)\end{array}$ \\
\hline 2 & $\begin{array}{l}27.93 \\
(3.43)\end{array}$ & $\begin{array}{l}14.79 \\
(4.51)\end{array}$ & $\begin{array}{c}3.98 \\
(2.00)\end{array}$ & $\begin{array}{c}0.91 \\
(0.70)\end{array}$ & $\begin{array}{c}1.48 \\
(2.43)\end{array}$ & $\begin{array}{l}12.92 \\
(3.93)\end{array}$ & $\begin{array}{l}21.43 \\
(3.59)\end{array}$ & $\begin{array}{c}0.08 \\
(0.15)\end{array}$ & $\begin{array}{l}27.82 \\
(3.68)\end{array}$ \\
\hline 3 & $\begin{array}{l}24.65 \\
(2.89)\end{array}$ & $\begin{array}{l}13.97 \\
(2.76)\end{array}$ & $\begin{array}{c}2.58 \\
(1.30)\end{array}$ & $\begin{array}{c}0.39 \\
(0.71)\end{array}$ & $\begin{array}{c}0.22 \\
(0.41)\end{array}$ & $\begin{array}{c}8.84 \\
(1.46)\end{array}$ & $\begin{array}{l}20.19 \\
(4.75)\end{array}$ & $\begin{array}{c}0.02 \\
(0.04)\end{array}$ & $\begin{array}{l}25.84 \\
(5.43)\end{array}$ \\
\hline 4 & $\begin{array}{l}24.23 \\
(3.82)\end{array}$ & $\begin{array}{l}14.04 \\
(1.78)\end{array}$ & $\begin{array}{c}2.68 \\
(2.16)\end{array}$ & $\begin{array}{c}0.05 \\
(0.05)\end{array}$ & $\begin{array}{c}0.45 \\
(0.54)\end{array}$ & $\begin{array}{c}6.65 \\
(2.33)\end{array}$ & $\begin{array}{l}18.11 \\
(2.43)\end{array}$ & $\begin{array}{c}0.05 \\
(0.07)\end{array}$ & $\begin{array}{l}23.91 \\
(3.24)\end{array}$ \\
\hline 5 & $\begin{array}{l}22.40 \\
(3.50)\end{array}$ & $\begin{array}{l}13.72 \\
(3.79)\end{array}$ & $\begin{array}{c}2.05 \\
(1.24)\end{array}$ & $\begin{array}{c}0.19 \\
(0.27)\end{array}$ & $\begin{array}{c}0.44 \\
(0.66)\end{array}$ & $\begin{array}{c}7.27 \\
(2.67)\end{array}$ & $\begin{array}{l}19.69 \\
(4.58)\end{array}$ & $\begin{array}{c}0.07 \\
(0.16)\end{array}$ & $\begin{array}{l}23.66 \\
(3.95)\end{array}$ \\
\hline 6 & $\begin{array}{l}20.90 \\
(4.06) \\
\end{array}$ & $\begin{array}{r}11.83 \\
(3.88) \\
\end{array}$ & $\begin{array}{c}1.40 \\
(0.82) \\
\end{array}$ & $\begin{array}{c}0.15 \\
(0.25) \\
\end{array}$ & $\begin{array}{c}0.12 \\
(0.18) \\
\end{array}$ & $\begin{array}{c}5.07 \\
(3.06) \\
\end{array}$ & $\begin{array}{l}22.12 \\
(6.93) \\
\end{array}$ & $\begin{array}{c}0.17 \\
(0.17) \\
\end{array}$ & $\begin{array}{l}24.30 \\
(5.05) \\
\end{array}$ \\
\hline \multicolumn{10}{|c|}{ Rat A8 } \\
\hline 1 & $\begin{array}{c}1.52 \\
(1.50)\end{array}$ & $\begin{array}{c}5.20 \\
(2.00)\end{array}$ & $\begin{array}{c}1.85 \\
(0.97)\end{array}$ & $\begin{array}{c}0.94 \\
(0.49)\end{array}$ & -- & -- & -- & -- & -- \\
\hline 2 & $\begin{array}{c}1.93 \\
(1.18)\end{array}$ & $\begin{array}{c}3.09 \\
(1.12)\end{array}$ & $\begin{array}{c}0.86 \\
(0.51)\end{array}$ & $\begin{array}{c}0.26 \\
(0.52)\end{array}$ & -- & -- & -- & -- & -- \\
\hline 3 & $\begin{array}{c}2.78 \\
(1.37)\end{array}$ & $\begin{array}{c}3.52 \\
(1.49)\end{array}$ & $\begin{array}{c}0.45 \\
(0.34)\end{array}$ & $\begin{array}{c}0.15 \\
(0.19)\end{array}$ & -- & -- & -- & -- & -- \\
\hline 4 & $\begin{array}{c}3.53 \\
(2.67)\end{array}$ & $\begin{array}{c}2.93 \\
(1.30)\end{array}$ & $\begin{array}{c}0.70 \\
(0.88)\end{array}$ & $\begin{array}{c}0.19 \\
(0.31)\end{array}$ & -- & -- & -- & -- & -- \\
\hline 5 & $\begin{array}{c}3.06 \\
(1.43)\end{array}$ & $\begin{array}{c}3.40 \\
(1.13)\end{array}$ & $\begin{array}{c}1.14 \\
(0.78)\end{array}$ & $\begin{array}{c}0.17 \\
(0.22)\end{array}$ & -- & -- & -- & -- & -- \\
\hline 6 & $\begin{array}{c}2.13 \\
(2.10)\end{array}$ & $\begin{array}{c}2.49 \\
(0.83)\end{array}$ & $\begin{array}{c}1.48 \\
(1.59)\end{array}$ & $\begin{array}{c}0.33 \\
(0.24)\end{array}$ & -- & -- & -- & -- & -- \\
\hline
\end{tabular}

Continued on next page 
Table C1 Continued

\begin{tabular}{|c|c|c|c|c|c|c|c|c|c|}
\hline \multicolumn{10}{|c|}{ Rat A9 } \\
\hline \multicolumn{10}{|c|}{ Food Deliveries per Min } \\
\hline $10-\min$ & 2 & 1 & 0.5 & 0.25 & 0.125 & 2 & High & Low & High \\
\hline Blocks & \multicolumn{6}{|c|}{ Limited Hold (Sucrose) } & \multicolumn{3}{|c|}{ Unlimited Hold (Pellets) } \\
\hline 1 & $\begin{array}{c}3.88 \\
(1.54)\end{array}$ & $\begin{array}{c}4.36 \\
(1.84)\end{array}$ & $\begin{array}{c}5.80 \\
(1.60)\end{array}$ & $\begin{array}{c}3.68 \\
(1.59)\end{array}$ & $\begin{array}{c}1.44 \\
(1.14)\end{array}$ & $\begin{array}{c}5.83 \\
(1.50)\end{array}$ & $\begin{array}{c}4.57 \\
(1.30)\end{array}$ & $\begin{array}{c}1.71 \\
(1.02)\end{array}$ & $\begin{array}{c}3.19 \\
(1.27)\end{array}$ \\
\hline 2 & $\begin{array}{c}4.49 \\
(1.48)\end{array}$ & $\begin{array}{c}2.99 \\
(1.21)\end{array}$ & $\begin{array}{c}4.93 \\
(1.44)\end{array}$ & $\begin{array}{c}2.69 \\
(1.72)\end{array}$ & $\begin{array}{c}0.43 \\
(0.44)\end{array}$ & $\begin{array}{c}5.05 \\
(1.71)\end{array}$ & $\begin{array}{c}3.33 \\
(1.48)\end{array}$ & $\begin{array}{c}0.53 \\
(0.63)\end{array}$ & $\begin{array}{c}3.02 \\
(1.27)\end{array}$ \\
\hline 3 & $\begin{array}{c}5.19 \\
(1.74)\end{array}$ & $\begin{array}{c}3.18 \\
(0.92)\end{array}$ & $\begin{array}{c}4.95 \\
(1.35)\end{array}$ & $\begin{array}{c}1.37 \\
(1.54)\end{array}$ & $\begin{array}{c}0.21 \\
(0.36)\end{array}$ & $\begin{array}{c}5.84 \\
(1.67)\end{array}$ & $\begin{array}{c}3.29 \\
(1.43)\end{array}$ & $\begin{array}{c}0.17 \\
(0.29)\end{array}$ & $\begin{array}{c}2.70 \\
(1.21)\end{array}$ \\
\hline 4 & $\begin{array}{c}4.96 \\
(1.05)\end{array}$ & $\begin{array}{c}3.07 \\
(1.05)\end{array}$ & $\begin{array}{c}4.55 \\
(1.22)\end{array}$ & $\begin{array}{c}1.56 \\
(1.16)\end{array}$ & $\begin{array}{c}0.09 \\
(0.13)\end{array}$ & $\begin{array}{c}5.71 \\
(1.15)\end{array}$ & $\begin{array}{c}2.81 \\
(1.45)\end{array}$ & $\begin{array}{c}0.11 \\
(0.19)\end{array}$ & $\begin{array}{c}2.34 \\
(1.32)\end{array}$ \\
\hline 5 & $\begin{array}{c}4.82 \\
(1.38)\end{array}$ & $\begin{array}{c}2.67 \\
(1.09)\end{array}$ & $\begin{array}{c}4.62 \\
(1.86)\end{array}$ & $\begin{array}{c}0.91 \\
(0.66)\end{array}$ & $\begin{array}{c}0.17 \\
(0.37)\end{array}$ & $\begin{array}{c}5.30 \\
(1.48)\end{array}$ & $\begin{array}{c}2.65 \\
(1.20)\end{array}$ & $\begin{array}{c}0.08 \\
(0.09)\end{array}$ & $\begin{array}{c}2.41 \\
(1.64)\end{array}$ \\
\hline 6 & $\begin{array}{c}4.46 \\
(1.68) \\
\end{array}$ & $\begin{array}{c}2.62 \\
(0.76) \\
\end{array}$ & $\begin{array}{c}4.60 \\
(1.63) \\
\end{array}$ & $\begin{array}{c}1.07 \\
(0.93) \\
\end{array}$ & $\begin{array}{c}0.22 \\
(0.33) \\
\end{array}$ & $\begin{array}{c}4.91 \\
(0.69) \\
\end{array}$ & $\begin{array}{c}2.24 \\
(0.90) \\
\end{array}$ & $\begin{array}{c}0.05 \\
(0.13) \\
\end{array}$ & $\begin{array}{c}2.21 \\
(1.41) \\
\end{array}$ \\
\hline \multicolumn{10}{|c|}{ Rat A10 } \\
\hline 1 & $\begin{array}{c}8.51 \\
(2.83)\end{array}$ & $\begin{array}{c}3.54 \\
(0.90)\end{array}$ & $\begin{array}{c}1.85 \\
(0.81)\end{array}$ & $\begin{array}{c}1.84 \\
(0.70)\end{array}$ & $\begin{array}{c}0.68 \\
(0.33)\end{array}$ & $\begin{array}{c}2.92 \\
(0.64)\end{array}$ & $\begin{array}{c}5.35 \\
(1.17)\end{array}$ & $\begin{array}{c}0.47 \\
(0.40)\end{array}$ & $\begin{array}{c}4.73 \\
(0.59)\end{array}$ \\
\hline 2 & $\begin{array}{c}6.51 \\
(2.16)\end{array}$ & $\begin{array}{c}1.34 \\
(0.70)\end{array}$ & $\begin{array}{c}0.37 \\
(0.49)\end{array}$ & $\begin{array}{c}0.72 \\
(0.57)\end{array}$ & $\begin{array}{c}0.46 \\
(0.23)\end{array}$ & $\begin{array}{c}2.40 \\
(0.97)\end{array}$ & $\begin{array}{c}5.29 \\
(1.33)\end{array}$ & $\begin{array}{c}0.11 \\
(0.14)\end{array}$ & $\begin{array}{c}4.73 \\
(0.82)\end{array}$ \\
\hline 3 & $\begin{array}{c}5.81 \\
(1.74)\end{array}$ & $\begin{array}{c}1.58 \\
(1.14)\end{array}$ & $\begin{array}{c}0.40 \\
(0.27)\end{array}$ & $\begin{array}{c}1.12 \\
(0.64)\end{array}$ & $\begin{array}{c}0.53 \\
(0.41)\end{array}$ & $\begin{array}{c}2.82 \\
(1.34)\end{array}$ & $\begin{array}{c}4.72 \\
(1.27)\end{array}$ & $\begin{array}{c}0.04 \\
(0.08)\end{array}$ & $\begin{array}{c}4.53 \\
(1.18)\end{array}$ \\
\hline 4 & $\begin{array}{c}6.02 \\
(2.04)\end{array}$ & $\begin{array}{c}1.47 \\
(0.95)\end{array}$ & $\begin{array}{c}0.38 \\
(0.25)\end{array}$ & $\begin{array}{c}1.18 \\
(0.65)\end{array}$ & $\begin{array}{c}0.40 \\
(0.27)\end{array}$ & $\begin{array}{c}2.29 \\
(0.78)\end{array}$ & $\begin{array}{c}4.47 \\
(1.00)\end{array}$ & $\begin{array}{c}0.08 \\
(0.11)\end{array}$ & $\begin{array}{c}3.83 \\
(0.74)\end{array}$ \\
\hline 5 & $\begin{array}{c}6.31 \\
(2.76)\end{array}$ & $\begin{array}{c}1.54 \\
(0.94)\end{array}$ & $\begin{array}{c}0.56 \\
(0.61)\end{array}$ & $\begin{array}{c}0.94 \\
(0.47)\end{array}$ & $\begin{array}{c}0.36 \\
(0.26)\end{array}$ & $\begin{array}{c}2.56 \\
(1.16)\end{array}$ & $\begin{array}{c}4.89 \\
(1.53)\end{array}$ & $\begin{array}{c}0.10 \\
(0.09)\end{array}$ & $\begin{array}{c}4.36 \\
(1.35)\end{array}$ \\
\hline 6 & $\begin{array}{c}6.53 \\
(3.04) \\
\end{array}$ & $\begin{array}{c}1.01 \\
(0.92) \\
\end{array}$ & $\begin{array}{c}0.26 \\
(0.19) \\
\end{array}$ & $\begin{array}{c}1.30 \\
(1.01)\end{array}$ & $\begin{array}{c}0.37 \\
(0.25) \\
\end{array}$ & $\begin{array}{c}2.41 \\
(1.16) \\
\end{array}$ & $\begin{array}{c}4.67 \\
(1.36) \\
\end{array}$ & $\begin{array}{c}0.14 \\
(0.15) \\
\end{array}$ & $\begin{array}{c}4.80 \\
(0.86) \\
\end{array}$ \\
\hline
\end{tabular}




\section{Appendix D}

Table D1

Within-Session Responding: Percentage of Timeouts Avoided (Experiment 1)

Experiment 1. Percentages of timeouts avoided as a function of 10-min blocks of time-in across the last 10 sessions. Standard deviations are shown in parentheses.

\begin{tabular}{|c|c|c|c|c|c|c|c|c|c|}
\hline \multicolumn{10}{|c|}{ Rat A1 } \\
\hline \multicolumn{10}{|c|}{ Food Deliveries per Min } \\
\hline 10-min & 2 & 1 & 0.5 & 0.25 & 0.125 & 2 & High & Low & High \\
\hline Blocks & \multicolumn{6}{|c|}{ Unlimited Hold (Pellets) } & \multicolumn{3}{|c|}{ Limited Hold (Sucrose) } \\
\hline 1 & $\begin{array}{l}99 \\
(3)\end{array}$ & $\begin{array}{c}70 \\
(11)\end{array}$ & $\begin{array}{c}35 \\
(15)\end{array}$ & $\begin{array}{c}26 \\
(15)\end{array}$ & $\begin{array}{c}23 \\
(14)\end{array}$ & $\begin{array}{l}93 \\
(6)\end{array}$ & $\begin{array}{l}91 \\
(5)\end{array}$ & $\begin{array}{c}19 \\
(18)\end{array}$ & $\begin{array}{c}80 \\
(10)\end{array}$ \\
\hline 2 & $\begin{array}{l}97 \\
(4)\end{array}$ & $\begin{array}{c}50 \\
(24)\end{array}$ & $\begin{array}{l}10 \\
(7)\end{array}$ & $\begin{array}{c}7 \\
(8)\end{array}$ & $\begin{array}{c}2 \\
(2)\end{array}$ & $\begin{array}{l}94 \\
(5)\end{array}$ & $\begin{array}{l}89 \\
(7)\end{array}$ & $\begin{array}{c}2 \\
(2)\end{array}$ & $\begin{array}{c}70 \\
(13)\end{array}$ \\
\hline 3 & $\begin{array}{l}93 \\
(8)\end{array}$ & $\begin{array}{c}25 \\
(16)\end{array}$ & $\begin{array}{l}11 \\
(7)\end{array}$ & $\begin{array}{c}6 \\
(7)\end{array}$ & $\begin{array}{c}4 \\
(5)\end{array}$ & $\begin{array}{l}88 \\
(9)\end{array}$ & $\begin{array}{l}86 \\
(8)\end{array}$ & $\begin{array}{c}1 \\
(2)\end{array}$ & $\begin{array}{c}66 \\
(10)\end{array}$ \\
\hline 4 & $\begin{array}{l}93 \\
(5)\end{array}$ & $\begin{array}{c}24 \\
(22)\end{array}$ & $\begin{array}{c}11 \\
(19)\end{array}$ & $\begin{array}{c}5 \\
(3)\end{array}$ & $\begin{array}{c}2 \\
(3)\end{array}$ & $\begin{array}{c}84 \\
(11)\end{array}$ & $\begin{array}{l}77 \\
(9)\end{array}$ & $\begin{array}{c}0 \\
(0)\end{array}$ & $\begin{array}{c}61 \\
(10)\end{array}$ \\
\hline 5 & $\begin{array}{l}95 \\
(4)\end{array}$ & $\begin{array}{l}14 \\
(8)\end{array}$ & $\begin{array}{c}2 \\
(3)\end{array}$ & $\begin{array}{c}3 \\
(3)\end{array}$ & $\begin{array}{c}1 \\
(2)\end{array}$ & $\begin{array}{c}83 \\
(11)\end{array}$ & $\begin{array}{c}78 \\
(12)\end{array}$ & $\begin{array}{c}1 \\
(2)\end{array}$ & $\begin{array}{c}48 \\
(25)\end{array}$ \\
\hline 6 & $\begin{array}{l}94 \\
(3) \\
\end{array}$ & $\begin{array}{c}16 \\
(19) \\
\end{array}$ & $\begin{array}{c}7 \\
(11) \\
\end{array}$ & $\begin{array}{r}3 \\
(3) \\
\end{array}$ & $\begin{array}{c}2 \\
(2) \\
\end{array}$ & $\begin{array}{l}88 \\
(8) \\
\end{array}$ & $\begin{array}{l}79 \\
(9) \\
\end{array}$ & $\begin{array}{c}3 \\
(4) \\
\end{array}$ & $\begin{array}{c}17 \\
(20) \\
\end{array}$ \\
\hline \multicolumn{10}{|c|}{ Rat A3 } \\
\hline 1 & $\begin{array}{l}100 \\
(0)\end{array}$ & $\begin{array}{l}96 \\
(4)\end{array}$ & $\begin{array}{l}66 \\
(8)\end{array}$ & $\begin{array}{c}21 \\
(11)\end{array}$ & $\begin{array}{l}14 \\
(6)\end{array}$ & $\begin{array}{l}98 \\
(3)\end{array}$ & $\begin{array}{l}94 \\
(5)\end{array}$ & $\begin{array}{l}12 \\
(8)\end{array}$ & $\begin{array}{l}79 \\
(8)\end{array}$ \\
\hline 2 & $\begin{array}{l}100 \\
(0)\end{array}$ & $\begin{array}{l}94 \\
(4)\end{array}$ & $\begin{array}{c}53 \\
(12)\end{array}$ & $\begin{array}{c}8 \\
(14)\end{array}$ & $\begin{array}{c}2 \\
(2)\end{array}$ & $\begin{array}{l}94 \\
(3)\end{array}$ & $\begin{array}{l}86 \\
(5)\end{array}$ & $\begin{array}{c}6 \\
(4)\end{array}$ & $\begin{array}{c}80 \\
(13)\end{array}$ \\
\hline 3 & $\begin{array}{l}100 \\
(2)\end{array}$ & $\begin{array}{l}95 \\
(5)\end{array}$ & $\begin{array}{c}39 \\
(10)\end{array}$ & $\begin{array}{c}3 \\
(6)\end{array}$ & $\begin{array}{c}7 \\
(9)\end{array}$ & $\begin{array}{l}94 \\
(4)\end{array}$ & $\begin{array}{l}87 \\
(8)\end{array}$ & $\begin{array}{c}2 \\
(2)\end{array}$ & $\begin{array}{c}73 \\
(15)\end{array}$ \\
\hline 4 & $\begin{array}{l}100 \\
(0)\end{array}$ & $\begin{array}{l}94 \\
(4)\end{array}$ & $\begin{array}{c}27 \\
(14)\end{array}$ & $\begin{array}{c}0 \\
(0)\end{array}$ & $\begin{array}{c}2 \\
(3)\end{array}$ & $\begin{array}{l}93 \\
(6)\end{array}$ & $\begin{array}{c}81 \\
(10)\end{array}$ & $\begin{array}{c}1 \\
(2)\end{array}$ & $\begin{array}{c}67 \\
(13)\end{array}$ \\
\hline 5 & $\begin{array}{l}100 \\
(2)\end{array}$ & $\begin{array}{l}95 \\
(3)\end{array}$ & $\begin{array}{c}14 \\
(15)\end{array}$ & $\begin{array}{c}1 \\
(2)\end{array}$ & $\begin{array}{c}2 \\
(3)\end{array}$ & $\begin{array}{l}93 \\
(4)\end{array}$ & $\begin{array}{c}75 \\
(13)\end{array}$ & $\begin{array}{c}2 \\
(2)\end{array}$ & $\begin{array}{c}62 \\
(15)\end{array}$ \\
\hline 6 & $\begin{array}{l}98 \\
(3) \\
\end{array}$ & $\begin{array}{l}95 \\
(5) \\
\end{array}$ & $\begin{array}{c}8 \\
(11) \\
\end{array}$ & $\begin{array}{c}2 \\
(2) \\
\end{array}$ & $\begin{array}{c}1 \\
(2)\end{array}$ & $\begin{array}{l}90 \\
(4) \\
\end{array}$ & $\begin{array}{c}75 \\
(13) \\
\end{array}$ & $\begin{array}{c}1 \\
(2) \\
\end{array}$ & $\begin{array}{c}67 \\
(15) \\
\end{array}$ \\
\hline
\end{tabular}

Continued on next page 
Table D1 Continued

\begin{tabular}{|c|c|c|c|c|c|c|c|c|c|}
\hline \multicolumn{10}{|c|}{ Rat A5 } \\
\hline \multicolumn{10}{|c|}{ Food Deliveries per Min } \\
\hline 10-min & 2 & 1 & 0.5 & 0.25 & 0.125 & 2 & High & Low & High \\
\hline Blocks & \multicolumn{6}{|c|}{ Unlimited Hold (Pellets) } & \multicolumn{3}{|c|}{ Limited Hold (Sucrose) } \\
\hline 1 & $\begin{array}{l}96 \\
(5)\end{array}$ & $\begin{array}{l}92 \\
(5)\end{array}$ & $\begin{array}{l}67 \\
(9)\end{array}$ & $\begin{array}{c}44 \\
(13)\end{array}$ & $\begin{array}{c}27 \\
(14)\end{array}$ & $\begin{array}{l}31 \\
(7)\end{array}$ & $\begin{array}{c}45 \\
(10)\end{array}$ & $\begin{array}{c}7 \\
(3)\end{array}$ & $\begin{array}{c}50 \\
(19)\end{array}$ \\
\hline 2 & $\begin{array}{l}93 \\
(7)\end{array}$ & $\begin{array}{c}79 \\
(11)\end{array}$ & $\begin{array}{c}51 \\
(18)\end{array}$ & $\begin{array}{c}15 \\
(11)\end{array}$ & $\begin{array}{c}7 \\
(8)\end{array}$ & $\begin{array}{l}32 \\
(9)\end{array}$ & $\begin{array}{c}44 \\
(12)\end{array}$ & $\begin{array}{c}4 \\
(5)\end{array}$ & $\begin{array}{c}45 \\
(16)\end{array}$ \\
\hline 3 & $\begin{array}{l}92 \\
(5)\end{array}$ & $\begin{array}{l}75 \\
(7)\end{array}$ & $\begin{array}{c}44 \\
(20)\end{array}$ & $\begin{array}{l}12 \\
(8)\end{array}$ & $\begin{array}{c}4 \\
(6)\end{array}$ & $\begin{array}{c}36 \\
(12)\end{array}$ & $\begin{array}{c}43 \\
(12)\end{array}$ & $\begin{array}{c}2 \\
(2)\end{array}$ & $\begin{array}{c}49 \\
(21)\end{array}$ \\
\hline 4 & $\begin{array}{l}91 \\
(9)\end{array}$ & $\begin{array}{c}67 \\
(15)\end{array}$ & $\begin{array}{c}26 \\
(22)\end{array}$ & $\begin{array}{c}7 \\
(5)\end{array}$ & $\begin{array}{c}1 \\
(2)\end{array}$ & $\begin{array}{l}34 \\
(6)\end{array}$ & $\begin{array}{c}44 \\
(11)\end{array}$ & $\begin{array}{c}3 \\
(4)\end{array}$ & $\begin{array}{c}43 \\
(17)\end{array}$ \\
\hline 5 & $\begin{array}{l}94 \\
(5)\end{array}$ & $\begin{array}{c}68 \\
(15)\end{array}$ & $\begin{array}{c}26 \\
(13)\end{array}$ & $\begin{array}{c}8 \\
(8)\end{array}$ & $\begin{array}{c}3 \\
(4)\end{array}$ & $\begin{array}{l}41 \\
(9)\end{array}$ & $\begin{array}{c}51 \\
(12)\end{array}$ & $\begin{array}{c}3 \\
(5)\end{array}$ & $\begin{array}{c}46 \\
(27)\end{array}$ \\
\hline 6 & $\begin{array}{l}92 \\
(7)\end{array}$ & $\begin{array}{c}57 \\
(13) \\
\end{array}$ & $\begin{array}{c}22 \\
(12) \\
\end{array}$ & $\begin{array}{c}7 \\
(8) \\
\end{array}$ & $\begin{array}{c}2 \\
(2) \\
\end{array}$ & $\begin{array}{c}36 \\
(11) \\
\end{array}$ & $\begin{array}{c}43 \\
(10) \\
\end{array}$ & $\begin{array}{c}3 \\
(3) \\
\end{array}$ & $\begin{array}{r}40 \\
(13) \\
\end{array}$ \\
\hline \multicolumn{10}{|c|}{ Rat A6 } \\
\hline 1 & $\begin{array}{l}83 \\
(9)\end{array}$ & $\begin{array}{l}88 \\
(7)\end{array}$ & $\begin{array}{c}44 \\
(16)\end{array}$ & $\begin{array}{c}28 \\
(13)\end{array}$ & -- & $\begin{array}{l}83 \\
(9)\end{array}$ & $\begin{array}{l}48 \\
(7)\end{array}$ & $\begin{array}{l}81 \\
(6)\end{array}$ & $\begin{array}{c}68 \\
(12)\end{array}$ \\
\hline 2 & $\begin{array}{c}84 \\
(13)\end{array}$ & $\begin{array}{c}79 \\
(11)\end{array}$ & $\begin{array}{l}22 \\
(7)\end{array}$ & $\begin{array}{c}6 \\
(6)\end{array}$ & -- & $\begin{array}{c}84 \\
(13)\end{array}$ & $\begin{array}{c}53 \\
(15)\end{array}$ & $\begin{array}{l}80 \\
(7)\end{array}$ & $\begin{array}{l}63 \\
(9)\end{array}$ \\
\hline 3 & $\begin{array}{c}75 \\
(13)\end{array}$ & $\begin{array}{c}73 \\
(15)\end{array}$ & $\begin{array}{l}11 \\
(8)\end{array}$ & $\begin{array}{c}6 \\
(4)\end{array}$ & -- & $\begin{array}{c}75 \\
(13)\end{array}$ & $\begin{array}{c}51 \\
(14)\end{array}$ & $\begin{array}{c}79 \\
(14)\end{array}$ & $\begin{array}{c}60 \\
(12)\end{array}$ \\
\hline 4 & $\begin{array}{c}79 \\
(12)\end{array}$ & $\begin{array}{c}65 \\
(16)\end{array}$ & $\begin{array}{c}8 \\
(7)\end{array}$ & $\begin{array}{c}6 \\
(3)\end{array}$ & -- & $\begin{array}{c}79 \\
(12)\end{array}$ & $\begin{array}{c}47 \\
(18)\end{array}$ & $\begin{array}{c}77 \\
(11)\end{array}$ & $\begin{array}{c}51 \\
(13)\end{array}$ \\
\hline 5 & $\begin{array}{c}83 \\
(11)\end{array}$ & $\begin{array}{c}56 \\
(19)\end{array}$ & $\begin{array}{l}11 \\
(9)\end{array}$ & $\begin{array}{l}10 \\
(7)\end{array}$ & -- & $\begin{array}{c}83 \\
(11)\end{array}$ & $\begin{array}{c}46 \\
(12)\end{array}$ & $\begin{array}{c}72 \\
(13)\end{array}$ & $\begin{array}{c}56 \\
(10)\end{array}$ \\
\hline 6 & $\begin{array}{l}76 \\
(9)\end{array}$ & $\begin{array}{c}53 \\
(16) \\
\end{array}$ & $\begin{array}{l}18 \\
(6)\end{array}$ & $\begin{array}{l}10 \\
(5)\end{array}$ & -- & $\begin{array}{r}76 \\
(9)\end{array}$ & $\begin{array}{c}45 \\
(15)\end{array}$ & $\begin{array}{l}80 \\
(8)\end{array}$ & $\begin{array}{c}54 \\
(10)\end{array}$ \\
\hline
\end{tabular}

Continued on next page 
Table D1 Continued

\begin{tabular}{|c|c|c|c|c|c|c|c|c|c|}
\hline \multicolumn{10}{|c|}{ Rat A7 } \\
\hline \multicolumn{10}{|c|}{ Food Deliveries per Min } \\
\hline $10-\min$ & 2 & 1 & 0.5 & 0.25 & 0.125 & 2 & High & Low & High \\
\hline Blocks & \multicolumn{6}{|c|}{ Limited Hold (Sucrose) } & \multicolumn{3}{|c|}{ Unlimited Hold (Pellets) } \\
\hline 1 & $\begin{array}{c}100 \\
(0)\end{array}$ & $\begin{array}{l}93 \\
(5)\end{array}$ & $\begin{array}{c}78 \\
(12)\end{array}$ & $\begin{array}{c}39 \\
(23)\end{array}$ & $\begin{array}{c}25 \\
(11)\end{array}$ & $\begin{array}{l}91 \\
(8)\end{array}$ & $\begin{array}{l}99 \\
(2)\end{array}$ & $\begin{array}{l}11 \\
(6)\end{array}$ & $\begin{array}{l}99 \\
(2)\end{array}$ \\
\hline 2 & $\begin{array}{c}100 \\
(0)\end{array}$ & $\begin{array}{c}87 \\
(12)\end{array}$ & $\begin{array}{c}44 \\
(20)\end{array}$ & $\begin{array}{l}10 \\
(7)\end{array}$ & $\begin{array}{c}13 \\
(21)\end{array}$ & $\begin{array}{c}75 \\
(10)\end{array}$ & $\begin{array}{l}94 \\
(6)\end{array}$ & $\begin{array}{c}1 \\
(2)\end{array}$ & $\begin{array}{l}94 \\
(3)\end{array}$ \\
\hline 3 & $\begin{array}{l}99 \\
(2)\end{array}$ & $\begin{array}{l}84 \\
(9)\end{array}$ & $\begin{array}{c}27 \\
(14)\end{array}$ & $\begin{array}{c}5 \\
(8)\end{array}$ & $\begin{array}{c}3 \\
(5)\end{array}$ & $\begin{array}{c}58 \\
(10)\end{array}$ & $\begin{array}{l}94 \\
(5)\end{array}$ & $\begin{array}{c}1 \\
(2)\end{array}$ & $\begin{array}{l}92 \\
(5)\end{array}$ \\
\hline 4 & $\begin{array}{l}98 \\
(3)\end{array}$ & $\begin{array}{l}82 \\
(8)\end{array}$ & $\begin{array}{c}26 \\
(15)\end{array}$ & $\begin{array}{c}2 \\
(2)\end{array}$ & $\begin{array}{c}6 \\
(5)\end{array}$ & $\begin{array}{c}50 \\
(16)\end{array}$ & $\begin{array}{l}94 \\
(3)\end{array}$ & $\begin{array}{c}1 \\
(2)\end{array}$ & $\begin{array}{l}91 \\
(4)\end{array}$ \\
\hline 5 & $\begin{array}{l}98 \\
(4)\end{array}$ & $\begin{array}{l}82 \\
(8)\end{array}$ & $\begin{array}{c}25 \\
(16)\end{array}$ & $\begin{array}{c}3 \\
(4)\end{array}$ & $\begin{array}{c}4 \\
(5)\end{array}$ & $\begin{array}{c}52 \\
(14)\end{array}$ & $\begin{array}{l}93 \\
(4)\end{array}$ & $\begin{array}{c}1 \\
(2)\end{array}$ & $\begin{array}{l}91 \\
(4)\end{array}$ \\
\hline 6 & $\begin{array}{l}97 \\
(5) \\
\end{array}$ & $\begin{array}{r}78 \\
(9) \\
\end{array}$ & $\begin{array}{c}19 \\
(12) \\
\end{array}$ & $\begin{array}{c}2 \\
(3) \\
\end{array}$ & $\begin{array}{c}3 \\
(4) \\
\end{array}$ & $\begin{array}{c}42 \\
(19) \\
\end{array}$ & $\begin{array}{l}92 \\
(5) \\
\end{array}$ & $\begin{array}{c}2 \\
(3) \\
\end{array}$ & $\begin{array}{l}91 \\
(5) \\
\end{array}$ \\
\hline \multicolumn{10}{|c|}{ Rat A8 } \\
\hline 1 & $\begin{array}{l}10 \\
(8)\end{array}$ & $\begin{array}{l}46 \\
(7)\end{array}$ & $\begin{array}{c}25 \\
(13)\end{array}$ & $\begin{array}{l}14 \\
(4)\end{array}$ & -- & -- & -- & -- & -- \\
\hline 2 & $\begin{array}{c}9 \\
(7)\end{array}$ & $\begin{array}{c}38 \\
(14)\end{array}$ & $\begin{array}{l}11 \\
(8)\end{array}$ & $\begin{array}{c}4 \\
(5)\end{array}$ & -- & -- & -- & -- & -- \\
\hline 3 & $\begin{array}{l}16 \\
(6)\end{array}$ & $\begin{array}{l}40 \\
(8)\end{array}$ & $\begin{array}{c}7 \\
(5)\end{array}$ & $\begin{array}{c}2 \\
(3)\end{array}$ & -- & -- & -- & -- & -- \\
\hline 4 & $\begin{array}{c}20 \\
(13)\end{array}$ & $\begin{array}{c}37 \\
(15)\end{array}$ & $\begin{array}{l}10 \\
(9)\end{array}$ & $\begin{array}{c}3 \\
(4)\end{array}$ & -- & -- & -- & -- & -- \\
\hline 5 & $\begin{array}{c}22 \\
(11)\end{array}$ & $\begin{array}{c}43 \\
(11)\end{array}$ & $\begin{array}{l}14 \\
(8)\end{array}$ & $\begin{array}{c}4 \\
(5)\end{array}$ & -- & -- & -- & -- & -- \\
\hline 6 & $\begin{array}{l}14 \\
(7)\end{array}$ & $\begin{array}{c}37 \\
(10) \\
\end{array}$ & $\begin{array}{c}15 \\
(17) \\
\end{array}$ & $\begin{array}{c}5 \\
(4) \\
\end{array}$ & -- & -- & -- & -- & -- \\
\hline
\end{tabular}


Table D1 Continued

\begin{tabular}{|c|c|c|c|c|c|c|c|c|c|}
\hline \multicolumn{10}{|c|}{ Rat A9 } \\
\hline \multicolumn{10}{|c|}{ Food Deliveries per Min } \\
\hline $10-\min$ & 2 & 1 & 0.5 & 0.25 & 0.125 & 2 & High & Low & High \\
\hline Blocks & \multicolumn{6}{|c|}{ Limited Hold (Sucrose) } & \multicolumn{3}{|c|}{ Unlimited Hold (Pellets) } \\
\hline 1 & $\begin{array}{c}62 \\
(18)\end{array}$ & $\begin{array}{c}58 \\
(12)\end{array}$ & $\begin{array}{l}72 \\
(9)\end{array}$ & $\begin{array}{c}41 \\
(13)\end{array}$ & $\begin{array}{c}16 \\
(10)\end{array}$ & $\begin{array}{c}79 \\
(12)\end{array}$ & $\begin{array}{c}61 \\
(11)\end{array}$ & $\begin{array}{c}25 \\
(13)\end{array}$ & $\begin{array}{c}42 \\
(15)\end{array}$ \\
\hline 2 & $\begin{array}{c}65 \\
(14)\end{array}$ & $\begin{array}{c}51 \\
(14)\end{array}$ & $\begin{array}{c}62 \\
(11)\end{array}$ & $\begin{array}{c}29 \\
(14)\end{array}$ & $\begin{array}{c}6 \\
(5)\end{array}$ & $\begin{array}{c}70 \\
(12)\end{array}$ & $\begin{array}{c}54 \\
(17)\end{array}$ & $\begin{array}{c}8 \\
(10)\end{array}$ & $\begin{array}{c}46 \\
(12)\end{array}$ \\
\hline 3 & $\begin{array}{c}67 \\
(16)\end{array}$ & $\begin{array}{c}58 \\
(14)\end{array}$ & $\begin{array}{c}62 \\
(10)\end{array}$ & $\begin{array}{c}14 \\
(12)\end{array}$ & $\begin{array}{c}3 \\
(3)\end{array}$ & $\begin{array}{l}78 \\
(7)\end{array}$ & $\begin{array}{c}60 \\
(12)\end{array}$ & $\begin{array}{c}2 \\
(5)\end{array}$ & $\begin{array}{c}36 \\
(14)\end{array}$ \\
\hline 4 & $\begin{array}{c}68 \\
(11)\end{array}$ & $\begin{array}{c}56 \\
(15)\end{array}$ & $\begin{array}{c}57 \\
(12)\end{array}$ & $\begin{array}{l}20 \\
(8)\end{array}$ & $\begin{array}{c}3 \\
(5)\end{array}$ & $\begin{array}{c}71 \\
(12)\end{array}$ & $\begin{array}{c}49 \\
(15)\end{array}$ & $\begin{array}{c}3 \\
(4)\end{array}$ & $\begin{array}{c}33 \\
(18)\end{array}$ \\
\hline 5 & $\begin{array}{c}67 \\
(14)\end{array}$ & $\begin{array}{c}50 \\
(14)\end{array}$ & $\begin{array}{c}57 \\
(16)\end{array}$ & $\begin{array}{l}13 \\
(9)\end{array}$ & $\begin{array}{c}3 \\
(6)\end{array}$ & $\begin{array}{l}69 \\
(9)\end{array}$ & $\begin{array}{c}54 \\
(17)\end{array}$ & $\begin{array}{c}2 \\
(3)\end{array}$ & $\begin{array}{c}33 \\
(16)\end{array}$ \\
\hline 6 & $\begin{array}{c}61 \\
(13)\end{array}$ & $\begin{array}{c}54 \\
(11)\end{array}$ & $\begin{array}{c}57 \\
(13)\end{array}$ & $\begin{array}{c}15 \\
(10)\end{array}$ & $\begin{array}{c}3 \\
(4)\end{array}$ & $\begin{array}{l}70 \\
(9)\end{array}$ & $\begin{array}{c}41 \\
(12)\end{array}$ & $\begin{array}{c}1 \\
(2)\end{array}$ & $\begin{array}{c}33 \\
(15)\end{array}$ \\
\hline \multicolumn{10}{|c|}{ Rat A10 } \\
\hline 1 & $\begin{array}{c}83 \\
(22)\end{array}$ & $\begin{array}{c}51 \\
(15)\end{array}$ & $\begin{array}{l}25 \\
(8)\end{array}$ & $\begin{array}{c}28 \\
(10)\end{array}$ & $\begin{array}{l}12 \\
(5)\end{array}$ & $\begin{array}{c}55 \\
(13)\end{array}$ & $\begin{array}{c}76 \\
(10)\end{array}$ & $\begin{array}{l}13 \\
(7)\end{array}$ & $\begin{array}{c}75 \\
(10)\end{array}$ \\
\hline 2 & $\begin{array}{c}79 \\
(17)\end{array}$ & $\begin{array}{c}30 \\
(15)\end{array}$ & $\begin{array}{c}8 \\
(9)\end{array}$ & $\begin{array}{l}12 \\
(8)\end{array}$ & $\begin{array}{c}7 \\
(3)\end{array}$ & $\begin{array}{c}49 \\
(16)\end{array}$ & $\begin{array}{l}81 \\
(9)\end{array}$ & $\begin{array}{c}2 \\
(3)\end{array}$ & $\begin{array}{l}78 \\
(9)\end{array}$ \\
\hline 3 & $\begin{array}{c}69 \\
(16)\end{array}$ & $\begin{array}{c}33 \\
(20)\end{array}$ & $\begin{array}{c}7 \\
(5)\end{array}$ & $\begin{array}{c}18 \\
(12)\end{array}$ & $\begin{array}{c}8 \\
(5)\end{array}$ & $\begin{array}{c}51 \\
(15)\end{array}$ & $\begin{array}{c}76 \\
(14)\end{array}$ & $\begin{array}{c}1 \\
(2)\end{array}$ & $\begin{array}{l}74 \\
(9)\end{array}$ \\
\hline 4 & $\begin{array}{c}72 \\
(23)\end{array}$ & $\begin{array}{c}29 \\
(20)\end{array}$ & $\begin{array}{c}9 \\
(7)\end{array}$ & $\begin{array}{c}19 \\
(11)\end{array}$ & $\begin{array}{c}8 \\
(7)\end{array}$ & $\begin{array}{c}41 \\
(12)\end{array}$ & $\begin{array}{c}72 \\
(11)\end{array}$ & $\begin{array}{c}3 \\
(4)\end{array}$ & $\begin{array}{c}71 \\
(10)\end{array}$ \\
\hline 5 & $\begin{array}{c}73 \\
(27)\end{array}$ & $\begin{array}{c}33 \\
(20)\end{array}$ & $\begin{array}{c}10 \\
(10)\end{array}$ & $\begin{array}{l}18 \\
(8)\end{array}$ & $\begin{array}{c}7 \\
(6)\end{array}$ & $\begin{array}{c}51 \\
(15)\end{array}$ & $\begin{array}{c}72 \\
(13)\end{array}$ & $\begin{array}{c}3 \\
(4)\end{array}$ & $\begin{array}{c}74 \\
(20)\end{array}$ \\
\hline 6 & $\begin{array}{c}75 \\
(25) \\
\end{array}$ & $\begin{array}{c}25 \\
(18) \\
\end{array}$ & $\begin{array}{c}5 \\
(4) \\
\end{array}$ & $\begin{array}{c}19 \\
(13) \\
\end{array}$ & $\begin{array}{c}8 \\
(4) \\
\end{array}$ & $\begin{array}{c}46 \\
(19) \\
\end{array}$ & $\begin{array}{c}71 \\
(17) \\
\end{array}$ & $\begin{array}{c}4 \\
(4) \\
\end{array}$ & $\begin{array}{c}79 \\
(11) \\
\end{array}$ \\
\hline
\end{tabular}




\section{Appendix E}

Table E1

Within-Session Responding: Avoidance Response Rates (Experiment 2)

Experiment 2. Rates of avoidance responding (responses per min) as a function of 10-min blocks of time-in across the last 10 sessions. Standard deviations are shown in parentheses.

\begin{tabular}{|c|c|c|c|c|c|c|c|c|c|}
\hline \multicolumn{10}{|c|}{ Rat A15 } \\
\hline \multicolumn{10}{|c|}{ Food Deliveries per Min } \\
\hline \multirow{2}{*}{$\begin{array}{l}\text { 10-min } \\
\text { Blocks }\end{array}$} & 2 & 1 & 0.5 & 0.25 & 0.125 & 2 & High & Low & High \\
\hline & \multicolumn{6}{|c|}{ Unlimited Hold (Sucrose) } & \multicolumn{3}{|c|}{ Limited Hold (Sucrose) } \\
\hline 1 & $\begin{array}{l}13.63 \\
(3.00)\end{array}$ & $\begin{array}{c}7.55 \\
(2.23)\end{array}$ & $\begin{array}{c}2.57 \\
(1.27)\end{array}$ & $\begin{array}{c}1.35 \\
(0.83)\end{array}$ & -- & $\begin{array}{c}3.45 \\
(1.03)\end{array}$ & $\begin{array}{c}2.91 \\
(0.89)\end{array}$ & $\begin{array}{c}0.81 \\
(0.49)\end{array}$ & $\begin{array}{c}3.07 \\
(1.26)\end{array}$ \\
\hline 2 & $\begin{array}{l}12.44 \\
(2.72)\end{array}$ & $\begin{array}{c}6.29 \\
(2.36)\end{array}$ & $\begin{array}{c}1.83 \\
(1.45)\end{array}$ & $\begin{array}{c}0.30 \\
(0.36)\end{array}$ & -- & $\begin{array}{c}3.64 \\
(1.40)\end{array}$ & $\begin{array}{c}2.85 \\
(1.14)\end{array}$ & $\begin{array}{c}0.35 \\
(0.46)\end{array}$ & $\begin{array}{c}2.83 \\
(0.64)\end{array}$ \\
\hline 3 & $\begin{array}{l}10.24 \\
(2.99)\end{array}$ & $\begin{array}{c}6.14 \\
(2.06)\end{array}$ & $\begin{array}{c}1.09 \\
(1.90)\end{array}$ & $\begin{array}{c}0.33 \\
(0.45)\end{array}$ & -- & $\begin{array}{c}3.28 \\
(1.33)\end{array}$ & $\begin{array}{c}2.41 \\
(0.66)\end{array}$ & $\begin{array}{c}0.48 \\
(0.68)\end{array}$ & $\begin{array}{c}2.15 \\
(0.67)\end{array}$ \\
\hline 4 & $\begin{array}{c}8.94 \\
(1.60)\end{array}$ & $\begin{array}{c}5.97 \\
(4.10)\end{array}$ & $\begin{array}{c}0.82 \\
(0.94)\end{array}$ & $\begin{array}{c}0.39 \\
(0.33)\end{array}$ & -- & $\begin{array}{c}2.93 \\
(0.85)\end{array}$ & $\begin{array}{c}2.57 \\
(0.81)\end{array}$ & $\begin{array}{c}0.39 \\
(0.32)\end{array}$ & $\begin{array}{c}1.91 \\
(0.72)\end{array}$ \\
\hline 5 & $\begin{array}{c}9.24 \\
(1.95)\end{array}$ & $\begin{array}{c}4.15 \\
(2.52)\end{array}$ & $\begin{array}{c}0.66 \\
(0.60)\end{array}$ & $\begin{array}{c}0.38 \\
(0.29)\end{array}$ & -- & $\begin{array}{c}2.47 \\
(0.76)\end{array}$ & $\begin{array}{c}2.82 \\
(0.47)\end{array}$ & $\begin{array}{c}0.22 \\
(0.17)\end{array}$ & $\begin{array}{c}2.33 \\
(0.90)\end{array}$ \\
\hline 6 & $\begin{array}{c}9.44 \\
(3.18) \\
\end{array}$ & $\begin{array}{c}3.50 \\
(1.71) \\
\end{array}$ & $\begin{array}{c}0.46 \\
(0.22) \\
\end{array}$ & $\begin{array}{c}0.39 \\
(0.33) \\
\end{array}$ & -- & $\begin{array}{c}2.87 \\
(1.20) \\
\end{array}$ & $\begin{array}{c}2.73 \\
(1.29) \\
\end{array}$ & $\begin{array}{c}0.19 \\
(0.27) \\
\end{array}$ & $\begin{array}{r}2.10 \\
(0.52) \\
\end{array}$ \\
\hline \multicolumn{10}{|c|}{ Rat A16 } \\
\hline 1 & $\begin{array}{c}3.45 \\
(2.61)\end{array}$ & $\begin{array}{l}10.52 \\
(2.59)\end{array}$ & $\begin{array}{c}4.46 \\
(1.37)\end{array}$ & $\begin{array}{c}1.29 \\
(1.09)\end{array}$ & -- & $\begin{array}{c}8.14 \\
(6.06)\end{array}$ & $\begin{array}{c}5.97 \\
(2.69)\end{array}$ & $\begin{array}{c}3.40 \\
(1.28)\end{array}$ & $\begin{array}{c}1.40 \\
(0.70)\end{array}$ \\
\hline 2 & $\begin{array}{c}2.97 \\
(1.53)\end{array}$ & $\begin{array}{l}11.82 \\
(2.37)\end{array}$ & $\begin{array}{c}3.50 \\
(1.01)\end{array}$ & $\begin{array}{c}0.75 \\
(1.23)\end{array}$ & -- & $\begin{array}{c}0.81 \\
(1.39)\end{array}$ & $\begin{array}{c}2.46 \\
(1.87)\end{array}$ & $\begin{array}{c}1.75 \\
(1.91)\end{array}$ & $\begin{array}{c}0.64 \\
(0.39)\end{array}$ \\
\hline 3 & $\begin{array}{c}2.86 \\
(1.35)\end{array}$ & $\begin{array}{l}12.00 \\
(3.42)\end{array}$ & $\begin{array}{c}3.08 \\
(1.32)\end{array}$ & $\begin{array}{c}0.56 \\
(0.63)\end{array}$ & -- & $\begin{array}{c}0.36 \\
(0.70)\end{array}$ & $\begin{array}{c}1.45 \\
(1.43)\end{array}$ & $\begin{array}{c}1.27 \\
(1.45)\end{array}$ & $\begin{array}{c}1.35 \\
(0.78)\end{array}$ \\
\hline 4 & $\begin{array}{c}2.65 \\
(1.28)\end{array}$ & $\begin{array}{l}11.48 \\
(2.65)\end{array}$ & $\begin{array}{c}2.37 \\
(1.23)\end{array}$ & $\begin{array}{c}0.37 \\
(0.29)\end{array}$ & -- & $\begin{array}{c}0.73 \\
(2.17)\end{array}$ & $\begin{array}{c}2.97 \\
(2.93)\end{array}$ & $\begin{array}{c}0.74 \\
(0.79)\end{array}$ & $\begin{array}{c}0.55 \\
(0.43)\end{array}$ \\
\hline 5 & $\begin{array}{c}3.41 \\
(1.75)\end{array}$ & $\begin{array}{l}11.70 \\
(2.54)\end{array}$ & $\begin{array}{c}2.37 \\
(1.36)\end{array}$ & $\begin{array}{c}0.14 \\
(0.16)\end{array}$ & -- & $\begin{array}{c}0.98 \\
(2.19)\end{array}$ & $\begin{array}{c}3.16 \\
(1.76)\end{array}$ & $\begin{array}{c}0.99 \\
(1.10)\end{array}$ & $\begin{array}{c}1.60 \\
(0.94)\end{array}$ \\
\hline 6 & $\begin{array}{c}2.45 \\
(0.71)\end{array}$ & $\begin{array}{r}12.09 \\
(3.45) \\
\end{array}$ & $\begin{array}{c}2.13 \\
(1.35)\end{array}$ & $\begin{array}{c}0.12 \\
(0.28)\end{array}$ & -- & $\begin{array}{c}2.10 \\
(2.64)\end{array}$ & $\begin{array}{c}3.84 \\
(1.60)\end{array}$ & $\begin{array}{c}0.48 \\
(0.36)\end{array}$ & $\begin{array}{c}1.06 \\
(0.49)\end{array}$ \\
\hline
\end{tabular}

Continued on next page 


\section{Table E1 Continued}

\section{Rat A17}

Food Deliveries per Min

\begin{tabular}{|c|c|c|c|c|c|c|c|c|c|}
\hline \multirow{2}{*}{$\begin{array}{l}\text { 10-min } \\
\text { Blocks }\end{array}$} & 2 & 1 & 0.5 & 0.25 & 0.125 & 2 & High & Low & High \\
\hline & \multicolumn{6}{|c|}{ Unlimited Hold (Sucrose) } & \multicolumn{3}{|c|}{ Limited Hold (Sucrose) } \\
\hline 1 & $\begin{array}{l}19.63 \\
(4.38)\end{array}$ & $\begin{array}{c}7.23 \\
(2.07)\end{array}$ & $\begin{array}{c}3.53 \\
(2.61)\end{array}$ & $\begin{array}{c}4.43 \\
(3.02)\end{array}$ & $\begin{array}{c}1.22 \\
(1.44)\end{array}$ & $\begin{array}{l}27.31 \\
(5.00)\end{array}$ & $\begin{array}{l}29.25 \\
(8.16)\end{array}$ & $\begin{array}{c}5.39 \\
(5.61)\end{array}$ & $\begin{array}{c}7.06 \\
(6.26)\end{array}$ \\
\hline 2 & $\begin{array}{l}21.53 \\
(6.89)\end{array}$ & $\begin{array}{c}6.57 \\
(1.54)\end{array}$ & $\begin{array}{c}1.66 \\
(1.38)\end{array}$ & $\begin{array}{c}0.44 \\
(0.63)\end{array}$ & $\begin{array}{c}0.09 \\
(0.12)\end{array}$ & $\begin{array}{l}21.97 \\
(5.83)\end{array}$ & $\begin{array}{l}20.24 \\
(9.83)\end{array}$ & $\begin{array}{c}1.47 \\
(3.06)\end{array}$ & $\begin{array}{c}3.90 \\
(3.86)\end{array}$ \\
\hline 3 & $\begin{array}{l}20.05 \\
(3.57)\end{array}$ & $\begin{array}{c}4.96 \\
(1.87)\end{array}$ & $\begin{array}{c}0.54 \\
(0.57)\end{array}$ & $\begin{array}{c}0.07 \\
(0.08)\end{array}$ & $\begin{array}{c}0.02 \\
(0.04)\end{array}$ & $\begin{array}{l}20.25 \\
(4.45)\end{array}$ & $\begin{array}{c}17.72 \\
(9.10)\end{array}$ & $\begin{array}{c}0.19 \\
(0.38)\end{array}$ & $\begin{array}{c}2.11 \\
(1.92)\end{array}$ \\
\hline 4 & $\begin{array}{l}20.99 \\
(3.71)\end{array}$ & $\begin{array}{c}2.96 \\
(2.22)\end{array}$ & $\begin{array}{c}0.55 \\
(0.77)\end{array}$ & $\begin{array}{c}0.13 \\
(0.25)\end{array}$ & $\begin{array}{c}0.03 \\
(0.07)\end{array}$ & $\begin{array}{l}18.39 \\
(1.71)\end{array}$ & $\begin{array}{c}17.48 \\
(11.46)\end{array}$ & $\begin{array}{c}0.30 \\
(0.95)\end{array}$ & $\begin{array}{c}1.30 \\
(1.86)\end{array}$ \\
\hline 5 & $\begin{array}{l}19.45 \\
(6.38)\end{array}$ & $\begin{array}{c}2.58 \\
(2.30)\end{array}$ & $\begin{array}{c}0.24 \\
(0.20)\end{array}$ & $\begin{array}{c}0.08 \\
(0.10)\end{array}$ & $\begin{array}{c}0.02 \\
(0.04)\end{array}$ & $\begin{array}{l}17.87 \\
(4.01)\end{array}$ & $\begin{array}{c}18.31 \\
(10.61)\end{array}$ & $\begin{array}{c}0.06 \\
(0.16)\end{array}$ & $\begin{array}{c}1.39 \\
(2.86)\end{array}$ \\
\hline 6 & $\begin{array}{l}18.74 \\
(3.86)\end{array}$ & $\begin{array}{c}1.52 \\
(2.08) \\
\end{array}$ & $\begin{array}{c}0.10 \\
(0.17) \\
\end{array}$ & $\begin{array}{c}0.02 \\
(0.06) \\
\end{array}$ & $\begin{array}{c}0.02 \\
(0.04) \\
\end{array}$ & $\begin{array}{r}18.44 \\
(4.30) \\
\end{array}$ & $\begin{array}{l}19.78 \\
(9.15)\end{array}$ & $\begin{array}{c}0.17 \\
(0.38) \\
\end{array}$ & $\begin{array}{c}1.31 \\
(2.61) \\
\end{array}$ \\
\hline \multicolumn{10}{|c|}{ Rat A18 } \\
\hline 1 & $\begin{array}{l}34.31 \\
(3.37)\end{array}$ & $\begin{array}{l}19.29 \\
(1.81)\end{array}$ & $\begin{array}{c}7.91 \\
(2.16)\end{array}$ & $\begin{array}{c}4.82 \\
(1.58)\end{array}$ & $\begin{array}{c}1.13 \\
(1.28)\end{array}$ & $\begin{array}{l}10.58 \\
(3.22)\end{array}$ & $\begin{array}{l}18.40 \\
(4.35)\end{array}$ & $\begin{array}{c}3.42 \\
(2.86)\end{array}$ & $\begin{array}{l}25.03 \\
(2.45)\end{array}$ \\
\hline 2 & $\begin{array}{l}30.42 \\
(3.19)\end{array}$ & $\begin{array}{l}15.04 \\
(2.40)\end{array}$ & $\begin{array}{c}5.12 \\
(2.39)\end{array}$ & $\begin{array}{c}1.27 \\
(0.95)\end{array}$ & $\begin{array}{c}0.11 \\
(0.17)\end{array}$ & $\begin{array}{c}7.62 \\
(2.52)\end{array}$ & $\begin{array}{l}21.39 \\
(4.00)\end{array}$ & $\begin{array}{c}0.44 \\
(0.71)\end{array}$ & $\begin{array}{l}21.21 \\
(3.75)\end{array}$ \\
\hline 3 & $\begin{array}{l}27.04 \\
(2.68)\end{array}$ & $\begin{array}{l}11.84 \\
(2.34)\end{array}$ & $\begin{array}{c}3.59 \\
(2.16)\end{array}$ & $\begin{array}{c}0.29 \\
(0.25)\end{array}$ & $\begin{array}{c}0.13 \\
(0.15)\end{array}$ & $\begin{array}{c}6.80 \\
(2.22)\end{array}$ & $\begin{array}{l}17.96 \\
(4.21)\end{array}$ & $\begin{array}{c}0.22 \\
(0.21)\end{array}$ & $\begin{array}{l}18.63 \\
(4.25)\end{array}$ \\
\hline 4 & $\begin{array}{l}25.42 \\
(4.36)\end{array}$ & $\begin{array}{l}10.37 \\
(2.38)\end{array}$ & $\begin{array}{c}2.90 \\
(1.19)\end{array}$ & $\begin{array}{c}0.42 \\
(0.34)\end{array}$ & $\begin{array}{c}0.13 \\
(0.22)\end{array}$ & $\begin{array}{c}6.14 \\
(2.19)\end{array}$ & $\begin{array}{l}16.86 \\
(4.57)\end{array}$ & $\begin{array}{c}0.33 \\
(0.38)\end{array}$ & $\begin{array}{l}15.43 \\
(3.73)\end{array}$ \\
\hline 5 & $\begin{array}{l}24.39 \\
(4.92)\end{array}$ & $\begin{array}{l}11.12 \\
(2.68)\end{array}$ & $\begin{array}{c}2.55 \\
(1.34)\end{array}$ & $\begin{array}{c}0.43 \\
(0.28)\end{array}$ & $\begin{array}{c}0.19 \\
(0.19)\end{array}$ & $\begin{array}{c}8.87 \\
(2.87)\end{array}$ & $\begin{array}{l}16.99 \\
(6.23)\end{array}$ & $\begin{array}{c}0.42 \\
(0.58)\end{array}$ & $\begin{array}{l}16.32 \\
(4.41)\end{array}$ \\
\hline 6 & $\begin{array}{l}24.03 \\
(5.33)\end{array}$ & $\begin{array}{l}10.11 \\
(2.85)\end{array}$ & $\begin{array}{c}2.50 \\
(1.27)\end{array}$ & $\begin{array}{c}0.42 \\
(0.31)\end{array}$ & $\begin{array}{c}0.37 \\
(0.36)\end{array}$ & $\begin{array}{c}8.10 \\
(5.84)\end{array}$ & $\begin{array}{l}13.12 \\
(4.72)\end{array}$ & $\begin{array}{c}0.41 \\
(0.52)\end{array}$ & $\begin{array}{l}12.29 \\
(2.84)\end{array}$ \\
\hline
\end{tabular}


Table E1 Continued

Rat A11

\begin{tabular}{|c|c|c|c|c|c|c|c|c|c|}
\hline \multicolumn{10}{|c|}{ Food Deliveries per Min } \\
\hline \multirow{2}{*}{$\begin{array}{l}\text { 10-min } \\
\text { Blocks }\end{array}$} & 2 & 1 & 0.5 & 0.25 & 0.125 & 2 & High & Low & High \\
\hline & \multicolumn{6}{|c|}{ Limited Hold (Sucrose) } & \multicolumn{3}{|c|}{ Unlimited Hold (Sucrose) } \\
\hline 1 & $\begin{array}{l}27.86 \\
(4.20)\end{array}$ & $\begin{array}{c}5.06 \\
(2.30)\end{array}$ & $\begin{array}{l}5.08 \\
(2.65)\end{array}$ & $\begin{array}{c}2.31 \\
(1.27)\end{array}$ & $\begin{array}{c}1.56 \\
(1.06)\end{array}$ & $\begin{array}{c}7.26 \\
(1.83)\end{array}$ & $\begin{array}{l}11.34 \\
(2.56)\end{array}$ & $\begin{array}{c}1.78 \\
(0.74)\end{array}$ & $\begin{array}{l}16.08 \\
(2.07)\end{array}$ \\
\hline 2 & $\begin{array}{l}28.97 \\
(5.06)\end{array}$ & $\begin{array}{c}3.75 \\
(1.76)\end{array}$ & $\begin{array}{c}1.99 \\
(0.88)\end{array}$ & $\begin{array}{c}0.66 \\
(0.48)\end{array}$ & $\begin{array}{c}0.53 \\
(0.64)\end{array}$ & $\begin{array}{c}7.36 \\
(2.82)\end{array}$ & $\begin{array}{c}9.23 \\
(3.59)\end{array}$ & $\begin{array}{c}0.06 \\
(0.11)\end{array}$ & $\begin{array}{l}13.56 \\
(2.24)\end{array}$ \\
\hline 3 & $\begin{array}{l}26.23 \\
(3.95)\end{array}$ & $\begin{array}{c}3.40 \\
(2.15)\end{array}$ & $\begin{array}{c}1.51 \\
(0.96)\end{array}$ & $\begin{array}{c}0.44 \\
(0.33)\end{array}$ & $\begin{array}{c}0.19 \\
(0.30)\end{array}$ & $\begin{array}{c}5.91 \\
(2.76)\end{array}$ & $\begin{array}{c}6.86 \\
(2.62)\end{array}$ & $\begin{array}{c}0.06 \\
(0.11)\end{array}$ & $\begin{array}{c}9.58 \\
(4.02)\end{array}$ \\
\hline 4 & $\begin{array}{l}25.39 \\
(5.39)\end{array}$ & $\begin{array}{c}2.38 \\
(1.55)\end{array}$ & $\begin{array}{c}1.25 \\
(0.97)\end{array}$ & $\begin{array}{c}0.21 \\
(0.13)\end{array}$ & $\begin{array}{c}0.31 \\
(0.43)\end{array}$ & $\begin{array}{c}5.01 \\
(3.29)\end{array}$ & $\begin{array}{c}5.70 \\
(1.89)\end{array}$ & $\begin{array}{c}0.06 \\
(0.13)\end{array}$ & $\begin{array}{l}11.91 \\
(2.35)\end{array}$ \\
\hline 5 & $\begin{array}{l}23.50 \\
(6.60)\end{array}$ & $\begin{array}{c}1.76 \\
(1.07)\end{array}$ & $\begin{array}{c}1.64 \\
(1.36)\end{array}$ & $\begin{array}{c}0.22 \\
(0.19)\end{array}$ & $\begin{array}{c}0.15 \\
(0.20)\end{array}$ & $\begin{array}{c}5.33 \\
(3.39)\end{array}$ & $\begin{array}{c}5.86 \\
(2.57)\end{array}$ & $\begin{array}{c}0.00 \\
(0.00)\end{array}$ & $\begin{array}{l}10.41 \\
(3.69)\end{array}$ \\
\hline 6 & $\begin{array}{l}24.46 \\
(7.34) \\
\end{array}$ & $\begin{array}{c}1.86 \\
(1.18) \\
\end{array}$ & $\begin{array}{c}1.11 \\
(1.02) \\
\end{array}$ & $\begin{array}{c}0.15 \\
(0.18) \\
\end{array}$ & $\begin{array}{c}0.24 \\
(0.35) \\
\end{array}$ & $\begin{array}{c}5.68 \\
(2.98) \\
\end{array}$ & $\begin{array}{c}5.74 \\
(3.63) \\
\end{array}$ & $\begin{array}{c}0.03 \\
(0.09) \\
\end{array}$ & $\begin{array}{c}9.92 \\
(3.71) \\
\end{array}$ \\
\hline \multicolumn{10}{|c|}{ Rat A12 } \\
\hline 1 & $\begin{array}{c}9.15 \\
(4.59)\end{array}$ & $\begin{array}{c}2.49 \\
(2.64)\end{array}$ & $\begin{array}{c}0.95 \\
(0.61)\end{array}$ & $\begin{array}{c}1.26 \\
(0.94)\end{array}$ & -- & $\begin{array}{c}5.16 \\
(1.12)\end{array}$ & $\begin{array}{c}6.62 \\
(1.60)\end{array}$ & $\begin{array}{c}2.39 \\
(1.72)\end{array}$ & $\begin{array}{c}4.93 \\
(1.24)\end{array}$ \\
\hline 2 & $\begin{array}{c}5.47 \\
(2.54)\end{array}$ & $\begin{array}{c}0.50 \\
(0.52)\end{array}$ & $\begin{array}{c}0.27 \\
(0.29)\end{array}$ & $\begin{array}{c}0.36 \\
(0.45)\end{array}$ & -- & $\begin{array}{c}2.87 \\
(1.17)\end{array}$ & $\begin{array}{c}4.00 \\
(1.13)\end{array}$ & $\begin{array}{c}0.92 \\
(1.47)\end{array}$ & $\begin{array}{c}4.16 \\
(1.20)\end{array}$ \\
\hline 3 & $\begin{array}{c}5.17 \\
(1.77)\end{array}$ & $\begin{array}{c}0.15 \\
(0.24)\end{array}$ & $\begin{array}{c}0.22 \\
(0.25)\end{array}$ & $\begin{array}{c}0.29 \\
(0.32)\end{array}$ & -- & $\begin{array}{c}3.32 \\
(1.29)\end{array}$ & $\begin{array}{c}3.37 \\
(1.31)\end{array}$ & $\begin{array}{c}0.90 \\
(0.59)\end{array}$ & $\begin{array}{c}3.13 \\
(0.94)\end{array}$ \\
\hline 4 & $\begin{array}{c}5.22 \\
(1.94)\end{array}$ & $\begin{array}{c}0.18 \\
(0.32)\end{array}$ & $\begin{array}{c}0.27 \\
(0.22)\end{array}$ & $\begin{array}{c}0.16 \\
(0.21)\end{array}$ & -- & $\begin{array}{c}3.15 \\
(0.89)\end{array}$ & $\begin{array}{c}3.86 \\
(1.33)\end{array}$ & $\begin{array}{c}0.84 \\
(1.00)\end{array}$ & $\begin{array}{c}3.21 \\
(0.79)\end{array}$ \\
\hline 5 & $\begin{array}{c}5.37 \\
(1.58)\end{array}$ & $\begin{array}{c}0.28 \\
(0.34)\end{array}$ & $\begin{array}{c}0.21 \\
(0.22)\end{array}$ & $\begin{array}{c}0.12 \\
(0.15)\end{array}$ & -- & $\begin{array}{c}3.40 \\
(1.07)\end{array}$ & $\begin{array}{c}4.66 \\
(1.49)\end{array}$ & $\begin{array}{c}0.80 \\
(0.40)\end{array}$ & $\begin{array}{c}3.37 \\
(1.30)\end{array}$ \\
\hline 6 & $\begin{array}{c}4.02 \\
(1.57) \\
\end{array}$ & $\begin{array}{c}0.20 \\
(0.24)\end{array}$ & $\begin{array}{c}0.14 \\
(0.11)\end{array}$ & $\begin{array}{c}0.26 \\
(0.24) \\
\end{array}$ & -- & $\begin{array}{c}2.85 \\
(1.11)\end{array}$ & $\begin{array}{c}4.51 \\
(2.10)\end{array}$ & $\begin{array}{c}0.20 \\
(0.13)\end{array}$ & $\begin{array}{c}3.13 \\
(0.56) \\
\end{array}$ \\
\hline
\end{tabular}

Continued on next page 
Table E1 Continued

Rat A13

\begin{tabular}{|c|c|c|c|c|c|c|c|c|c|}
\hline \multicolumn{10}{|c|}{ Food Deliveries per Min } \\
\hline 10-min & 2 & 1 & 0.5 & 0.25 & 0.125 & 2 & High & Low & High \\
\hline Blocks & \multicolumn{6}{|c|}{ Limited Hold (Sucrose) } & \multicolumn{3}{|c|}{ Unlimited Hold (Sucrose) } \\
\hline 1 & $\begin{array}{c}8.45 \\
(1.08)\end{array}$ & $\begin{array}{c}5.82 \\
(1.62)\end{array}$ & $\begin{array}{c}3.08 \\
(1.23)\end{array}$ & $\begin{array}{c}1.86 \\
(0.95)\end{array}$ & $\begin{array}{c}0.87 \\
(0.75)\end{array}$ & $\begin{array}{c}4.88 \\
(1.05)\end{array}$ & $\begin{array}{c}8.80 \\
(1.43)\end{array}$ & $\begin{array}{c}1.61 \\
(1.13)\end{array}$ & $\begin{array}{c}6.19 \\
(1.69)\end{array}$ \\
\hline 2 & $\begin{array}{c}5.30 \\
(1.27)\end{array}$ & $\begin{array}{c}4.71 \\
(1.07)\end{array}$ & $\begin{array}{c}1.17 \\
(0.71)\end{array}$ & $\begin{array}{c}0.94 \\
(0.73)\end{array}$ & $\begin{array}{c}0.35 \\
(0.73)\end{array}$ & $\begin{array}{c}3.85 \\
(1.24)\end{array}$ & $\begin{array}{c}8.62 \\
(1.79)\end{array}$ & $\begin{array}{c}0.18 \\
(0.30)\end{array}$ & $\begin{array}{c}6.23 \\
(2.10)\end{array}$ \\
\hline 3 & $\begin{array}{c}5.45 \\
(1.12)\end{array}$ & $\begin{array}{c}4.58 \\
(1.17)\end{array}$ & $\begin{array}{c}0.82 \\
(0.53)\end{array}$ & $\begin{array}{c}0.52 \\
(0.50)\end{array}$ & $\begin{array}{c}0.09 \\
(0.16)\end{array}$ & $\begin{array}{c}3.95 \\
(0.68)\end{array}$ & $\begin{array}{c}7.68 \\
(2.39)\end{array}$ & $\begin{array}{c}0.19 \\
(0.28)\end{array}$ & $\begin{array}{c}5.09 \\
(2.12)\end{array}$ \\
\hline 4 & $\begin{array}{c}5.14 \\
(1.08)\end{array}$ & $\begin{array}{c}5.02 \\
(1.22)\end{array}$ & $\begin{array}{c}0.75 \\
(0.56)\end{array}$ & $\begin{array}{c}0.46 \\
(0.51)\end{array}$ & $\begin{array}{c}0.10 \\
(0.16)\end{array}$ & $\begin{array}{c}3.69 \\
(1.08)\end{array}$ & $\begin{array}{c}7.32 \\
(2.92)\end{array}$ & $\begin{array}{c}0.04 \\
(0.10)\end{array}$ & $\begin{array}{c}5.27 \\
(1.85)\end{array}$ \\
\hline 5 & $\begin{array}{c}5.69 \\
(1.82)\end{array}$ & $\begin{array}{c}4.51 \\
(1.06)\end{array}$ & $\begin{array}{c}0.71 \\
(0.55)\end{array}$ & $\begin{array}{c}0.28 \\
(0.34)\end{array}$ & $\begin{array}{c}0.48 \\
(0.72)\end{array}$ & $\begin{array}{c}3.69 \\
(1.55)\end{array}$ & $\begin{array}{c}7.03 \\
(2.59)\end{array}$ & $\begin{array}{c}0.09 \\
(0.25)\end{array}$ & $\begin{array}{c}5.69 \\
(1.27)\end{array}$ \\
\hline 6 & $\begin{array}{c}4.96 \\
(1.25)\end{array}$ & $\begin{array}{c}4.11 \\
(1.79) \\
\end{array}$ & $\begin{array}{c}0.39 \\
(0.35) \\
\end{array}$ & $\begin{array}{c}0.45 \\
(0.47) \\
\end{array}$ & $\begin{array}{c}0.21 \\
(0.32) \\
\end{array}$ & $\begin{array}{c}3.51 \\
(1.27) \\
\end{array}$ & $\begin{array}{c}6.28 \\
(2.18) \\
\end{array}$ & $\begin{array}{c}0.19 \\
(0.43)\end{array}$ & $\begin{array}{c}4.90 \\
(1.65)\end{array}$ \\
\hline \multicolumn{10}{|c|}{ Rat A14 } \\
\hline 1 & $\begin{array}{l}10.97 \\
(2.86)\end{array}$ & $\begin{array}{l}11.74 \\
(1.99)\end{array}$ & $\begin{array}{c}4.63 \\
(3.19)\end{array}$ & $\begin{array}{c}0.72 \\
(0.71)\end{array}$ & $\begin{array}{c}1.63 \\
(1.84)\end{array}$ & $\begin{array}{l}15.33 \\
(2.56)\end{array}$ & $\begin{array}{c}6.31 \\
(2.50)\end{array}$ & $\begin{array}{c}2.80 \\
(1.48)\end{array}$ & $\begin{array}{c}7.91 \\
(2.10)\end{array}$ \\
\hline 2 & $\begin{array}{c}7.86 \\
(2.09)\end{array}$ & $\begin{array}{c}9.72 \\
(2.48)\end{array}$ & $\begin{array}{c}1.91 \\
(1.54)\end{array}$ & $\begin{array}{c}0.28 \\
(0.41)\end{array}$ & $\begin{array}{c}0.19 \\
(0.25)\end{array}$ & $\begin{array}{l}11.00 \\
(2.72)\end{array}$ & $\begin{array}{c}4.15 \\
(1.56)\end{array}$ & $\begin{array}{c}0.34 \\
(0.47)\end{array}$ & $\begin{array}{c}7.24 \\
(1.70)\end{array}$ \\
\hline 3 & $\begin{array}{c}7.33 \\
(1.58)\end{array}$ & $\begin{array}{l}11.06 \\
(3.82)\end{array}$ & $\begin{array}{c}0.91 \\
(0.44)\end{array}$ & $\begin{array}{c}0.27 \\
(0.32)\end{array}$ & $\begin{array}{c}0.10 \\
(0.13)\end{array}$ & $\begin{array}{c}9.92 \\
(2.04)\end{array}$ & $\begin{array}{c}4.74 \\
(1.27)\end{array}$ & $\begin{array}{c}0.02 \\
(0.04)\end{array}$ & $\begin{array}{c}6.75 \\
(2.38)\end{array}$ \\
\hline 4 & $\begin{array}{c}6.46 \\
(1.91)\end{array}$ & $\begin{array}{l}10.34 \\
(3.91)\end{array}$ & $\begin{array}{c}0.73 \\
(0.51)\end{array}$ & $\begin{array}{c}0.10 \\
(0.16)\end{array}$ & $\begin{array}{c}0.10 \\
(0.22)\end{array}$ & $\begin{array}{l}12.61 \\
(3.68)\end{array}$ & $\begin{array}{c}5.87 \\
(2.18)\end{array}$ & $\begin{array}{c}0.39 \\
(0.39)\end{array}$ & $\begin{array}{c}7.24 \\
(1.72)\end{array}$ \\
\hline 5 & $\begin{array}{c}7.44 \\
(1.61)\end{array}$ & $\begin{array}{c}9.52 \\
(3.77)\end{array}$ & $\begin{array}{c}1.00 \\
(0.68)\end{array}$ & $\begin{array}{c}0.12 \\
(0.19)\end{array}$ & $\begin{array}{c}0.01 \\
(0.03)\end{array}$ & $\begin{array}{l}13.18 \\
(2.76)\end{array}$ & $\begin{array}{c}6.14 \\
(2.11)\end{array}$ & $\begin{array}{c}0.36 \\
(0.59)\end{array}$ & $\begin{array}{c}7.64 \\
(2.66)\end{array}$ \\
\hline 6 & $\begin{array}{c}8.53 \\
(2.74)\end{array}$ & $\begin{array}{r}10.66 \\
(4.56) \\
\end{array}$ & $\begin{array}{c}0.60 \\
(0.47) \\
\end{array}$ & $\begin{array}{c}0.25 \\
(0.33) \\
\end{array}$ & $\begin{array}{c}0.20 \\
(0.28)\end{array}$ & $\begin{array}{l}11.14 \\
(2.45)\end{array}$ & $\begin{array}{c}6.21 \\
(2.25)\end{array}$ & $\begin{array}{c}0.33 \\
(0.35)\end{array}$ & $\begin{array}{c}7.26 \\
(2.24)\end{array}$ \\
\hline
\end{tabular}




\section{Appendix F}

Table F1

Within-Session Responding: Percentage of Timeouts Avoided (Experiment 2)

Experiment 2. Percentages of timeouts avoided as a function of 10-min blocks of time-in across the last 10 sessions. Standard deviations are shown in parentheses.

\begin{tabular}{|c|c|c|c|c|c|c|c|c|c|}
\hline \multicolumn{10}{|c|}{ Rat A15 } \\
\hline \multicolumn{10}{|c|}{ Food Deliveries per Min } \\
\hline 10-min & 2 & 1 & 0.5 & 0.25 & 0.125 & 2 & High & Low & High \\
\hline Blocks & \multicolumn{6}{|c|}{ Unlimited Hold (Sucrose) } & \multicolumn{3}{|c|}{ Limited Hold (Sucrose) } \\
\hline 1 & $\begin{array}{c}74 \\
(13)\end{array}$ & $\begin{array}{c}64 \\
(11)\end{array}$ & $\begin{array}{c}31 \\
(11)\end{array}$ & $\begin{array}{l}16 \\
(6)\end{array}$ & -- & $\begin{array}{c}40 \\
(11)\end{array}$ & $\begin{array}{l}33 \\
(4)\end{array}$ & $\begin{array}{r}12 \\
(7)\end{array}$ & $\begin{array}{c}35 \\
(14)\end{array}$ \\
\hline 2 & $\begin{array}{c}72 \\
(15)\end{array}$ & $\begin{array}{c}59 \\
(15)\end{array}$ & $\begin{array}{c}22 \\
(10)\end{array}$ & $\begin{array}{c}3 \\
(4)\end{array}$ & -- & $\begin{array}{c}36 \\
(16)\end{array}$ & $\begin{array}{l}39 \\
(7)\end{array}$ & $\begin{array}{c}3 \\
(4)\end{array}$ & $\begin{array}{l}36 \\
(9)\end{array}$ \\
\hline 3 & $\begin{array}{c}63 \\
(19)\end{array}$ & $\begin{array}{c}57 \\
(13)\end{array}$ & $\begin{array}{c}11 \\
(13)\end{array}$ & $\begin{array}{c}3 \\
(5)\end{array}$ & -- & $\begin{array}{c}36 \\
(16)\end{array}$ & $\begin{array}{c}33 \\
(10)\end{array}$ & $\begin{array}{c}7 \\
(7)\end{array}$ & $\begin{array}{l}34 \\
(9)\end{array}$ \\
\hline 4 & $\begin{array}{c}61 \\
(10)\end{array}$ & $\begin{array}{c}51 \\
(21)\end{array}$ & $\begin{array}{c}11 \\
(10)\end{array}$ & $\begin{array}{c}5 \\
(4)\end{array}$ & -- & $\begin{array}{c}31 \\
(14)\end{array}$ & $\begin{array}{l}35 \\
(8)\end{array}$ & $\begin{array}{c}5 \\
(6)\end{array}$ & $\begin{array}{c}26 \\
(11)\end{array}$ \\
\hline 5 & $\begin{array}{l}59 \\
(8)\end{array}$ & $\begin{array}{c}42 \\
(14)\end{array}$ & $\begin{array}{c}9 \\
(9)\end{array}$ & $\begin{array}{c}7 \\
(5)\end{array}$ & -- & $\begin{array}{l}29 \\
(9)\end{array}$ & $\begin{array}{l}36 \\
(5)\end{array}$ & $\begin{array}{c}3 \\
(3)\end{array}$ & $\begin{array}{c}33 \\
(13)\end{array}$ \\
\hline 6 & $\begin{array}{r}62 \\
(13) \\
\end{array}$ & $\begin{array}{c}41 \\
(18) \\
\end{array}$ & $\begin{array}{c}9 \\
(7) \\
\end{array}$ & $\begin{array}{r}9 \\
(6) \\
\end{array}$ & -- & $\begin{array}{c}36 \\
(12) \\
\end{array}$ & $\begin{array}{c}35 \\
(12) \\
\end{array}$ & $\begin{array}{c}3 \\
(3) \\
\end{array}$ & $\begin{array}{l}32 \\
(5) \\
\end{array}$ \\
\hline \multicolumn{10}{|c|}{ Rat A16 } \\
\hline 1 & $\begin{array}{c}36 \\
(16)\end{array}$ & $\begin{array}{l}80 \\
(9)\end{array}$ & $\begin{array}{c}58 \\
(12)\end{array}$ & $\begin{array}{c}20 \\
(13)\end{array}$ & -- & $\begin{array}{c}27 \\
(12)\end{array}$ & $\begin{array}{c}37 \\
(14)\end{array}$ & $\begin{array}{l}30 \\
(9)\end{array}$ & $\begin{array}{l}21 \\
(9)\end{array}$ \\
\hline 2 & $\begin{array}{c}37 \\
(16)\end{array}$ & $\begin{array}{l}82 \\
(9)\end{array}$ & $\begin{array}{c}48 \\
(13)\end{array}$ & $\begin{array}{c}11 \\
(13)\end{array}$ & -- & $\begin{array}{c}3 \\
(4)\end{array}$ & $\begin{array}{l}11 \\
(7)\end{array}$ & $\begin{array}{c}13 \\
(10)\end{array}$ & $\begin{array}{l}10 \\
(5)\end{array}$ \\
\hline 3 & $\begin{array}{l}34 \\
(7)\end{array}$ & $\begin{array}{c}80 \\
(12)\end{array}$ & $\begin{array}{c}43 \\
(16)\end{array}$ & $\begin{array}{c}8 \\
(7)\end{array}$ & -- & $\begin{array}{c}1 \\
(2)\end{array}$ & $\begin{array}{c}9 \\
(6)\end{array}$ & $\begin{array}{c}12 \\
(10)\end{array}$ & $\begin{array}{c}14 \\
(10)\end{array}$ \\
\hline 4 & $\begin{array}{c}30 \\
(11)\end{array}$ & $\begin{array}{l}81 \\
(9)\end{array}$ & $\begin{array}{c}37 \\
(14)\end{array}$ & $\begin{array}{c}6 \\
(5)\end{array}$ & -- & $\begin{array}{c}2 \\
(5)\end{array}$ & $\begin{array}{c}15 \\
(13)\end{array}$ & $\begin{array}{c}9 \\
(8)\end{array}$ & $\begin{array}{c}8 \\
(6)\end{array}$ \\
\hline 5 & $\begin{array}{c}40 \\
(15)\end{array}$ & $\begin{array}{l}79 \\
(8)\end{array}$ & $\begin{array}{c}37 \\
(18)\end{array}$ & $\begin{array}{c}4 \\
(4)\end{array}$ & -- & $\begin{array}{c}4 \\
(6)\end{array}$ & $\begin{array}{l}15 \\
(8)\end{array}$ & $\begin{array}{l}12 \\
(9)\end{array}$ & $\begin{array}{c}18 \\
(11)\end{array}$ \\
\hline 6 & $\begin{array}{c}34 \\
(11) \\
\end{array}$ & $\begin{array}{c}80 \\
(10) \\
\end{array}$ & $\begin{array}{c}34 \\
(13) \\
\end{array}$ & $\begin{array}{c}3 \\
(5) \\
\end{array}$ & -- & $\begin{array}{l}13 \\
(9) \\
\end{array}$ & $\begin{array}{l}26 \\
(9) \\
\end{array}$ & $\begin{array}{c}6 \\
(5) \\
\end{array}$ & $\begin{array}{l}18 \\
(6) \\
\end{array}$ \\
\hline
\end{tabular}

Continued on next page 


\section{Table F1 Continued}

\section{Rat A17}

Food Deliveries per Min

\begin{tabular}{|c|c|c|c|c|c|c|c|c|c|}
\hline \multirow{2}{*}{$\begin{array}{l}\text { 10-min } \\
\text { Blocks }\end{array}$} & 2 & 1 & 0.5 & 0.25 & 0.125 & 2 & High & Low & High \\
\hline & \multicolumn{6}{|c|}{ Unlimited Hold (Sucrose) } & \multicolumn{3}{|c|}{ Limited Hold (Sucrose) } \\
\hline 1 & $\begin{array}{l}89 \\
(8)\end{array}$ & $\begin{array}{l}62 \\
(7)\end{array}$ & $\begin{array}{c}31 \\
(15)\end{array}$ & $\begin{array}{c}26 \\
(11)\end{array}$ & $\begin{array}{l}15 \\
(9)\end{array}$ & $\begin{array}{l}84 \\
(5)\end{array}$ & $\begin{array}{c}66 \\
(11)\end{array}$ & $\begin{array}{c}26 \\
(13)\end{array}$ & $\begin{array}{c}49 \\
(15)\end{array}$ \\
\hline 2 & $\begin{array}{l}87 \\
(9)\end{array}$ & $\begin{array}{l}55 \\
(7)\end{array}$ & $\begin{array}{c}15 \\
(10)\end{array}$ & $\begin{array}{c}5 \\
(6)\end{array}$ & $\begin{array}{c}1 \\
(2)\end{array}$ & $\begin{array}{l}68 \\
(8)\end{array}$ & $\begin{array}{c}50 \\
(16)\end{array}$ & $\begin{array}{c}6 \\
(10)\end{array}$ & $\begin{array}{c}24 \\
(14)\end{array}$ \\
\hline 3 & $\begin{array}{l}86 \\
(7)\end{array}$ & $\begin{array}{c}46 \\
(10)\end{array}$ & $\begin{array}{c}6 \\
(6)\end{array}$ & $\begin{array}{c}3 \\
(3)\end{array}$ & $\begin{array}{c}1 \\
(2)\end{array}$ & $\begin{array}{c}66 \\
(10)\end{array}$ & $\begin{array}{c}43 \\
(16)\end{array}$ & $\begin{array}{c}2 \\
(3)\end{array}$ & $\begin{array}{c}17 \\
(13)\end{array}$ \\
\hline 4 & $\begin{array}{l}86 \\
(8)\end{array}$ & $\begin{array}{c}30 \\
(11)\end{array}$ & $\begin{array}{c}7 \\
(10)\end{array}$ & $\begin{array}{c}2 \\
(3)\end{array}$ & $\begin{array}{c}1 \\
(2)\end{array}$ & $\begin{array}{l}63 \\
(7)\end{array}$ & $\begin{array}{c}35 \\
(20)\end{array}$ & $\begin{array}{c}2 \\
(6)\end{array}$ & $\begin{array}{c}9 \\
(11)\end{array}$ \\
\hline 5 & $\begin{array}{c}85 \\
(11)\end{array}$ & $\begin{array}{c}23 \\
(16)\end{array}$ & $\begin{array}{c}7 \\
(5)\end{array}$ & $\begin{array}{c}2 \\
(3)\end{array}$ & $\begin{array}{c}1 \\
(2)\end{array}$ & $\begin{array}{c}61 \\
(10)\end{array}$ & $\begin{array}{c}41 \\
(22)\end{array}$ & $\begin{array}{c}2 \\
(3)\end{array}$ & $\begin{array}{c}10 \\
(15)\end{array}$ \\
\hline 6 & $\begin{array}{r}81 \\
(9) \\
\end{array}$ & $\begin{array}{c}14 \\
(15) \\
\end{array}$ & $\begin{array}{c}2 \\
(2) \\
\end{array}$ & $\begin{array}{c}1 \\
(2) \\
\end{array}$ & $\begin{array}{c}1 \\
(2) \\
\end{array}$ & $\begin{array}{c}64 \\
(10) \\
\end{array}$ & $\begin{array}{c}42 \\
(15) \\
\end{array}$ & $\begin{array}{c}2 \\
(3) \\
\end{array}$ & $\begin{array}{c}7 \\
(11) \\
\end{array}$ \\
\hline \multicolumn{10}{|c|}{ Rat A18 } \\
\hline 1 & $\begin{array}{c}100 \\
(0)\end{array}$ & $\begin{array}{l}98 \\
(4)\end{array}$ & $\begin{array}{l}67 \\
(9)\end{array}$ & $\begin{array}{c}46 \\
(16)\end{array}$ & $\begin{array}{c}13 \\
(11)\end{array}$ & $\begin{array}{c}68 \\
(14)\end{array}$ & $\begin{array}{l}83 \\
(9)\end{array}$ & $\begin{array}{c}28 \\
(18)\end{array}$ & $\begin{array}{l}88 \\
(8)\end{array}$ \\
\hline 2 & $\begin{array}{c}100 \\
(0)\end{array}$ & $\begin{array}{l}92 \\
(9)\end{array}$ & $\begin{array}{c}41 \\
(19)\end{array}$ & $\begin{array}{l}11 \\
(9)\end{array}$ & $\begin{array}{c}2 \\
(3)\end{array}$ & $\begin{array}{c}54 \\
(12)\end{array}$ & $\begin{array}{c}78 \\
(10)\end{array}$ & $\begin{array}{c}5 \\
(7)\end{array}$ & $\begin{array}{l}79 \\
(8)\end{array}$ \\
\hline 3 & $\begin{array}{c}100 \\
(0)\end{array}$ & $\begin{array}{l}86 \\
(6)\end{array}$ & $\begin{array}{c}30 \\
(12)\end{array}$ & $\begin{array}{c}5 \\
(4)\end{array}$ & $\begin{array}{c}2 \\
(3)\end{array}$ & $\begin{array}{l}46 \\
(9)\end{array}$ & $\begin{array}{c}71 \\
(12)\end{array}$ & $\begin{array}{c}4 \\
(4)\end{array}$ & $\begin{array}{c}73 \\
(11)\end{array}$ \\
\hline 4 & $\begin{array}{c}100 \\
(0)\end{array}$ & $\begin{array}{l}85 \\
(8)\end{array}$ & $\begin{array}{c}22 \\
(13)\end{array}$ & $\begin{array}{c}5 \\
(4)\end{array}$ & $\begin{array}{c}2 \\
(3)\end{array}$ & $\begin{array}{c}46 \\
(12)\end{array}$ & $\begin{array}{c}69 \\
(13)\end{array}$ & $\begin{array}{c}4 \\
(5)\end{array}$ & $\begin{array}{l}67 \\
(9)\end{array}$ \\
\hline 5 & $\begin{array}{c}100 \\
(0)\end{array}$ & $\begin{array}{c}84 \\
(10)\end{array}$ & $\begin{array}{c}22 \\
(12)\end{array}$ & $\begin{array}{c}5 \\
(4)\end{array}$ & $\begin{array}{c}3 \\
(4)\end{array}$ & $\begin{array}{c}56 \\
(11)\end{array}$ & $\begin{array}{c}63 \\
(12)\end{array}$ & $\begin{array}{c}6 \\
(6)\end{array}$ & $\begin{array}{l}69 \\
(9)\end{array}$ \\
\hline 6 & $\begin{array}{l}98 \\
(3) \\
\end{array}$ & $\begin{array}{c}83 \\
(15) \\
\end{array}$ & $\begin{array}{l}26 \\
(9) \\
\end{array}$ & $\begin{array}{c}7 \\
(5) \\
\end{array}$ & $\begin{array}{c}9 \\
(7) \\
\end{array}$ & $\begin{array}{c}48 \\
(21) \\
\end{array}$ & $\begin{array}{r}55 \\
(14) \\
\end{array}$ & $\begin{array}{c}6 \\
(8) \\
\end{array}$ & $\begin{array}{c}58 \\
(14) \\
\end{array}$ \\
\hline
\end{tabular}


Table F1 Continued

\begin{tabular}{|c|c|c|c|c|c|c|c|c|c|}
\hline \multicolumn{10}{|c|}{ Rat A11 } \\
\hline \multicolumn{10}{|c|}{ Food Deliveries per Min } \\
\hline $10-\min$ & 2 & 1 & 0.5 & 0.25 & 0.125 & 2 & High & Low & High \\
\hline Blocks & \multicolumn{6}{|c|}{ Limited Hold (Sucrose) } & \multicolumn{3}{|c|}{ Unlimited Hold (Sucrose) } \\
\hline 1 & $\begin{array}{l}98 \\
(3)\end{array}$ & $\begin{array}{c}48 \\
(13)\end{array}$ & $\begin{array}{c}44 \\
(18)\end{array}$ & $\begin{array}{c}25 \\
(10)\end{array}$ & $\begin{array}{l}15 \\
(8)\end{array}$ & $\begin{array}{c}73 \\
(12)\end{array}$ & $\begin{array}{l}87 \\
(6)\end{array}$ & $\begin{array}{l}18 \\
(9)\end{array}$ & $\begin{array}{l}88 \\
(6)\end{array}$ \\
\hline 2 & $\begin{array}{l}99 \\
(3)\end{array}$ & $\begin{array}{c}40 \\
(10)\end{array}$ & $\begin{array}{c}20 \\
(10)\end{array}$ & $\begin{array}{c}9 \\
(7)\end{array}$ & $\begin{array}{c}6 \\
(7)\end{array}$ & $\begin{array}{c}64 \\
(14)\end{array}$ & $\begin{array}{c}79 \\
(16)\end{array}$ & $\begin{array}{c}1 \\
(2)\end{array}$ & $\begin{array}{c}78 \\
(10)\end{array}$ \\
\hline 3 & $\begin{array}{l}99 \\
(3)\end{array}$ & $\begin{array}{c}38 \\
(20)\end{array}$ & $\begin{array}{c}18 \\
(12)\end{array}$ & $\begin{array}{c}7 \\
(3)\end{array}$ & $\begin{array}{c}2 \\
(2)\end{array}$ & $\begin{array}{c}55 \\
(14)\end{array}$ & $\begin{array}{c}66 \\
(15)\end{array}$ & $\begin{array}{c}1 \\
(2)\end{array}$ & $\begin{array}{c}58 \\
(18)\end{array}$ \\
\hline 4 & $\begin{array}{l}95 \\
(8)\end{array}$ & $\begin{array}{c}25 \\
(14)\end{array}$ & $\begin{array}{l}16 \\
(8)\end{array}$ & $\begin{array}{c}4 \\
(4)\end{array}$ & $\begin{array}{c}5 \\
(5)\end{array}$ & $\begin{array}{c}47 \\
(19)\end{array}$ & $\begin{array}{c}63 \\
(15)\end{array}$ & $\begin{array}{c}2 \\
(2)\end{array}$ & $\begin{array}{c}75 \\
(11)\end{array}$ \\
\hline 5 & $\begin{array}{l}97 \\
(5)\end{array}$ & $\begin{array}{c}29 \\
(17)\end{array}$ & $\begin{array}{c}20 \\
(13)\end{array}$ & $\begin{array}{c}3 \\
(3)\end{array}$ & $\begin{array}{c}3 \\
(3)\end{array}$ & $\begin{array}{c}52 \\
(19)\end{array}$ & $\begin{array}{c}62 \\
(16)\end{array}$ & $\begin{array}{c}0 \\
(0)\end{array}$ & $\begin{array}{c}69 \\
(14)\end{array}$ \\
\hline 6 & $\begin{array}{c}93 \\
(10)\end{array}$ & $\begin{array}{c}27 \\
(16)\end{array}$ & $\begin{array}{c}16 \\
(11)\end{array}$ & $\begin{array}{c}2 \\
(3)\end{array}$ & $\begin{array}{c}3 \\
(4)\end{array}$ & $\begin{array}{c}50 \\
(13)\end{array}$ & $\begin{array}{c}57 \\
(18)\end{array}$ & $\begin{array}{c}0 \\
(0)\end{array}$ & $\begin{array}{c}71 \\
(10)\end{array}$ \\
\hline \multicolumn{10}{|c|}{ Rat A12 } \\
\hline 1 & $\begin{array}{c}75 \\
(11)\end{array}$ & $\begin{array}{c}29 \\
(15)\end{array}$ & $\begin{array}{c}21 \\
(11)\end{array}$ & $\begin{array}{c}21 \\
(11)\end{array}$ & -- & $\begin{array}{c}71 \\
(12)\end{array}$ & $\begin{array}{l}80 \\
(7)\end{array}$ & $\begin{array}{c}34 \\
(19)\end{array}$ & $\begin{array}{c}76 \\
(13)\end{array}$ \\
\hline 2 & $\begin{array}{c}63 \\
(15)\end{array}$ & $\begin{array}{l}10 \\
(8)\end{array}$ & $\begin{array}{c}5 \\
(8)\end{array}$ & $\begin{array}{c}9 \\
(9)\end{array}$ & -- & $\begin{array}{c}54 \\
(18)\end{array}$ & $\begin{array}{l}62 \\
(6)\end{array}$ & $\begin{array}{c}14 \\
(17)\end{array}$ & $\begin{array}{c}72 \\
(12)\end{array}$ \\
\hline 3 & $\begin{array}{c}60 \\
(15)\end{array}$ & $\begin{array}{c}3 \\
(5)\end{array}$ & $\begin{array}{c}7 \\
(7)\end{array}$ & $\begin{array}{c}7 \\
(4)\end{array}$ & -- & $\begin{array}{c}57 \\
(19)\end{array}$ & $\begin{array}{l}57 \\
(9)\end{array}$ & $\begin{array}{c}17 \\
(11)\end{array}$ & $\begin{array}{c}63 \\
(11)\end{array}$ \\
\hline 4 & $\begin{array}{c}63 \\
(13)\end{array}$ & $\begin{array}{c}4 \\
(5)\end{array}$ & $\begin{array}{c}7 \\
(5)\end{array}$ & $\begin{array}{c}5 \\
(4)\end{array}$ & -- & $\begin{array}{c}58 \\
(16)\end{array}$ & $\begin{array}{l}57 \\
(9)\end{array}$ & $\begin{array}{c}14 \\
(13)\end{array}$ & $\begin{array}{c}63 \\
(10)\end{array}$ \\
\hline 5 & $\begin{array}{c}61 \\
(15)\end{array}$ & $\begin{array}{c}6 \\
(7)\end{array}$ & $\begin{array}{c}4 \\
(5)\end{array}$ & $\begin{array}{c}5 \\
(5)\end{array}$ & -- & $\begin{array}{c}58 \\
(15)\end{array}$ & $\begin{array}{l}58 \\
(7)\end{array}$ & $\begin{array}{l}17 \\
(8)\end{array}$ & $\begin{array}{c}64 \\
(17)\end{array}$ \\
\hline 6 & $\begin{array}{c}55 \\
(14) \\
\end{array}$ & $\begin{array}{c}7 \\
(7) \\
\end{array}$ & $\begin{array}{c}5 \\
(3) \\
\end{array}$ & $\begin{array}{c}8 \\
(5) \\
\end{array}$ & -- & $\begin{array}{c}52 \\
(16) \\
\end{array}$ & $\begin{array}{c}60 \\
(14) \\
\end{array}$ & $\begin{array}{c}6 \\
(3) \\
\end{array}$ & $\begin{array}{r}64 \\
(8) \\
\end{array}$ \\
\hline
\end{tabular}


Table F1 Continued

\begin{tabular}{|c|c|c|c|c|c|c|c|c|c|}
\hline \multicolumn{10}{|c|}{ Rat A13 } \\
\hline \multicolumn{10}{|c|}{ Food Deliveries per Min } \\
\hline $10-\min$ & 2 & 1 & 0.5 & 0.25 & 0.125 & 2 & High & Low & High \\
\hline Blocks & \multicolumn{6}{|c|}{ Limited Hold (Sucrose) } & \multicolumn{3}{|c|}{ Unlimited Hold (Sucrose) } \\
\hline 1 & $\begin{array}{l}85 \\
(8)\end{array}$ & $\begin{array}{c}77 \\
(9)\end{array}$ & $\begin{array}{c}54 \\
(12)\end{array}$ & $\begin{array}{c}37 \\
(17)\end{array}$ & $\begin{array}{l}17 \\
(9)\end{array}$ & $\begin{array}{l}83 \\
(7)\end{array}$ & $\begin{array}{l}81 \\
(8)\end{array}$ & $\begin{array}{c}23 \\
(14)\end{array}$ & $\begin{array}{c}68 \\
(12)\end{array}$ \\
\hline 2 & $\begin{array}{c}72 \\
(10)\end{array}$ & $\begin{array}{c}71 \\
(12)\end{array}$ & $\begin{array}{c}23 \\
(15)\end{array}$ & $\begin{array}{c}18 \\
(12)\end{array}$ & $\begin{array}{c}6 \\
(10)\end{array}$ & $\begin{array}{c}68 \\
(11)\end{array}$ & $\begin{array}{l}79 \\
(7)\end{array}$ & $\begin{array}{c}3 \\
(5)\end{array}$ & $\begin{array}{c}71 \\
(14)\end{array}$ \\
\hline 3 & $\begin{array}{l}72 \\
(8)\end{array}$ & $\begin{array}{c}72 \\
(12)\end{array}$ & $\begin{array}{c}22 \\
(12)\end{array}$ & $\begin{array}{c}9 \\
(6)\end{array}$ & $\begin{array}{c}3 \\
(5)\end{array}$ & $\begin{array}{l}74 \\
(4)\end{array}$ & $\begin{array}{l}75 \\
(9)\end{array}$ & $\begin{array}{c}3 \\
(4)\end{array}$ & $\begin{array}{c}66 \\
(15)\end{array}$ \\
\hline 4 & $\begin{array}{c}66 \\
(14)\end{array}$ & $\begin{array}{l}75 \\
(8)\end{array}$ & $\begin{array}{c}18 \\
(10)\end{array}$ & $\begin{array}{l}10 \\
(9)\end{array}$ & $\begin{array}{c}2 \\
(3)\end{array}$ & $\begin{array}{c}68 \\
(12)\end{array}$ & $\begin{array}{c}69 \\
(19)\end{array}$ & $\begin{array}{c}2 \\
(3)\end{array}$ & $\begin{array}{c}66 \\
(16)\end{array}$ \\
\hline 5 & $\begin{array}{c}69 \\
(13)\end{array}$ & $\begin{array}{c}73 \\
(11)\end{array}$ & $\begin{array}{c}15 \\
(12)\end{array}$ & $\begin{array}{c}5 \\
(6)\end{array}$ & $\begin{array}{c}9 \\
(12)\end{array}$ & $\begin{array}{c}64 \\
(18)\end{array}$ & $\begin{array}{c}71 \\
(14)\end{array}$ & $\begin{array}{c}2 \\
(5)\end{array}$ & $\begin{array}{c}69 \\
(10)\end{array}$ \\
\hline 6 & $\begin{array}{c}62 \\
(12) \\
\end{array}$ & $\begin{array}{r}66 \\
(20) \\
\end{array}$ & $\begin{array}{r}10 \\
(8) \\
\end{array}$ & $\begin{array}{l}11 \\
(8) \\
\end{array}$ & $\begin{array}{c}4 \\
(7) \\
\end{array}$ & $\begin{array}{c}65 \\
(17) \\
\end{array}$ & $\begin{array}{c}68 \\
(16) \\
\end{array}$ & $\begin{array}{c}2 \\
(5) \\
\end{array}$ & $\begin{array}{c}66 \\
(17) \\
\end{array}$ \\
\hline \multicolumn{10}{|c|}{ Rat A14 } \\
\hline 1 & $\begin{array}{l}72 \\
(9)\end{array}$ & $\begin{array}{l}79 \\
(9)\end{array}$ & $\begin{array}{c}37 \\
(15)\end{array}$ & $\begin{array}{c}9 \\
(6)\end{array}$ & $\begin{array}{l}16 \\
(9)\end{array}$ & $\begin{array}{c}86 \\
(12)\end{array}$ & $\begin{array}{c}59 \\
(11)\end{array}$ & $\begin{array}{c}28 \\
(11)\end{array}$ & $\begin{array}{c}74 \\
(14)\end{array}$ \\
\hline 2 & $\begin{array}{c}57 \\
(13)\end{array}$ & $\begin{array}{c}69 \\
(10)\end{array}$ & $\begin{array}{l}19 \\
(9)\end{array}$ & $\begin{array}{c}2 \\
(3)\end{array}$ & $\begin{array}{c}3 \\
(4)\end{array}$ & $\begin{array}{c}77 \\
(10)\end{array}$ & $\begin{array}{l}47 \\
(6)\end{array}$ & $\begin{array}{c}5 \\
(4)\end{array}$ & $\begin{array}{c}64 \\
(16)\end{array}$ \\
\hline 3 & $\begin{array}{c}50 \\
(14)\end{array}$ & $\begin{array}{c}64 \\
(14)\end{array}$ & $\begin{array}{l}12 \\
(5)\end{array}$ & $\begin{array}{c}3 \\
(3)\end{array}$ & $\begin{array}{c}1 \\
(2)\end{array}$ & $\begin{array}{c}74 \\
(14)\end{array}$ & $\begin{array}{c}42 \\
(12)\end{array}$ & $\begin{array}{c}1 \\
(2)\end{array}$ & $\begin{array}{c}60 \\
(13)\end{array}$ \\
\hline 4 & $\begin{array}{c}46 \\
(17)\end{array}$ & $\begin{array}{c}65 \\
(11)\end{array}$ & $\begin{array}{l}11 \\
(6)\end{array}$ & $\begin{array}{c}1 \\
(2)\end{array}$ & $\begin{array}{c}2 \\
(3)\end{array}$ & $\begin{array}{c}76 \\
(11)\end{array}$ & $\begin{array}{c}46 \\
(12)\end{array}$ & $\begin{array}{c}4 \\
(4)\end{array}$ & $\begin{array}{c}64 \\
(14)\end{array}$ \\
\hline 5 & $\begin{array}{c}48 \\
(12)\end{array}$ & $\begin{array}{c}57 \\
(10)\end{array}$ & $\begin{array}{l}11 \\
(9)\end{array}$ & $\begin{array}{c}1 \\
(2)\end{array}$ & $\begin{array}{c}1 \\
(2)\end{array}$ & $\begin{array}{c}77 \\
(10)\end{array}$ & $\begin{array}{c}48 \\
(15)\end{array}$ & $\begin{array}{c}6 \\
(8)\end{array}$ & $\begin{array}{c}68 \\
(15)\end{array}$ \\
\hline 6 & $\begin{array}{c}49 \\
(11) \\
\end{array}$ & $\begin{array}{c}64 \\
(13) \\
\end{array}$ & $\begin{array}{l}10 \\
(7) \\
\end{array}$ & $\begin{array}{c}5 \\
(6) \\
\end{array}$ & $\begin{array}{c}5 \\
(5) \\
\end{array}$ & $\begin{array}{r}74 \\
(9) \\
\end{array}$ & $\begin{array}{c}52 \\
(14) \\
\end{array}$ & $\begin{array}{c}5 \\
(5) \\
\end{array}$ & $\begin{array}{c}61 \\
(21) \\
\end{array}$ \\
\hline
\end{tabular}

